Aus der Universitäts-Frauenklinik zu Kiel. - Director:

Prof. Dr. W. Stoeckel.

\title{
Experimentelle Untersuchungen iiber den Schutz des Thierkörpers gegen peritoneale Infection ${ }^{1}$ ).
}

Von

\author{
Prof. Dr. Ottomar Hoehne, \\ oberarzt. \\ (Hierzn Tafel XI und 1 Textfigur.)
}

Trotz aller Fortschritte, die in der technischen und aseptischen Durchführung von Bauchhöhlenoperationen gemacht worden sind, erkrankt immer noch eine Anzahl Laparotomirter an einer Infection des Peritoneums; und nicht selten erliegen diese peritoneal inficirten Kranken der postoperativen Peritonitis. Bei der grossen Mehrzahl solcher Fälle bilden nicht pathogene Keime, die während der Operation von aussen in das Operationsgebiet bezw. in die Bauchhöhle hineingebracht wurden, die Ursache der Infection, sondern Depots von Bakterien, die im erkrankten Gewebe am Operationsorte lagerten, durch den operativen Eingriff mobilisirt wurden und so in das Peritonealcavum und in die Operationswunden gelangten. Ohne diese Erklärung würde man gar nieht verstehen können, dass Hunderte von Laparotomien, keimfreie Gewebe vorausgesetzt, reactionslos verlaufen, während gerade die Operationen am bakteriologisch unsauberen Object unverhältnissmässig oft von entzündlichen Processen verschiedener Art und verschiedener Localisation gefolgt sind. Gleichgültig sind natürlich die Infectionen der Bauchdecken nicht und selbstverständlich die der grossen Beckenwunden erst recht nicht. Im Allgemeinen aber kann man doch sagen, dass diese Infectionen meist prompt ab-

1) Vgl. Hoehne, Experimentelle Versuche zur Prophylaxe der Peritonitis. Verhandl. d. Deutschen Ges. f. Gyn. XIII. S. 281-287. - Zur Prophylaxe der postoperativen Peritonitis. Münch. med. Wochenseht. 1909. S. 2508-2511. 
gegrenzt und, falls günstige Abflussbedingungen für den producirten Eiter sich ermöglichen lassen, gut und schnell überstanden werden. Ganz anders liegen die Verhältnisse am Peritoneum. Zweifellos wird auch das Peritoneum dank seiner natürlichen Schutzkräfte mit einer gewissen Menge nicht allzu virulenten Bakterienmaterials fertig. Die Bakterien werden theils schnell resorbirt und im Blute abgetödtet, theils gehen sie, ohne sich wesentlich vermehren zu können, im Peritonealsack zu Grunde. Sobald aber die Zahl und Virulenz der Bakterien eine bestimmte Grenze überschreiten, wird die peritoneale Infection für den betreffenden Kranken eine bedrohliche, sei es durch die acutest einsetzende peritoneale Sepsis, sei es durch eine ausgedehnte eiterige Peritonitis mit begleitender schwerer Toxinämie.

Da wir nun in dem gegebenen Falle Menge und Pathogenität des Bakterienmaterials nicht genau einzuschätzen vermögen, so sind die Patienten mit keimhaltigen Fiter- bezw. Geschwulstherden bei einem eventuellen operativen Eingriff immer mehr oder weniger gefährdet. Das kommt anch darin deutlich zum Ausdruck, dass solche Operationen möglichst lange hinausgeschoben werden, weil erfahrungsgemäss die Keime an Virulenz allmählich einbüssen und sehliesslich absterben. Das Hinausschieben der Operation ist nun bei vielen gynäkologischen Leiden mit bakterienhaltigen Krankheitsproducten durchaus möglich und sogar allein richtig, andere Erkrankungen aber zwingen zu s ofortige m oder wenigstens baldigem Eingreifen.

Ob man nicht in solchen Fällen durch Erhöhung der natürlichen Schutzkräfte des Peritoneums eine grössere Juebenssicherheit für die zu Operirenden schaffen kann, das war die Frage, die vor 2 Jahren Pfannenstiel und mich besonders lebhaft beschäftigte. Eine Veranlassung, dieser Frage auf einem bestimmten Wege näher zu treten, gab mir das genaue Studium der Glimm'schen ${ }^{1}$ ) Arbeit über die Bauchfellresorption. Glimm wies zunächst durch sehr exact durchgeführte Experimente überzeugend nach, dass die Resorption wasserlöslicher Substanzen (Milchzucker) bei bestehender bakterieller Peritonitis beschleunigt ist, im Widerspruch mit Ewald und Schnitzler, in Uebereinstimmung mit Clairmont und Haberer; und dass die Resorptionsbeschleunigung auch für die vorgeschrittene

1) P. Glimm, Ueber Bauchfellresorption und ihre Beeinflussung bei Peritonitis. Deutsche Zeitschr. f. Chir. Bd. 83. S. 254-287. Leipzig 1906. 
Peritonitis, dic zum Tode führt, zutrifft (Gegensatz zu Clairmont und Haberer). Dabei ist aber wohl zu berücksichtigen, dass alle diese Resorptionsversuche sich innerhalb von 9 bis höchstens innerbalb vòn 20 Stunden post infectionem peritonei abspielten. Glimm bemerkt daher S. 261, mit Recht einschränkend, dass sich seine Resorptionsergebnisse nur auf die Zeit "bald nach Beginn der peritonealen Infection" beziehen. Das Verbalten der Resorption bei einer subacuten, geschweige denn ebronischen Peritonitis hat Glimm nicht klargestellt, weil er diese Stadien einer bakteriellen Peritonitis bei seinen Thieren nicht mit Sicherheit zu erzeugen im Stande war. Im weiteren Verlaufe seiner Arbeit versuchte Glimm die peritoneale Resorption von Bakterien und der an sie gebundenen Toxine zu beschränken, und zwar durch intraperitoneale Injectionen von Olivenöl und anderen Oelen. Er erreichte in der That durch seine Bauchfellölung eine wesentliche Verringerung oder gar Aufhebung der Bakterienresorption aus der Peritonealhöhle. Dieses Resultat, das er als lebensrettendes Moment für die peritoneal inficirten Thiere erkannte, fand für ihn seine Erklärung in der Verlegung der aus dem Cavum peritonei führenden Lymphstrassen mit dem injicirten Oel. Schon seit Wegner und v. Recklinghausen sei es bekannt, dass in die Bauchhöhle eingespritztes Oel die Lymphwege, vor Allem des Zwerchfells, sehr bald und für mehrere Tage strotzend anfülle. Da nun die Resorption der Bakterien als corpusculärer Elemente auf dem Lymphwege vor sich ginge, so würden die Infectionskeime in Folge der Oelverlegung der Resorptionsbahn vom Blutkreislauf ferngehalten, das Versuchsthier aber durch die Beschränkung des bakteriellen Processes auf die Bauchhöhle vơr dem sonst sicheren Tode gerettet. Glimm verspricht sich auch von der resorptionshemmenden Wirkung der intraperitonealen Oelinjection einen 'Erfolg für die Behandlung der Peritonitis beim Menschen (S. 287) and empfiehlt, "zunächst bei ganz aussichtslosen Peritonitisfällen, die einen schwer septischen Eindruck machen, nach Versagen anderer Hülfsmittel eine intraperitoneale Oelinjection von etwa $130 \mathrm{ccm}$ 1 proc. Kampferöls vorzunehmen. Vor prophylaktischen Injectionen warnt er zunächst dringend, da wir nicht wüssten, wie normales Menschenperitoneum auf Oelinjectionen reagire".

Die von Glimm mittels bakteriologischer Blutuntersuchungen nachgewiesene Beeinflussung der Bakterienresorption durch intraperitoneale Oelinjection musste für das Verständniss des Ablaufes 
einer Peritonitis und für ihre rationelle Behandlung bedeutungsvoll erscheinen und forderte zur Nachprüfung und weiteren Forschung in dieser Richtung auf. Die Erklärung, die Glimm für den Vorgang der Bakterienresorptionshemmung gab, leuchtete mir nicht ein, weil ich eine bakteriendichte Oelverlegung der aus dem Peritonealcavum abführenden Lymphwege für unwahrscheinlich hielt, und weil ich mir schwer vorzustellen vermochte, dass bei einer solchen Lymphgefässanfüllung mit Oel eine Oelüberschüttung des kleinen Kreislaufs und eine Gefährdung der Lunge durch Fettembolie vermieden werden könnte. Die Frage der Fettembolie hat Glimm in seiner Arbeit nicht berührt, auch nicht erwähnt, ob dahingehende Untersuchungen der Lunge vorgenommen wurden, was ich um so mehr als eine Lücke empfand, als von seinen Thieren einige, an denen gerade sehr wichtige Oelinjectionsversuche gemacht waren, an Lungenerkrankungen zu Grunde gegangen sind. Wenn nun auch ohne Weiteres zugegeben werden muss, dass Kaninchen recht häufig Krankheiten der Athmungswege erliegen, so schien es doch immerhin möglich, dass beim Tode der erwähnten Versuchsthiere die Fettembolie der Lunge mit im Spiele war ${ }^{1}$ ). Ausserdem gab mir die von anderer Seite beobachtete Fettembolie der Lunge nach subcutaner Injection reichlicher Oeldosen beim Menschen Veranlassung, die Folgen intraperitonealer Oelinjectionen, mit besonderer Berücksichtigung des kleinen Kreislaufs, beim Thier noch einmal zu prüfen. Eine etwaige Lungenschädigung durch Fettembolie nach Oelung des Peritoneums musste im Thierversuch sicher ausgeschlossen werden vor der Anwendung intraperitonealer Oelinjectionen beim Menschen.

Nachdem 4 Meerschweinchen von 350 bis $760 \mathrm{~g}$ Körpergewicht Injectionen von ca. $5 \mathrm{ccm}$ sterilisirten Olivenöls in die unter aseptischen Cautelen eröffnete Bauchhöhle überstanden hatten, ohne die geringsten Krankheitserscheinungen zu zeigen, experimentirte ich weiter an Kaninchen mit folgender Technik, die bei den vielen Versuchen höchstens in unwesentlichen Punkten differirte:

1) Nach Uebersendung eines Separatabdruckes meiner Arbeit "Zur Prophylaxe der postoperativen Peritonitis" theilte mir Herr Dr. Glimm am 27. December 1909 freundlichst mit, dass bei den Thieren, die an rechtsseitiger T'otalpneumonie bezw. eitriger Entzündung der Lunge und Pleura zu Grunde gingen, sich keine Fettembolien fanden. 


\section{Versuchsanordnung.}

Obwohl es bekannt ist, dass man bei Thieren auch ohne directes Freilegen und Eröffnen des Peritoneums mit einer Spritzenkanüle leicht in die Bauchhöhle hineingelangen und die zum Versuche gewählten Substanzen auf diese Weise denkbar einfach intraperitoneal injiciren kann, verzichtete ich doch auf das wegen seiner Einfachheit so verlockende Verfahren, weil ich dem naheliegenden Einwand begegnen musste, es könnte die Flüssigkeit beim Injiciren nicht in die Bauchhöhle, sondern in die Bauchdecken unter das Peritoneum, wie ich es in der That 1 mal beobachtet habe, oder in den verletzten Darm hineingeraten sein, und wählte den complicirteren, aber einwandsfreien Weg der Laparotomie.

Das leicht mit Aether narkotisirte Versuchsthier (bei sehr ruhigen Thieren wurde gelegentlich von der Narkose Abstand genommen), dessen Bauchhaut in grosser Ausdehnung sorgfältig rasirt war, wurde in Rückenlage auf eine geeignete Unterlage geschnallt, die Bauchhaut mit Seife und Wasser gewaschen, mit Alkohol und Sublimat desinficirt und an der Operationsstelle kurz vor dem Hautschnitt mit Aether abgerieben. Nach Abdecken des Operationsterrains mit sterilen Tüchern schnitt jch unter Anwendung einer möglichst kleinen (2-3 cm langen) Incision bis auf das Bauchfell ein, schlitzte das Peritoneum und fixirte die beiden Enden des peritonealen Längsschlitzes mit je einem Catgutfaden. Durch das Peritonealfenster wurde sodann ein kleines Stück dünnen Gummischlauches in das Carum peritonei geleitet und mit dem einen der situirten Peritonealfäden unter gleichzeitigem Angezogenhalten des anderen umschnürt, so dass der Schnürfaden die ganze Randparthie der angelegten Peritonealöffnung umfasste. Durch das in die Peritonealöffnung eingebundene kurze Gummirohr injicirte ich die auf Körpertemperatur erwärmte Versuchsfliissigkeit langsam mit Spritze oder liess sie mittelst passenden Trichters einlaufen. War die gewünschte Menge Flüssigkeit in die Bauchhöhle gebracht, so zog ich den Schnürfaden kräftiger an, entfernte den eingebundenen Schlauch vorsichtig, wobei die in ihm noch enthaltene geringe Flüssigkeitsmenge in Folge der Fadenschnürung restlos nach dem Bauchraum hin ausgestreift wurde, und schloss durch sicheres Knoten des Schnürfadens die Bauchhöhle wieder dicht ab.

Für die intraperitoneale Bakterieninjection bediente ich mich desselben Verfahrens; nur wurde die Culturflüssigkeit nicht direct 
durch den Schlauch in das Carum peritonei injicirt, sondern durch eine stumpfe, mit der Spritze festvereinigte Canüle, nachdem diese durch den eingeschnürten Schlauch bis in die Bauchhöhle vorgeschoben war.

Bei solchem Vorgehen hatte ich die Gewissheit, dass die verwendete Oelmenge bezw. Bakterienkulturflüssigkeit stets $\mathrm{nur}$ in die Bauchhöhle des Thieres hineingelangte. Es musste die Oel- bezw. Bakterienresorption eine rein peritoneale sein; die Bauchwunde kam als Resorptionspforte sicher nicht in Betracht.

Ueber dem wieder geschlossenen Peritoneum wurden die einzelnen Schichten der Bauchwand mit einigen Catgutknopfnähten vereinigt, die vernähte Wunde mit Dermatol bestreut und darüber flüssiger Asphaltlack gepinselt, damit sich die Thiere nicht leckten.

Operateur und $\Lambda$ ssistent arbeiteten mit sterilen Gummihandschuben. Dass alles mit der Wunde in Berührung kommende Material an Wäsche und Instrumenten sterilisirt war, versteht sich natürlich von selbst.

Bei allen getödteten Thieren wurde sofort, bei den gestorbenen Thieren möglichst bald nach dem Tode die. Bauchhöhle controlirt, über den Befund in der Bauchhöhle, an den Bauch - und Brustorganen Aufzeichnungen gemacht, nöthigenfalls aus der Bauchhöhle und aus verschiedenen Organen Proben zur bakteriologischen Untersuchung entnommen und die wichtig erscheinenden Organe zum genaueren mikroskopischen Studium in 10 proc. Formalin eingelegt. Von den in Formalin fixirten und gehärteten Organen wurden geeignete Stücke herausgeschnitten, mit dem Gefriermikrotom in $15 \mu$ dicke Schnitte zerlegt und diese ungefärbt, nach blosser Sudanfärbung oder nach Sudan-Hämatoxylinfärbung durchmustert. Sollte auf Bakterien im Schnittpräparat gefahndet werden, so wurden die betreffenden Gewebsstücke weiter in Alkohol gehärtet, in Paraffin eingebettet und die von den eingebetteten Organstücken angefertigten mikroskopischen Schnitte entsprechend gefärbt.

\section{Intraperitoneale Oelinjection beim Kaninchen.}

Für die intraperitonealen Oelinjectionen verwandte ich zunächst ein gefärbtes Oel, weil ich meinte, dieses nach geschehener Resorption in den Organen des Versuchsthieres bequemer aufinden und als das injicirte Oel leichter erkennen zu können. Ich wählte mit Alkanna gefärbtes Olivenöl (Extr. Alcannae 10,0, Ol. Olivarum 90,0), also 
10 pCt. Alkannaöl, das für die Versuche mit sterilisirtem Olivenöl verdünnt wurde.

\section{Versuchsgruppe (11. XI. 1908).}

No. 1. Weibliches Kaninchen, weiss, $1730 \mathrm{~g}$ schwer. Eröffnung des Abdomens in der Mittellinie der Oberbauchgegend. Langsame Injection von $20 \mathrm{ccm}$ intensiv dunkelroth gefärbter 1 proc. Alkannaöllösung.

Operation gut überstanden. In den ersten 24 Stunden ruhiges Dasitzen, ohne dass das Thier einen schwerkranken Eindruck macht. Vom 2. Tage ab zeigt es Interesse für die Umgebung und läuft, Gegenstände beschnuppernd, munter umber. - Am aufgefangenen Urin wird eine besondere Färbung nicht bemerkt, auch kein Oel darin gefunden.

Nach $3 \times 24$ Stunden wird das Thier getödtet. Die genähte Bauchwunde schliesst in allen Etagen dicht, erscheint nicht gereizt. Nach Eröffnung der Bauchböhle sieht man die Därme untereinander verklebt und von dicken kirschrothen Fibrinmembranen überlagert. Aüch das Bauchwandperitoneum ist grösstentheils mit einer von Alkannaöl durchsetzten Fibrinlage überzogen. Aus dem Cavum peritonei werden $35 \mathrm{ccm}$ einer öligen, zahlreiche kirschroth gefärbte Fibrinflocken enthaltenden Flüssigkeit entfernt. Nicht nur die verklebten Därme, sondern alle Bauchorgane sind in mehr oder weniger dicker Schicht von den beschriebenen Fibrinmassen bedeckt. Besonders auffallend ist der Unterschied zwischen der pleuralen nud peritonealen Seite des Zwerchfells. Während jene ganz glatt und spiegelnd ist, erscheint diese von einer massigen, das rothe Oel umschliessenden Fibrinschicht übergossen. Weder im Ausstrichpräparat, noch in den mehrere Tage hindurch controlirten Culturen (aerob and anaerob; Agar aud Bouillon bei $37^{\circ} \mathrm{C}$.) eill Bakterienbefund.

Mikroskopisch zeigt sich das Alkannaöl in ausserordentlich verschieden grossen Tropfen, theils frei, theils von Fibrin umscheidet. An keiner der untersuchten Stellen ist das Alkannaöl nennenswerth in das Gewebe eingedrungen. In der Lunge wird wohl resorbirtes Alkannaöl angetroffen, aber nicht in grossen Massen. Nur hier und da sind in den Gefässen stärkere Anhäufungen von $\mathrm{Oel}$, ohne dass dadurch nachweisbare Circulationsstörungen veranlasst wären. - Der ölige Bauchhöhleninhalt weist enorme Mengen von Fibrin, massenhafte Leukocyten und rothe Blutkörperchen auf. Meist liegen die Oelkugeln und Oelkügelchen in den Maschen des Fibrinnetzes.

Das 1 proc. Alkannaöl hat bei diesem Kaninchen eine starke universelle, nicht bakterielle fibrinös-eitrig-hämorrhagische Entzündung des Peritoneums bewirkt. Zum Theil ist das am Bauchwandperitoneum und an der Visceralserosa haftende Exsudat in Organisation begriffen. Im kleinen Kreislauf lassen sich wohl mässige Mengen von resorbirten Oelkugeln nachweisen, aber keine eigentlichen Gefässverstopfungen mit ihren Folgen.

No. 2. Weibliches Kaninchen, schwarz-weiss, $2800 \mathrm{~g}$ schwer. Eröffnung des Abdomens in der Mittellinie der Oberbauchgegend. Lang- 
same Injection von $20 \mathrm{ccm} \mathrm{1/2} \mathrm{proc.,} \mathrm{auch} \mathrm{in} \mathrm{dieser} \mathrm{Verdünnnung} \mathrm{noch}$ immer intensiv gefärbter Alkannä̈llösung.

Verhalten des Thieres genau so wie No. 1. Auch dieses Kaninchen macht nach der Injection wohl einen kranken, aber keinen schwerkranken Eindruck. Auch hier ist der Urin nicht auffallend verändert. Vom 3. Tage post operationem ab zeigt sich etwas Blutabgang aus dem Genitalapparat; am 4. Tage post op. abortirt das Thier (4 Föten). Weiterhin erscheint das Thier ganz gesund, frisst wieder und holt den Anfangs eingetretenen Gewichtsverlust bald wieder ein. - Nach 1/4 Jahr ist die Wunde im Haarkleide der Bauchhaut nicht mehr zu erkennen. Nach 1/2 Jahr (26. V. 09) ergiebt eine Controllaparotomie, dass das Peritoneum spiegelnd glatt ist, sich keine Adhäsionen gebildet haben, und von dem Alkannaöl kaum noch Spuren im Abdomen vorhanden sind.

Aus den beiden Versuchen der Versuchsgruppe I geht hervor, dass man mit dem stark reizenden Alkannä̈l ohne gleichzeitige Einbringung von Bakterien beim Kaninchen eine sehr intensive, mit lebhafter Exsudation einhergehende fibrinös-eitrig-bämorrhagische Peritonitis hervorzurufen vermag, und dass eine so enorme Peritonitis, ohne gröbere Spuren zu hinterlassen, ausheilen kann. Die Oelresorption der Bauchhöhle war bei dem controlirten Thier 1 in allen untersuchten Organen nur gering. Speciell waren in der Lunge Verlegungen grösserer Gefässe und dadurch bedingte Circulationsstörungen nicht erkennbar. Es handelte sich nicht um eine Fettembolie in der Lunge, sondern nur um ein Circuliren mässiger Mengen emulgirten Oels im Iungenkreislauf, also um eine Lipämie.

Wenn auch die beiden Thiere die Injection der für ein Kaninchen grossen Menge Alkannaöls ohne dauernde Schädigung vertragen hatten, so lag es doch nicht in meiner Absicht, eine so starke Reizung des Bauchfells hervorzurufen, sondern ich wollte ja nur die Oelresorption aus dem Peritonealcavum beobachten. Um künftig eine derartig intensive Peritonealreizung zu vermeiden, verzichtete ich auf den Alkannazusatz und benutzte für die nächsten Versuche (No. 3 u. 4) blosses Oel, behielt aber dieselbe Dosis bei. Meine Wahl fiel auf Sesamöl, das sich durch seine leichte Haltbarkeit, Unschädlichkeit, Reizlosigkeit und ausserdem durch seine specifische Färbbarkeit mit Furfurol auszeichnet. Die bakteriologische Untersuchung von mehreren Proben erwiesen das sterilisirte Sesamöl als wirklich frei von Bakterien. Eine richtige Bewerthung und ein Urtheil über den Einfluss der Laparotomie und der Aethernarkose suchte ich dadurch zu gewinnen, dass ich ein Controlthier (No.5) genau so wie die eigentlichen Versuchsthiere (No. 3 u. 4) operirte, aber kein Oel in den Peritonealraum injicirte. 


\section{Versuchsgruppe (20. XI. 1908).}

No. 3. Weibliches Kaninchen, weiss, $2900 \mathrm{~g}$ schwer. Eröffnung der Bauchhöhle in der Oberbauchgegend mit kleinem Medianschnitt. Langsame Injection von $20 \mathrm{cem}$ sterilisirten Sesamöls. - Das Thier erholt sich bald nach der gut überstandenen Operation, frisst vom nächsten Tage $a b$ und läuft munter umher. Primäre Wundheilungg.

No. 4. Weibliches Kaninchen, grau, $2350 \mathrm{~g}$ schwer. Apfelgrosser Abscess am Kopfe vor dem rechten Ohr (Reincultur kleiner Kokken). Eröffnung der Bauchhöhle wie bei No. 3. Ebenfalls Injection von $20 \mathrm{ccm}$ sterilisirten Sesamöls. Auch dieses Thier erholt sich nach der Operation gut, frisst am folgenden Tage und weist am 3. Tage post inject. keine merkliche Störung auf.

No. 5. Weibliches Kaninchen, schwarz, $1850 \mathrm{~g}$ schwer. Eröffnung der Bauchhöhle in der Oberbanchgegend etwas rechts von der Medianlinie. Das festgeschnallte Thier bewegt sich energisch beim Einschneiden des äusserst empfindlichen Parietalperitoneums und presst ein Convolut von Dünndärmen hervor, die leicht wieder reponirt werden. Wohl auch Einführen des sonst zur Oelinjection dienenden Schlauches in das Abdomen, aber keine Injection von Oel.

Operation schnell und gut überstanden. Das Thier läuft bald gesund umher. Wundheilung nur gestört durch eine leichte, ganz oberflächliche Eiterung.

Bei allen 3 Thieren dieser Versuchsgruppe wird nach $3 \times 24$ Stunden (23. XI. 1908) in nochmaliger leichter Aethernarkose eirie Relaparotomie mit kleinem Medianschnitt in der Unterbauchgegend, also weit unterhalb der ersten Narbe ausgeführt. Abimpfungen von der neu angelegten blutenden Bauchwunde und aus der wieder eröffneten Bauchhöhle ergaben bei allen 3 Thieren sichere Keimfreiheit (Ausstrichpräparat und Cultur). Bei Kaninchen No. 3 und 4 besteht die bei der zweiten Laparotomie entnommene Bauchinhaltprobe aus verschieden fein emulgirtem Oel und aus zahlreichen Leukocyten. Allen 3 Thieren werden je 5 ccm einer 20 stündigen Bouilloncultur von Bacterium coli, stammend von einem an Coliperitonitis gestorbenen Kaninchen, unter sorgfältiger Vermeidung einer Bauchwundverunreinigung intraperitoneal injicirt und die Wunde mit der gewohnten Schichtnaht exact geschlossen.

No. 3. Nach dentlichem Kranksein am Operationstage erbolt sich das Thier im Verlaufe des folgenden Tages, beginnt nach und nach wieder zu fressen, gleicht die anfängliche Gewichtsabnahme wieder aus und zeigt ungestörte Wundheilung. 24 Stunden post infect. aus der Ohrvene entnommes Blut steril (Agar, Bouillon). 10 Wochen nach der abdominalen Coliinfection stellt sich, während das Körpergewicht wieder abnimmt, eine sich immer mehr steigernde Gleichgewichtsstörung ein, weshalb das Thier am 12. II. 1909, also fast $1 / 4$ Jahr nach der Peritonealinfection getödtet wird. In der sogleich nach dem Tode eröffneten 
Bauchböhle zeigen sich flächenhafte Adhäsionen zwischen der vorderen Bauchwand und den anliegenden untereinander verwachsenen Darmschlingen, und mitten in dem Verwachsungseonvolut ein halbwalnuss. grosser ovaler gelber Körper, der nur locker haftet und sich ohne weiteres herausnehmen ]ässt. Ausserdem noch Adhäsionen zwischen Dünndarmschlingen and unterer Leberfläche und zwischen Leber und Zwerchfeli. Im verwachsungsfreien Bauchhöhlengebiet Peritoneum glatt und spiegelnd, nirgends Spuren von dem injicirten Oel.

Während aus der Bauchhöhle weder in der Bouillon noch auf Agar, weder aerob noch anaerob bei $37^{\circ} \mathrm{C}$. Keime gezüchtet werden konnten, auch die Brust- und Bauchorgane und das Gehirn bakterienfrei waren, finden sich in dem von Adhäsionen eingesargten fibrösen Körper eine Reihe kleiner $A$ bscesse, die neben Oel und massenhaften Leukocyten unzählige Gram-negative Stäbchen (Colibakterien in Reincultur) enthalten. Der fibröse Körper stellt also nichts weiter als ein bei dem stehenden Thier an der tiefsten Stelle der Bauchhöhle umscheidetes und abgekapseltes Oel- und Bakteriendepot dar. In den Lungengefässen werden reichliche Mengen von Fett gefunden, doch keine Circulationsstörungen. An der Leberoberfäche ist das emulgirte Oel fest umscheidet und zum Theil direct in die oberflächlichen Leberzelllagen eingedrungen, offenbar von Zelle zu Zelle gewandert.

No. 4. Das Thier erscheint nach der Relaparotomie und intraperitonealen Coliinjection sehwer krank, sitzt zusammengekauert da mit mattem Blick und sehr beschlennigter Athmung. Unter żunehmender Unruhe, jagender Athmung und Ringen nach Luft stirbt das Thier 22 Stunden nach der Relaparotomie, also am Ende des 4. Tages post inject. Ol. Sesami. - Section: Im Abdomen $25 \mathrm{ccm}$ ölige, sehr reichliche Eiterkörperchen und spärliche Erythrocyten enthaltende Flüssigkeit mit grossen Mengen der am Tage vorher injicirten Colibakterien, während im Blut, Leber, Milz und Lungen Bakterien nicht gefunden wurden. Keine Adhäsionen. Milz nicht geschwollen.

Die auffallende Atemnoth des Thieres erklärt sich aus einer enormen Fettembolie der Lunge mit weit verbreiteten Blutextravasaten und compensatorischem Emphysem der spärlichen athmungsfähig gebliebenen Lungenabschnitte.

Aus dem Sectionsbefunde geht mit Sicherheit hervor, dass an dem Tode des Thieres die peritoneale Coliinjection nur eine sehr geringe Schuld trägt, vielmehr die Fettembolie den Exitus herbeigeführt hat, allerdings beschleunigt dureh den erneuten operativen Eingriff in Aethernarkose und durch die Coliinjection. Eine Anschauung von den schweren Veränderungen der Lunge in Folge der allmählich immer stärker gewordenen Fettembolie giebt die Abbildung auf Tafel XI. 
No. 5. Nach anfänglichem deutlichen Kranksein am Tage der peritonealen Coliinjection erholt sich das Thier schnell. 24 Stunden post infect. aus der Ohrvene entnommenes Blut ergiebt kein Bakterienwachsthum. Am Tage nach der Injection macht das Thier im Vergleich zu den anderen Kaninchen, auch im Vergleich zu No. 3, einen gesunden Eindruck und verhält sich vom 3. Tage post relaparot. ab, als ob ihm nichts geschehen sei. Es nimmt weiter an Gewicht zu und erreicht am 12. II. 09 ein Gewicht von $2610 \mathrm{~g}$ (vor der 1. Operation am 20. XI. 08 $1850 \mathrm{~g})$. - Vergl. XIII. Versuch No. 38 und XXVIII. Versuchsgruppe No. 69 .

Aus der II. Versuchsgruppe lernte ich, dass die intraperitoneale Injection von $20 \mathrm{ccm}$ Sesamöl keineswegs gleichgültig für das Kaninchen ist, sondern zu einer tödtlichen Fettembolie der Lunge führen kann. Ferner überzeugte ich mich, dass die zum Versuch benutzte Colicultur, obwohl sie von einem an Coliperitonitis gestorbenen Kaninchen stammte, nur wenig virulent. war, da das Controlthier die Injection sehr gut überstand, sogar weniger krank war als die beiden Versuchsthiere, von denen das eine an Fettembolie starb. Da bei Kaninchen No. 3 auch nach $1 / 4 \mathrm{Jahr}$ nicht unbeträchtliche Oelmengen in der Lunge gefunden wurden, so erscheint die Annahme nicht unberechtigt, dass das unverhältnissmässige Kranksein dieses Thieres nach der abdominalen Coliinjection im Vergleich zu dem Controlthier No. 5 gar nicht auf die Coliinjection, sondern auf eine Fettüberladung des kleinen Kreislaufs zu beziehen war, die zwar nicht wie bei dem Parallelthier No. 4 zum. Tode an Fettembolie führte, aber doch eine wesentliche Complication darstellte. Endlich musste auffallen, dass bei der gleichen Menge intraperitoneal injicirten Oels in Versuchsgruppe I viel weniger Oel resorbirt war und im kleinen Kreislauf gefunden wurde als in Versuchsgruppe II, hingegen die peritoneale Reizung in Folge des Alkannazusatzes in Versuchsreihe I eine ungleich stärkere war. Die Menge des resorbirten Oeles stand also in umgekehrt proportionalem Verhältniss zur Intensität des peritonitischen Exsudationsprocesses.

Nach den bisherigen Versuchsergebnissen musste als feststehend gelten, dass Sesamöl in einer Menge von $20 \mathrm{ccm}$ intraperitoneal injicirt, Kaninchen krankmachen und sogar durch Fettembolie der Lunge tödten kann. Um diese Experimente zu ergänzen, ging ich nun zu Versuchen mit wechselnden Mengen von Sesamöl über, theils wesentlich geringeren, theils noch grösseren und sehr grossen Dosen. 


\section{Versuchsgruppe (7. XII. 1908).}

No. 6. Männliches Kaninchen, grauweiss, $2050 \mathrm{~g}$ schwer. Eröffnung der Abdominalhöhle in der mittleren Bauchgegend mit kleinem Medianschnitt. Langsame Injection von $8 \mathrm{ccm}$ sterilisirten Sesamöls. - Schon am Operationstage läuft das Thier munter umher, beschnuppert die erreichbaren Gegenstände und frisst wenige Stunden nach dem Eingriff. Es verhält sich ähnlich wie Kaninchen No. 5 nach der 1. Laparotomie ohne peritoneale Oelung. - 21 Stunden nach der Oelinjection wird das Thier durch Nackenschlag getödtet. In der eröffneten Bauchhöhle zeigen sich nirgends Verklebungen. Das Bauchfell ist gleichmässig mit Sesamöl bedeckt. Hier und da bemerkt man kleine Flocken, bestehend ans Fibrin und Leakocyten. Nirgends auch nur kleinere Anhäufungen von $\mathrm{Oel}$, auch keine Bildung flüssigen Exsudates. Abgeimpftes Material aus verschiedenen Theilen der Bauchhöhle ergiebt Keimfreiheit. Im Lungenkreislauf resorbirtes 0 el theils in einzelnen, theils mehr gehäuften Kugeln circulirend, aber keine Verstopfung grösserer Gefässe, nu r harmlose Lipärnie.

No. 7. Männliches Kaninchen, dunkelgrau, $2600 \mathrm{~g}$ schwer. Eröffnung der Bauchhöhle wie bei $N_{0} .6$. Langsame Injection von $50 \mathrm{ccm}$ Sesamöl. - Am Abend des Operationstages macht das Thier einen recht kranken Eindruck, sitzt zusammengekauert ruhig da und frisst nicht, während Kaninchen No. 6 zu derselben Zeit schon munter umherspringt. 22 Stunden nach der Oelinjection wird das Thier durch Nackenschlag getödtet. In der Bauchhöhle sehr reichliche Oelmengen. Es werden gut $30 \mathrm{ccm}$ Oel ausgeschöpft. Das Oel ist untermischt mit weissen flockigen Massen, die einen bedeutenden Bodensatz liefern und aus grossen Mengen von Leukocyten und Fibrin bestehen. Auf der Leber, an der oberen und unteren Fläche, findet sich ein weisser Ueberzug von Fibrin und Leukocyten, ziemlich festhaftend, von wechselnder Dicke, meist dünn wie ein zarter Schleier. - Abimpfungen aus der Bauchhöble beweisen die Sterilität des Peritonealinhaltes (Agar- und Bouillonculturen). - - Von einer Oelüberschüttung der Lunge ist auch bei diesem Thier keine Rede. Es bat innerhalb 22 Stunden trotz der sehr grossen in das Peritoneum gebrachten Oelmenge nur eine mässige Resorption von emulgirtem Oel stattgefunden, durch die sichtbare Scbädigungen des Lungengewebes nicht hervorgerufen sind.

Diese Experimente zeigten mir: eine für das Kaninchen mässige Menge Sesamöl $(8 \mathrm{ccm})$ wird binnen kurzer Zeit emulgirt und gleichmässig in dem Peritonealraum vertheilt, so dass jede Stelle des Bauchfells von einer Oelschicht überzogen ist. Auf die Reizung durch die kleine Oelmenge hin wird ein geringes aus Fibrin und Leukocyten bestehendes Exsudat gebildet. Im auffallenden Gegensatz zu Kaninchen No. 6 war das andere Kaninchen No. 7, das $50 \mathrm{cem}$ desselben 0 els intraperitoneal injicirt erhalten hatte, deutlich krank. Die peritoneale Reizung erwies sich bei der Bauchhöhlencontrolle. am getödteten Thier bedeutend stärker, was den sinnfälligen Unterschied in der Schwere der Krankheitserschei- 
nungen befriedigend erklärt. Bezüglich der Oelresorptionsgrösse im Bereiche des kleinen Kreislaufes bestand zwischen beiden Thieren keine gröbere Differenz. Eine ausgesprochene Fettembolie konnte freilich bei Kaninchen No. 7 nach 22 Stunden auch nicht erwartet werden, da ja immer einige Tage dazu gehören, um einen genügend grossen Bezirk von Lungengefässen durch Oel zu verlegen.

$\mathrm{Ob}$ bei Anwendung grosser Oelmengen häufig oder gar regelmässig schwere, womöglich tödliche Fettembolien zu Stande kommen, musste nun klargelegt werden. Es wurden deshalb weitere Versuche mit sehr grossen Quantitäten Sesamöl angestellt.

\section{Versuchsgruppe (14. XII. 08).}

No. 8. Männliches Kaninchen, grau, $2400 \mathrm{~g}$ schwer. Eröffnung der Peritonealhöhle in der mittleren Bauchgegend mit kleinem Medianschnitt. Die langsame Injection von $100 \mathrm{ccm}$ sterilisirten Sesamöls gelingt leicht und glatt ohne Oelverunreinigung der Bauchwunde. Am Operationstage mässiges Kranksein, das am folgenden Tage zunimmt. Keine Nahrungsaufnahme. Die Wunde sieht gut aus; es ist kein Oel herausgeflossen. Das Thier sitzt ruhig da, rührt dargebotene Lieblingsspeisen nicht all, nimmt an Gewicht und an Kräften - sichtliç bedeutend ab und wird immer kurzluftiger. Tod im Verlaufe des 6. Tages post injectionem. In der Abdominalhöhle werden grosse Mengen gänseschmalzartiger Massen gefunden, die sämmtliche Därme und die anderen Bauchorgane, sowie das Parietal- und Zwerchfellperitoneum in einer mehr oder weniger dicken Schicht überziehen. Mikroskopisch setzen sich diese Massen aus Fibrin, gut emulgirtem Oel und dicht gedrängten, mit Fettkörnchen vollgepfropften Eiterkörperchen zusammen. Bakterien werden weder im Ausstrich noch in der Cultur nachgewiesen. Die starre Emulsionsmasse der Bauchhöhle liess ich im NahrungsmittelUntersuchungsamt genauestens untersuchen. Im Vacuum-Exsiccator wurde die Emulsion allmählich aufgehoben. Es sonderten sich Oel und Exsudat wieder voneinander. Freie Fettsäuren waren in dem freigewordenen Oel nur in minimalster Menge, wie in jedem käuflichen Sesamöl enthalten; eine Verseifung war nicht erfolgt. Das von dem Exsudat geschiedene Oel war unverändertes Sesamöl. In dem sehr concentrirten, der Blase entnommenen orangefarbenen Urin reichliche Fettkügelchen verschiedener Grösše.

Wenn auch die Gefässbahnen in der Lunge theilweise durch Oel verlegt sind, hat man doch nicht den Eindruck, dass diese immerhin nur mässigen. und im Verhältniss zu Kaninchen No. 4 geringen Gefässverstopfungen den Tod verursacht haben. Auffallend sind die im Herzen und in den Lungen vorhandenen a usgedehnten Thrombosen. Offenbar tragen diese die Schuld an dem Tode des Thieres in erster Linie, während die fettembolischen Processe in der Lunge nur eine untergeordnete Rolle spielen. 
No. 9. Weibliches Kaninchen, grau, $1960 \mathrm{~g}$ schwer. Eröffnung der Bauchhöhle wie bei No. 8. Auch hier geht die Injection von $100 \mathrm{ccm}$ sterilisirten Sesamöls ohne Störung, speciell ohne Verschüttung von Oel und ohne Oelberährung der Bauchwunde vor sich. Während das Thier am Operationstage einen nur mässig kranken Eindruck macht, verschlechtert sich der Zustand mit jedem Tage. Kein Fressen. Am 3. Tage post injectionem sitzt es ganz ruhig da, kann sich bei leichter Berührung kaum aufrecht halten. Collapstemperatur, Tod noch im Verlaufe des 3. Tages. In der eröffneten Bauchhöhle reichlich ölige Flüssigkeit (ca. $70 \mathrm{ccm}$ ausgeschöpft). Därme, Magen, Leber an ibrer Ober- und Unterfläche, Milz bedeckt mit weissen Membranen, bezw. dünnen weissen Beschlägen von Fibrin, emulgirtem Oel und zahlreichen mehrkörnigen Leukocyten. Von besonderem Interesse ist der Befund an der Leber. Sie ist überlagert von einem sehr zellreichen Exsudat, das grosse Menge emulgirten Oels umschliesst. Es stellt im sudangefärbten Schnittpräparat einen rothen Streifen an der Oberfläche dar. Ausserdem findet sich aber noch ein anderer rother Streifen entsprechend den obersten Leberzelllagen. Dieser rührt von den direct in die Leberzellen eingetretenen und von Zelle zu Zelle gewanderten Oeltheilchen her. Das Oel lagert in den Zellen theils in dichten feinsten Tröpfchen, theils in grösseren zusammengeflossenen Tropfen und betrifft in dieser massenhaften Ablagerung gewöhnlich die beiden obersten Zelllagen des Lebergewebes. Wo sich Bindegewebs- und Gefässstrassen von der Leberoberfläche in die Tiefe einsenken, ziehen sich Reihen feinster Fettkörnchen entlang, intra- und extravasculär, innerhalb und ausserbalb von Zellen. Die Lungenoberfiäche erscheint matt, namentlich entsprechend den Unterlappen, die sich derb anfühlen. Grössere Partien der Lungen sind luftleer, ihre Alveolen erfüllt von fibrinöseitrigem oder mehr eitrigem Exsudat. Auch in den Bronchiolen massenhaft eitriges Exsudat. An spärlichen Stellen Verlegung grösserer Gefässzweige mit Oel, neben feinsten Fettkörnchen auch grössere Fettpartikel.

Es kann keinem Zweifel unterliegen, dass dieses Thier an der fibrinöseiterigen Pleuro-Pneumonie zu Grunde gegangen ist. Bei beiden Thieren dieser Gruppe hatte das viele Oel im A bdomen $(100 \mathrm{ccm})$, ähnlich wie bei der 1 . Versuchsgruppe das Alkannaöl, einen mächtigen abakteriellen Entzündungsprocess, vorwiegend fibrinöser Art, am Peritoneum hervorgerufen. Die Resorption von Oel aus dem Peritonealcavum war relativ gering und hatte keine gröberen mechanischen Störungen im Lungenkreislauf veranlasst. Trotz Fehlens nennenswerther fettembolischer Bezirke hat aber doch wohl die Oelüberschwemmung der Bauchhöhle den Tod der Thiere mitverschuldet.

Zur Probe auf die Richtigkeit dieses Ergebnisses, dass zwar durch die intraperitoneale Einspritzung übergrosser Oelmengen keine Embolie der Tunge erzeugt wird, die Thiere aber darunter schwer leiden, wiederholte ich in einer neuen Versuchsgruppe das 
Experiment mit der Injection von $100 \mathrm{ccm}$, also einer für Kaninchen sehr grossen Dosis sterilisirten Sesamöls.

\section{Versuchsgruppe. (15. I. 1909),}

No. 10. Weibliches Kaninchen, grauweiss, $2780 \mathrm{~g}$ schwer. Fröffnung der Peritonealhöhle und Art der Injection wio sonst. Ein Hineinfliessen von 0 el in die Bauchwunde wird sorgfältigst vermieden. Das Thier ist nach der Injection deutlich krank, frisst in den nächsten Tagen nicht und nimmt in Folge der anfangs fehlenden, später geringen Nahrungsaufnahme ein volles Pfund an Gewicht ab. Allmählich erholt es sich und verbält sich von da $a b$ wie ein gesundes Thier. Wundheilung per primam. Auch späterhin haben sich Lungenerscheinungen nicht bemerkbar gemacht. Das Thier hat noch mebrfach Junge geworfen.

No. 11. Männliches Kaninchen, weissgrau, $2010 \mathrm{~g}$ schwer. Hier gelingt das Einbringen der sebr grossen Oeldosis in die eröffnete Peritonealhöhle ebenfalls ohne Oelverunreinigung der Banchwunde. Wie No. 10 ist auch dieses Kaninchen entschieden krank und frisst in den ersten Tagen nicht, verliert $225 \mathrm{~g}$ an Gewicht. Vom 4. Tage ab ist es munterer. Glatte Wundheilung.

Zweeks Aufnahme des anatomischen Befundes zum Vergleich mit den Kaninchen der vorigen Versuchsgruppe (No. 8 und 9) wird das Thier ain 6. Tage post operationem getödtet. Im Abdomen finden sich neben sehr reichlichen Mengen unveränderten Sesamöls (ca. $80 \mathrm{ccm}$ ) weissliche starre Gerinnungsmassen, bestehend aus einer Fülle von Fibrin, mehrkörnigen Leukocyten und aus verschieden fein emulgirtem Oel. Die Gesammtmenge des ausgeschöpften Inhaltes an nicht emulgirtem und emulgirtem Oel, sowie an Exsudationsproducten beträgt $140 \mathrm{ccm}$. Die Baucheingeweide, besonders Leber und Milz von einer weissen Exsudatschicht überzogen. In den Lungen, die nicht adhärent und gut retrahirt erscheinen, werden nur inässige Mengen resorbirten Oelmaterials gefunden. Wohl sind auch grössere Arterien mit dichtliegenden Fettkugeln erfüllt, aber nur selten werden kleine hämorrhagische Lungenpartien angetroffen. Der bei weitem grösste Theil des Lungengewebes ist sehr Jufthaltig. Es zeigt sich an keiner Stelle eine Fet tembolie mit gröberen Circulationsstörungen.

Auch bei diesen beiden Thieren der V. Versuchsgruppe hatte die sehr grosse Oeldosis eine starke fibrinös-eiterige Peritonitis erzeugt, wie aus dem Verhalten von Thier No. 10 geschlossen werden konnte, und aus dem anatomischen Befunde bei dem getödteten Tier No. 11 zu 'ersehen war. Einer tödtlichen Fettembolie wurde offenbar entgegengewirkt durch den intensiven Exsudationsprocess, der das Oel im Abdomen festhielt, einen fortwährenden Nachschub resorbirten Oels verhütete und damit mechanische Kreislaufstörungen in der Lunge verhinderte. Um nun zu einem abschliessenden Urtheil über den Einfluss geringerer Oeldosen auf das Kaninchenperitoneum und auf den 
Kaninchenkörper zu gelangen, injicirte ich in einer weiteren Versuchsgruppe entsprechend Kaninchen No. 6 (III. Versuchsgruppe) $8 \mathrm{cem}$, verwandte aber nicht mehr wie früher Sesamöl, sondern 10 proc. Campheröl, weil ich mich den Pfannenstiel'schen Beobachtungen über die Einwirkung des officinellen Campheröls auf das menschliche Peritoneum möglichst anpassen wollte.

\section{Versuchsgruppe (11. I. 1909).}

No. 12. Weibliches Kaninchen, graa, $2610 \mathrm{~g}$ schwer. Einbringung ron $8 \mathrm{ccm} 10$ proc. Campheröls in die eröffnete Bauchhöhle ohne Zwischenfall; es fliesst kein Tropfen verbei. Nach merklichem Unbehagen in den ersten Stunden post injectionem wird das Thier bald munter, putzt sich und frisst. Die Wunde heilt gut. Das Thier nimmt nicht an Gewicht ab, erscheint vollkommen gesund. -- Ueber das weitere Verhalten des Kaninchens siehe VIII. Versuchsgruppe, No. 24.

No. 13. Männliches Kaninchen, weissgrau, $1940 \mathrm{~g}$ schwer. Glattes. Injiciren der $8 \mathrm{~cm} 10$ proc. Campheröls in die eröffnete Bauchböhle, ohne dass die Bauchwunde mit dem Oel in Berührung kommt. Sobald sich das Thier von der Narkose erholt hat, benimmt es sich wie ein gesundes Kaninchen, frisst und springt umher. Von einer Einwirkung der intraperitonealen Oelinjection auf den Allgemeinzustand ist nichts zu bemerken. Gute Wundheilung. Nicht nur keine Gewichtsabnahme, sondern sogar Gewichtszunahme, in der 1. Woche post injectionem um $160 \mathrm{~g}$. - Ueber das weitere Verbalten des Kaninchens siehe VIII. Versuchsgruppe, No. 25.

No. 14. Männliches Kaninchen, grau, $1830 \mathrm{~g}$ schwer. Rechts am Rippenbogen ein kleiner Bauchwandabscess. Die Injection der $8 \mathrm{ccm}$ 10 proc. Campheröls an einer dem Bauchwandabscess möglichst ferngelegewen Stelle gelingt, ohne dass nur ein Tropfen davon die Bauchwunde berührt. In den ersten Stunden nach der Injection fühlt sich das Thier anseheinend unbehaglich, erholt sich aber sehr schnell, ist noch vor Ablauf der ersten 24 Stuuden ganz munter, läuft herum und frisst. Die Wunde heilt gut. Im Verlaufe der 2. Woche vergrössert sich der schon vor der Injection vorhandene Bauchwandabscess, bricht. durch und entleert sehr zähen, Streptobacillen und kleine Kokken enthaltendeı Eiter. Entwickklung weiterer. Bauchwandabscesse, Auftreten von Durchfall, Gewichtsabnahme, Tod gut 4 Wochen nach der intraperitonealen Campherölinjection. Bei der Section zeigen sich die Därme in Folge der Enteritis stark aufgetrieben. In der Bauchhöble etwas seröse Flüssigkeit, die weder im Ausstrich noch culturell Bakterien erkennen lässt. Von Oel ist am Peritoneum nichts mehr zu seben; nur ein dünner weisser Belag auf der Leber und auf der abdominalen Zwerchfellseite ist bemerkbar. Pleura glatt und glänzend. Lungen und Herz ohne Besonderheiten. Auch mikroskopisch werden in den gehärteten Stückchen der Bauch- und Brustorgane Bakterien nicht gefunden. Von dem intraperitoneal injicirten Oel sind in den Lungen, die sich aus ziemlich gleichmässig grossen, gut lufthaltigen Alveolen zusammensetzen, nur minimale, sicher ganz uuschädliche Mengen zu finden. 
Bei diesen 3 Thieren der VI. Versuchsgruppe folgten auf die intraperitoneale Injection von $8 \mathrm{ccm} 10$ proc. Campheröls ebenso wenig stärkere locale Störungen oder eine nennenswerthe Allgemeinreaction, wie bei Kaninchen No. 6 nach der Einspritzung von $8 \mathrm{cem}$ Sesamöl.

Fügte ieh 'den $8 \mathrm{ccm} 10$ proc. Campheröls Argilla $(4 \mathrm{ccm}$ $=2 \mathrm{~g})$ oder Zinnober $(4 \mathrm{~cm}=6 \mathrm{~g})$ in feinpulverisirtem Zustande (Sieb 6) hinzu, so wurden die peritonealen Reizerscheinungen sofort stärker, besonders bei dem Zinnoberzusatz. Die Thiere litten darunter sichtlich, frassen nicht und nahmen an Gewicht ab.

\section{Versuchsgruppe (19. I. 1909).}

No. 15, 16, 17 u. 18. Die Argilla-Campherö]-Kaninchen (No. 15 und 16) erholten sich allerdings allmählich, begannen wieder zu fressen und blieben am Leben, die mit Zinnoberöl behandelten Kaninchen (No. 17 und No. 18) aber gingen im Verlauf von 6 Wochen unter starker Abmagerung, Anämie, Entkräftung und secundären Erkrankungen zu Grunde. Auf die schweren, offenbar durch Zinnober bewirkten Organveränderungenen, namentlich im Gebiete der Lungengefässe (enorme Intimawucherungen) gehe ich an dieser Stelle nicht näher ein.

24 Stunden nach der Argilla- bezw. Zinnober-Campheröl-Injection aus der Ohrvene entnommenes Blut (1 ccm) enthielt keine Argilla- oder Zinnoberpartikelchen.

Wenn wir die 21 peritonealen Oelresorptionsversuche (4 Meerschweinchen und 17 Kaninchen) noch einmal überblicken, so kommen wir zu dem Resultat, dass Oel keinesfalls, in jeder beliebig hohen-Dosis intraperitoneal injicirt, als unschädlich angesehen werden darf. Sehr grosse Mengen 0el (50-100 ccm) lösen regelmässig im Peritonealcavum eine starke fibrinös-eiterige Peritonitis aus und wirken in dieser Beziehung ähnlich wie kleinere Mengen Oel mit reizenden Zusätzen (Alkanna; Argilla, Zinnober). Die unter beiden Bedingungen gelieferte massige Exsudatschicht verhütet eine lebhafte Resorption aus dem Oeldepot und einen fortwährenden Nachschub von resorbirtem Oel, so dass der Lunge keine Gefahr einer Oelverstopfung ihrer zuführenden Blutstrassen droht. Also nicht die Fettembolie der Lunge ist es, was die. Thiere bei starker Oelanfüllung der Bauchhöhle gefährdet, sondern die Schädigung des Allgemeinzustandes, die damit einhergehende, zuweilen beträchtliche Gewichtsabnahme und secundäre Erkrankungen. Der Verminderung der Oeldosis $(20 \mathrm{ccm})$ geht parallel eine geringere Peritonealreizung mit geringerer und langsamer erfolgender Exsudation. Dafür ist die Oelresorption 
eine viel bedeutendere, und diese kann schwerere und tödliche Fettembolie der Lunge verursachen (Kaninchen No. 4). Noch kleinere Oelmengen etwa bis zu $10 \mathrm{ccm}$ (Olivenöl, Sesamöl, Campheröl) bringen das Kaninchen weder in die Gefahr einer Oelüberschüttung des Lungenkreislaufes noch bewirken sie eine übermässige exsudative Peritonitis oder eine wesentliche Beeinträchtigung des Allgemeinzustandes. Das nach peritonealer Injection so geringer Oeldosen im Lungenblut circulirende Oel entspricht den Oelmengen, die wir nach reichlichen subcutanen Campherölinjectionen beim Menschen in der Lunge zu finden pflegen und liefert ein mikroskopisches Lungenbild, wie ich es von einem Kaninchen gewann, bei dem das Oel versebentlich nicht in die Bauchhöhle, sondern intramusculär und subperitoneal in die Bauchwunde hineingerathen war.

Eine Allgemeinschädigung des Kaninchens und speciell eine Schädigung durch Fettembolie der Lunge ist demnach bei intraperitonealer Oelinjection ausgeschlossen, wenn man die Dosis nicht zu hoch wählt, d. h. nicht über etwa $10 \mathrm{cem}$ hinausgeht. Auf den Menschen rein gewichtsmässig berechnet, würde diese für das Kaninchen unschädliche Oeldosis etwa ciner Oelmenge von 200 bis $300 \mathrm{ccm}$ gleichkommen.

Nachdem ich so für das Kaninchen die sichere Unschädlichkeit einer intraperitonealen Injection von $8 \mathrm{ecm} 10$ proc. Campheröls nachgewiesen hatte, wandte ich mich der weiteren experimentellen Frage zu:

U eberstehen Kaninchen eine peritoneale Infection mit einem fïr sie virulenten Bakterienstamm leichter, wenn man vorher die als unschädlich erkannte Campheröldosis intraperitoneal injicirt?

Ich experimentirte wie Glimm mit Bacterium coli, und zwar mit einem Stamm, der aus einem an peritonealer Colieiterung gestorbenen Kaninchen gezüchtet war.

Inficirt mit $2 \mathrm{cem}$ einer ca. 24 stündigen Bouilloncultur dieses Colistammes, starben 2 kleine Kaninchen von 1175 bezw. $1310 \mathrm{~g}$ Körpergewicht (No. 19 und No. 20: 18. 1. 1909) nach 6 bezw. 10 Stunden an Colisepsis.

Die Versuchsanordnung und Versuchstechnik blieben dieselben wie bisher. In der früher beschriebenen Weise wurden zunächst $8 \mathrm{ccm}$ sterilen 10 proc. Campheröls in die Bauchhöhle gebracht und entweder unmittelbar danach oder später genau 
abgemessen $2 \mathrm{ccm}$ einer natürlich für jede Versuchsgruppe frisch angelegten Bouilloncultur des gewählten Colistammes unter subtilster Vermeidung der Bauchwunde intraperitoneal injicirt.

VIII. Versuchsgruppe (22. I. 1909).

Auf die 5 Thiere dieser Gruppe werden mehrere miteinander vermischte 20 stündige Bouillonculturen so vertheilt, dass jedes $2 \mathrm{ccm}$ Culturflüssigkeit mit ungefähr gleichen Mengen von Bakterien eingespritzt erhält.

No. 21. Männliches Kaninchen, weiss, $1900 \mathrm{~g}$ schwer. Oel und Bakterien werden unmittelbar nacheinander ohne Verunreinigung der Bauchwunde in das geöffnete Peritonealcavum gebracht, das Peritoneum sogleich exact geschlossen. Das Thier ist nach dem inficirenden Eingriff schwer krank, erholt sich nicht und stirbt ca. 12 Stunden nach der peritonealen Colinfection. Die Section ergiebt das Oel im Abdominalraum sehr gut vertheilt, viscerales und parietales Peritoneum gleichmässig von einer dünnen Oelschicht bedeckt; MiJz und Leber von einer feinen ölumschliessenden Fibrinlage überzogen. An den Brustorganen keine Besonderheiten, speciell Pleura in ihren verschiedenen Abschnitten glatt und glänzend. Wie zu erwarten, keine Fettembolie, sondern nur mässiger Grad von Lipämie in den Lungen. Nicht nur aus der Bauchhöhle, sondern auch aus allen untersuchten Organen (Leber, Milz, Lunge) und aus dem Herzblut lassen sich Colibakterien in Reincultur züchten. Besonders üppiges Coliwachsthum liefert das Herzblut. Diesem Culturergebniss entspricht ganz der Bakterienbefund in den Schnittpräparaten. Vor allem finden sich im Herzen, aber auch in den Milzgefässen sehr reichliche, zum grössten Theil freiliegende Colibakterien. In der Leber und Lunge werden diese vielfach phagocytirt angetroffen.

Trotz der gleichzeitig mit der peritonealen Coliinfection ausgeführten Campheröl-Behandlung des Bauchfelīs ist eine ungeheure Resorption von Bakterienmaterial aus der Bauchhöhle erfolgt; der kleine Kreislauf zeigt sich geradezu übersehwemmt von Colibakterien. Das Thier ist zweifellos an der Colibakteriämie zu Grunde gegangen.

No. 22. Controlthier. Vännliches Kaninchen, grau, $1960 \mathrm{~g}$ schwer. Ohne vorherige Oelinjection werden lediglich $2 \mathrm{ccm}$ der 20 stündigen Coli-Bouilloncultur in die eröffnete Bauchhöhle gespritzt. Das Thier ist nach der Injection krank, erscheint aber nach Erwachen aus der Narkose bedeutend wohler als No. 21 mit seiner der abdominalen Colïnfection vorausgeschickten intraperitonealen Campherölein spritzung. Am folgenden Tage bessert sich der Zustand; das Thier fängt an, für die Umgebung Interesse zu zeigen. Am 3. Tage post infectionem läuft es umher, frisst und macht wieder einen gesunden Eindruck. Auch weiterhin ist es dauernd munter; die Wunde heilt gut. 3 Wochen post infectionem beträgt sein Gewicht $2040 \mathrm{~g}$.

Das Controlthier hat also ohne Oelbehandlung des Bauchfells die peritoneale Coliinfection nach mässig schwerer Erkrankung gut überstanden. 
No. 23. Männliches Kaninchen, grauweiss, $1410 \mathrm{~g}$ schwer. Oel und Bakterien werden unmittelbar nacheinander in die Bauchhöhle gebracht. Da der das Peritoneum umschliessende Faden reisst, lässt sich das Zurückfliessen einer allerdings nur geringen Menge der intraperitoneal injicirten Coliculturflüssigkeit and damit eine Verunreinigung des Bauchwundgebietes nicht vermeiden. Gleich nach dem Aufwachen aus der Aethernarkose etwa 3 Stunden lang heftige Krampfanfälle mit Betheiligung aller Körpertheile (Kopf, Rumpf und Extremitäten). Nach Aufhören der Krämpfe sehr elender Zustand, niedrige Körpertemperatur. Am folgenden Tage Durchfall, Unsicherheit auf den Beinen, aber im Ganzen etwas besserer Allgemeinzustand. Die Besserung schreitet nur langsam fort. Leichte Eiterung der Bauchwunde. Bei aller Munterkeit und Fresslust nach überstandener Infection hat das Thier nach 3 Wocheu die anfangs eingetretene Gewichtsabnahme noch nicht wieder ausgeglichen (Gewicht am 12. Il. 09: $1320 \mathrm{~g}$ ).

Trotz Campheröl-Behandlung des Bauchfells unmittelbar vor der peritonealen Coliinfection ist dies Kaninchen aufs Schwerste erkrankt und hat die Erkrankung nur sehr allmählich überwunden.

No. 24. Weiblicbes Kaninchen, grau, $2620 \mathrm{~g}$ schwer. Das Thier hatte vor 11 Tagen am 11. I. 1909 eine intraperitonele Injection von $8 \mathrm{ccm} 10$ proc. Campheröls ohne nennenswerthe Erscheinungen von Kranksein durchgemacht (cf. VI. Versuchsgruppe No. 12). Heute lediglich Injection von $2 \mathrm{ccm}$ der 20 stündigen Colibouilloncultur in die wiedergeöffnete Bauchhöhle. Die Coliinfection verläuft mit auffallend geringer Reaction. Das Thier frisst vom 2. Tage post infectionem $a b$ und läuft munter umher. In der 2. Woche post injectionem aber erkrankt das Thier, sitzt viel ruhig da, frisst wenig, leidet an Durchfall und Kurzluftigkeit und stirbt am 9. II. 1909, also gut vier Wochen nach der intraperitonealen Campherölinjection, $21 / 2$ Wochen nach der abdominalen Coliinfection. Sectionsbefund: In der Bauchhöhle keine Flüssigkeit; von Oel nichts erkennbar. Peritoneum fast überall glatt, Leber bedeckt mit einem feinen weissen Belag. Därme stark aufgetrieben, mit dünnem Iuhalt bis in die unteren Partien gefüllt $\mathrm{Ab}$ impfungen aus der Bauchböhle ergeben weder auf Agar noch in Bouillon Bakterienwachsthum; auch im Ausstrichpräparat keine färbbaren Colibakterien. Beide Unterlappen der Lungen fast luftleer, derb und fest; die übrigen Lungenlappen gut lufthaltig. Mikroskopisch die Lungenalveolen und Bronchioli beider Unterlappen von eitrigem resp. fibrinöseitrigem Exsudat ausgefüllt, die Alveolen der anderen Lappen compensatorisch erweitert. Hier und da enthalten kleinere Gefässe Oelkügelchen, dagegen sind alle grösseren Gefässe frei von Oel.

Die peritoneale Coliinfection hat auf dieses Thier wenig schädigend eingewirkt. Es trat keine tödtliche Colisepsis auf wie bei Kaninchen No. 21, noch eine so schwere septische Erkrankung wie bei Kaninchen No.23. Das Thier ist zwar $2 \frac{1}{2}$ Wochen post infect. einer Pneumonie beider Unterlappen und einer schweren Enteritis erlegen; doch standen diese Erkrankungen 
nach dem Sectionsergebniss weder mit der Oelinjection noch mit der Coliinfection in einem ursächlichen Zusammenhang. Colibaktcrien: waren in der Bauchhöhle, im Blute und in den Orgaren des eben gestorbenen Thieres nicht mehr nachweisbar.

No. 25. Männliches Kaninchen, weissgrau, $2140 \mathrm{~g}$ sehwer. Ebenso wie No. 24 hatte dies Thier vor 11 Tagen am 11. I. 09 eine intraperitoneale Injection von $8 \mathrm{ccm} 10$ proc. Campheröls ohne Einwirkung auf den Allgemeinzustand und ohne irgendwelche Krankheitserscheinungen durchgemacht (cf. VI. Versuchsgruppe No. 13). Heute wie bei No. 24 lediglich Injection von $2 \mathrm{ccm}$ der 20 stündigen Colibouilloncultur in die wieder geöffnete Bauchhöhle. Die peritoneale Coliinfection wird ganz auffallend leicht überwunden. Schon am 1. Tage erscheint das Thier nicht nennenswerth krank, wird am nächsten Tage lebhafter, frisst und tummelt sich wie ein gesundes Kaninchen. Auch weiterhin kein Zeichen von Krankheit. Am 12. II. 09, also 3 Wochen nach der Coliinfection, Bauchwunde nicht mehr aufzufinden. Das sehr muntere Thier wiegt $2320 \mathrm{~g}$, hat demnach trotz der peritonealen Infection in 3 Wochen $180 \mathrm{~g}$ an Gewicht zugenommen.

Von allen 5 Thieren derVIII. Versuchsgruppe hat dies Kaninchen unter der peritonealen Coliinfection am allerwenigsten gelitten.

Werfen wir einen prüfenden Blick auf die Resultate dieser 5 Versuche (VIII. Versuchsgruppe), so müssen wir zunächst constatiren, dass das Controlthier No. 22 die peritoneale Coliinfection nach mässig schwerer Erkrankung gut überstanden hat. Also musste entweder die zu dem Versuche verwendete Cultur keine hochgradige Virulenz haben, trotzdem sie kleine Kaninchen binnen wenigen -Stunden getödtet hatte, oder es musste bei der Auswahl des Controlthieres ein ungewöhnlich widerstandsfähiges, bezw. gegen Coli immunes Kaninchen getroffen worden sein. Ferner. jst hervorzuheben, dass beide unmittelbar vor der Coliinfection mit Campheröl behandelten Thiere (No. 21 u. 23) besonders schwere Krankheitserscheinungen aufwiesen, No. 21 nach 12 Stunden an Colisepsis starb und No. 23 nur mit grosser Mühe und sehr allmählich der recht schweren septischen Erkrankung Herr wurde. Im auffallenden Gegensatz dazu überwanden die 11 Tage vor der Coliinfection mit derselben Menge Campheröls vorbehandelten Kaninchen (No. 24 und 25) die bakterielle Ueberschüttung des Peritoneums leicht, No. 25 sogar sehr leicht. Der an Unterlappen-Pneumonie und Enteritis $21 / 2$ Wochen nach der peritonealen Coliinfection erfolgte Tod des Kaninchens No. 24 hatte offenbar mit der experimentellen Coli- 
infection gar nichts zu thun, da bei der Section die Bauchhöhle wieder keimfrei war und auch sonst im Körper des Kaninchens ein Colibakteriendepot nicht gefunden wurde.

Die als These aufgestellte Unschädlichkeit einer intraperitonealen Injection von $8 \mathrm{ccm} 10$ proc. Campheröls wurde durch den Lungenbefund bei den Kaninchen No. 21 u. 2412 Stunden bezw. gut 4 Wochen nach der Oelung bestätigt.

Enttäuscht wurde ich durch die ungünstige Einwirkung der Campherölbehandlung des Peritoneums auf die unmittelbar folgende abdominale Coliinfection. Nach den Angaben Glimm's (vergl. seine Versuche $43-46$ 1. c., S. 281) hätte man bei den so mit Oel intraperitoneal behandelten Thieren ein leichteres Ueberstehen der peritonealen Coliinfection gegenüber dem Controlthier erwarten müssen. Zu meiner Ueberraschnng war aber gerade das Gegentheil der Fall. Diese Thiere erkrankten sogar schwerer als das nicht geölte Controlthier, und No. 21 war sogar der Colisepsis, die man ja gerade vermeiden wollte, und die man nach Glimm durch die Oelung sollte verhüten können, in rapider Weise erlegen.

War dies Ergebniss die Folge eines Versuchsfehlers meinerseits, oder spielte der Zufall dabei eine Rolle? Um diese sich mir aufdrängenden Fragen beantworten zu können, wiederholte ich die. gleichen Versuche an einer weiteren Reihe von Thieren.

\section{Versuchsgruppe (23. II. 1909).}

2 Kaninchen werden unmittelbar nach der in gewohnter Weise ausgeführten intraperitonealen Injection von $8 \mathrm{ccm}$ sterilen 10 proc. Campheröls $2 \mathrm{ccm}$ einer 16 stündigen Bouilloncultur des schon für die VIII. Versuchsgruppe verwendeten Colistammes in die Bauchhöhle injicirt, während 2 andere Kaninchen, 1 gesundes und 1 an Bauch wandabscessen und Hodenverletzung leidendes Kaninchen als Controlthiere dienen.

No. 26. Männliches Kaninchen, schwarz mit weissen Flecken, $2010 \mathrm{~g}$ schwer. Oel und gleich darauf die Bakteriencultur werden ohne Verunreinigung der in der mittleren Bauchgegend angelegten Wunde in die Bauchhöhle gebracht. - Post infect. deutliches Kranksein, ruhiges Dasitzen, kein Fressen. Auch am nächsten Tage keine Besserung. Im Anschluss an eine Blutentnahme aus der linken Vena cruralis $(2 \times 1 \mathrm{ccm})$ verliert das Thier unbemerkt noch ca. $20 \mathrm{ccm}$ Blut und stirbt bald nach der Blatstillung, 27 Stunden nach der Oel- und Coliinjection.

Sectionsbefund: Das Oel gleichmässig im Abdomen vertheilt, alle Organe und die Parietalserosa von einer dünnen aus Fibrin, Oel und Leukocyten bestehenden Schicht überzogen. In Leber und Milz werden reichlich, in Lunge und Herzblut spärlichere Colibakterien gefunden. 
Wahrscheinlich hätte das Thier ohne den vermeidbaren Blutverlust den Infectionsprocess überstanden, da es vor der acuten Anämie keinen schwerkranken Eindruck machte und die bakteriologische Untersuchung post mortem keine hochgradige Colibakteriämie ergab.

No. 27. Männliches Kaninchen, graubraun, $1790 \mathrm{~g}$ schwer. Oel und gleich darauf die Colicultur gelangen wie bei No. 26 ohne Zwischenfall in das Peritonealcavum. - Deutliches Kranksein, ruhiges Dasitzen, kein Fressen, wie bei No. 26. Vorsichtige Blutentnahme aus der freigelegten Vena femoralis $(2 \mathrm{ccm}) 24$ Stunden $\mathrm{p}$. infect. Aus dem Venenblut gehen nur vereinzelte Colicolonien an. Nach 4 Tagen erscheint das Thier wieder munterer und frisst (Bauchwunde und Oberschenkelwunde geschlossen).

Das" Thier hat also die Coliinfection nach 3 tägigem, mässig schwerem Kranksein gut überstanden.

No. 28. Gesundes Controlthier. Männliches Kaniwchen, aschgrau, $1830 \mathrm{~g}$ schwer. Ohne vorherige Oelinjection werden lediglich $2 \mathrm{ccm}$ der 16 stündigen Colibouilloncultur in die eröffnete Bauchhöhle eingespritzt. - Das Thier macht einen entschieden weniger kranken Eindruck als No. 26. Es läuft schon am Operationstage herum und putzt sich. Am nächsten Tage frisst es und erscheint bald ganz und danernd gesund. Bauchwunde und Oberschenkelwunde heilen p. primam. Aus $2 \mathrm{ecm}$ der Vena cruralis 24 Stunden p. inject. entnommenen Blutes wird ein nur sehr spärliches Coliwachsthum erzielt.

Das Controlkaninchen ist über die peritoneale Coliinfection leichter, schneller und glatter hinweggekommen als die gleichzeitig mit Campheröl behandelten eigentlichen Versuchsthiere.

No. 29. Krankes Controlthier. Männliches Kaninchen, gelb $1550 \mathrm{~g}$ sehwer. Das Thier leidet an je einem Bauchdeckenabscess rechts oben und links unten. Ausserdem Hodenverletzung durch Biss seitens eines anderen Kaninchenbockes. - Ohne vorherige Oelinjection werden lediglich $2 \mathrm{~cm}$ der 16 stündigen Colibouilloncultur in die eröffnete Bauchhöhle eingespritzt. - Das Thjer macht nach Erwachen aus der Aethernarkose einen sehr elenden Eindruck und stirbt nach 5 Stunden an der Coliinfection. Aus allen Organen, auch aus dem Herzblut konnten Colibakterien gezüchtet werden.

Mit dieser Versuchsgruppe gewann ich insofern grössere Klarheit, als ich den verwendeten Colistamm mit Sicherheit als einen nur mässig virulenten erkannte, der sogar gegenüber der vorigen Versuchsgruppe noch an Virulenz eingebüsst hatte. Von den Controlthieren hatte das gesunde die Infection spielend leicht überwunden, während das kranke zu elend war, um selbst der geringen Virulenz des injicirten Bakterienmaterials Widerstand leisten zu können. In dieser Versuchsgruppe 
wiederholte sich dasselbe Spiel wie in der VIII. Versuchsgruppe. Dem gesunden Controlthier No. 28 war ron der abdominalen Coliinfection viel weniger anzumerken als den unmittelbar ante infectionem mit Campheröl behandelten Versuchsthieren No. 26 u. 27. Auf Grund dieser Erfahrungen gelangte ich zu dem Wahrscheinlichkeitsschluss, dass die gleichzeitige Oelbehandlung des Peritoneums dem Kaninchen im Kampfe gegen die peritoneale Coliinfection nicht nur nicht nützt, sondern sogar schadet. Um aber zu diesem Schluss voll berechtigt zu sein, machte ich zum 3. Mal das gleiche Experiment und verwandte dazu Colibakterien aus der Bauchhöhle der gestorbenen Kaninchen No. 26 u. 29, in der Erwartung, es habe der Colistamm in Folge der neuen Thierpassage an Virulenz zugenommen.

\section{Versuchsgruppe.}

Am 27. II. 1910 werden 3 Kaninchen unmittelbar vach der intraperitonealen Injection von $8 \mathrm{ccm}$ sterilen 10 proc.Campheröls $2 \mathrm{ccm}$ der 20 stündigen Colibakterienbouillon in die Bauch höhle injicirt, während ein mittelgrosses, gesundes Kaninchen als Controlthier diente.

No. 30. Männliches Kaninchen, weissgrau, $3140 \mathrm{~g}$ schwer. Oel und Colibouilloncultur werden nacheinander unterhalb der Mitte des Bauches etwas rechts von der Medianlinie in das eröffuete Peritonealcavum ohne Verunreinigung der Bauchwunde unter langsamem Einfliessenlassen mittels Trichters eingebracht. Intraperitoneale Coliinfection 11 Uhr 6 Min. a. m. Nach dem Erwachen aus der leichten Narkose ist das Thier recht elend. 12 Uhr 32 Min. Mittags, also 1 Stunde 26 Min. p. infect. aus der Ohrvene entnommenes, auf Agar ausgestrichenes Blut ergiebt reichlich in Reincultur gewachsene Colicolonien. 1 Uhr 5 Min. Mittags, also 2 Stunden nach der Coliinfection stirbt das Thier, nachdem es vorher sehr unruhig und kurzluftig geworden ist. Sectionsbefund: Auf allen Bauchorganen eine dünne Oelschicht, nur minimale Oelanhäufungen an den tiefsten Stellen der Abdomina höhle. Ausser mässiger Hyperämie keine Btsonderheiten an den Baucheingeweiden. Auch Herz und Lungen lassen makroskopisch Veränderungen nicht erkennen. Aus allen Organen (Leber, Milz, Lunge) und aus dem Herzblut ( $1 \mathrm{ccm}$ des rechten Ventrikels) werden grosse Mengen von Colibakterien gezüchtet.

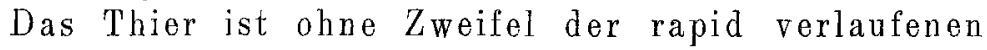
Colisepsis erlegen.

No. 31. Männliches Kaninchen, gelbschwarz, $2320 \mathrm{~g}$ schwer. Einfliessenlassen von $\mathrm{Oel}$ und Colibouilloncultur mittelst Gummischlauchs und Trichters in derselben Menge und in derselben Weise wie bei No. 30 in das median unterhalb der Bauchmitte eröffnete Peritonealcavum: 11 Uhr 28 Min. a. m. Das aus der Narkose erwachte Thier dentlich krank. 12 Uhr 35 Min. Hittags, also 67 Minuten nach der ab- 
dominalen Coliinfection aus der Obrvene entnommenes Blut ergiebt wie bei No. 30, auf Agar ausgestrichen, reichliches Wachsthum von Colibakterien in Reincultur. Allmählich erholt sich das Thier, fängt wieder an zu fressen und befindet sich nach einigen Tagen ganz wohl. 4 Wochen später erkrankt es und stirbt 5 Wochen nach der peritonealen Colinfection an ausgedehnter eiteriger Bronchitis und fibrinös-eiteriger Pleuritis. In der Abdominalhöhle keine Adhäsionen. Colibakterien lassen sich nicht mehr aus dem Peritonealcavum züchten. In den Lungen keine nemnenswerthen Oelmengen.

Dies Kaninchen hatte die Coliinfection überwunden und ist einer Erkrankung, die nicht mit der intraperitonealen Oelinfection (keine Fettembolie) und nicht mit der abdominalen Coliinfection (Colibakterien aus dem Körper verschwunden) zusammenhängt, dem acut-eitrigen Entzündungsprocess der Athmungswege mit Betheiligung der Pleura zum Opfer gefallen.

No. 32. Männliches Kaninchen, grau, $2150 \mathrm{~g}$ schwer. Ohne Störung wird Oel und Bakterienmaterial in die median unterhalb der Bauchmitte eröffnete Bauchhöhle gebracht, in derselben Weise und Menge wie bei No. 30 und 31 (11 Uhr 46 Jlin. a. m.). Das Thier ist nach beendeter Operation recht elend. 56 Min. nach der abdominalen Coliinfection aus der Ohrvene entnommenes Blut giebt, auf Agar ausgestrichen, sehr reichliches Wachsthum von Colibakterien neben einigen Luftkeimen. In den ersten Tagen ist das Thier sehr kümmerlich, sitzt ruhig und traurig da, wird erst vom 3. Tage ab munterer, frisst dann wieder und erscheint zunächst gesund. Nach 11 Wochen stirbt das Thier. Sectionsbefund: Ausgedehnte fibrinös-eiterige Peritonitis mit festen Adhäsionen, vor Allem an der vorderen Bauchwand. Hinter der vernarbten Bauchwunde ein rundlicher, fast gänseeigrosser, allseitig mit Bauchwand, Dünnund Dickdärmen locker verwachsener Körper, ein abgekapselter Herd von emulgirtem 0 el und von Eiter, der Colibakterien in Reincultur enthält. Die adhäsive fibrinös-eiterige Peritonitis erstreckt sich bis hinauf zur Leber. Im unteren Theil der Bauchhöble kein Exsudat. Das Blut ist bakterienfrei.

Es handelt sich also bei dem Thier um einen abgekapselten Eiterungsprocess in der Bauchböhle, entstanden im Gefolge der abdominalen Coliinfection.

No. 33. Controlthier. Männliches Kaninchen, grau, $2120 \mathrm{~g}$ schwer. Ohne vorherige Oelinjection werden lediglich gut $2 \mathrm{ccm}$ derselben 20 stündigen Colibouilloneultur in die median unterhalb der Bauchmitte eröffnete Abdominalhöhle eingespritzt, ohne dass ein Tropfen vorbeifliesst und etwa die Bauchwunde verunreinigt (12 Uhr 1 Min. mittags). Das inficirte Thier scheint mässig krank, am wenigsten von allen vier Thieren dieser Versuchsgruppe. 46 Min. nach der abdominalen Coliinfection aus der Ohrvene entnommenes Blut liefert, auf Agarplatten ausgestrichen, reichliches Wachsthum von Colibakterien. Schon am folgenden Tage wird das Thier munterer, schnuppert umber und nimmt Nahrung zu sich. Die Wunde heilt gut. Das Thier bleibt am Leben. 
Wenn ich auch nur einmal bei jedem Thier dieser Versuchsgruppe $3 / 4$ bis $1 \frac{1}{2}$ Stunden post infectionem Blut aus der Ohrvene entnommen und den daraus culturell erzielten Bakteriennachweis nicht zahlenmässig geführt hatte, so ging doch klar aus diesen 4. Versuchen der X. Versuchsgruppe hervor, dass trotz der peritonealen Campherölbehandlung eine beträchtliche Bakterienresorption aus der Bauchhöhle stattgefunden hatte, keinesfalls eine geringere, als bei dem nicht geölten Controlthier. Auch diesmal war das Controlthier mit der Coliinfection am besten und schnellsten fertig geworden. Da nun 3 Versuchsgruppen immer wieder dasselbe Resultat ergeben hatten, konnte ein Zufall ausgeschlossen werden. Es musste damit als bewiesen gelten, dass die der abdominalen Coliinfection unmittelbar vorausgeschickte Campherölbehandlung des Peritoneums dem Kaninchenkörper im Kampfe mit den Colibakterien sicher nicht nützt, sondern dass sie im Gegentheil nachtheilig wirkt. Ein Einfluss auf die Bakterienresorption im Sinne einer Verhütung oder auch nur auffälligen Verminderung des Uebertritts der peritoneal injicirten Bakterien in die Blutbahn war nach den im Groben angestellten Blutculturproben nicht zu erkennen.

Diese Incongruenz mit den Angaben Glimm's konnte ihre Aufklärung nur durch systematische bakteriologische Prüfungen der Keimresorption aus der Bauchhöhle bei geölten und nicht geölten Thiereñ finden.

Für die damit nothwendig werdenden häufigen Blutuntersuchungen zeigte sich die zunächst noch gewählte Entnahme aus der Ohrvene immer klarer als unzulänglich. Die Ohrvene musste als eine genügend ergiebige Blutentnahmequelle deshalb ausscheiden, weil bekanntlich mit jeder Peritonealreizung eine Anämie der Körperoberfläche einhergeht, und das Gewinnen von einigen Cubikcentimetern Blut auch für den Geübten bei gutem technischen Geschick zu einem schwierigen und zeitraubenden Manöver wird. Die Freilegung von grösseren Venen, wie der Jugularis oder Femoralis, ist $\mathrm{zu}$ umständlich und hat überhaupt nur dann einen Zweck, wenn man einmal eine grössere Menge Blut benöthigt. Die am häufigsten angewandte Art der Blutentnahme aus der mit einer Klemme verschlossenen Carotis erschien mir unnöthig grausam und aus einem doppelten Grunde unzweckmässig, wegen der Verblutungs- und Infectionsgefahr. Ich kehrte deswegen zu einem 
Modus der Blutgewinnung zurück, den ich schon bei früheren Versuchsgruppen als ungefährlich, sauber und technisch einfach erprobt hatte. Ich entnahm die für die bakteriologische Untersuchung nothwendigen Blutmengen direct dem Herzen mittels feinen Troicarts. Von den Troicartcanülen liess ich mir mehrere anfertigen, genau passend zu einer in Zehnteltheile eingetheilten 2 ccm haltenden Spritze.

Die folgende Abbildung soll die zur Herzpunction nothwendigen Hülfsmittel in ihrer Einfachheit veranschaulichen.

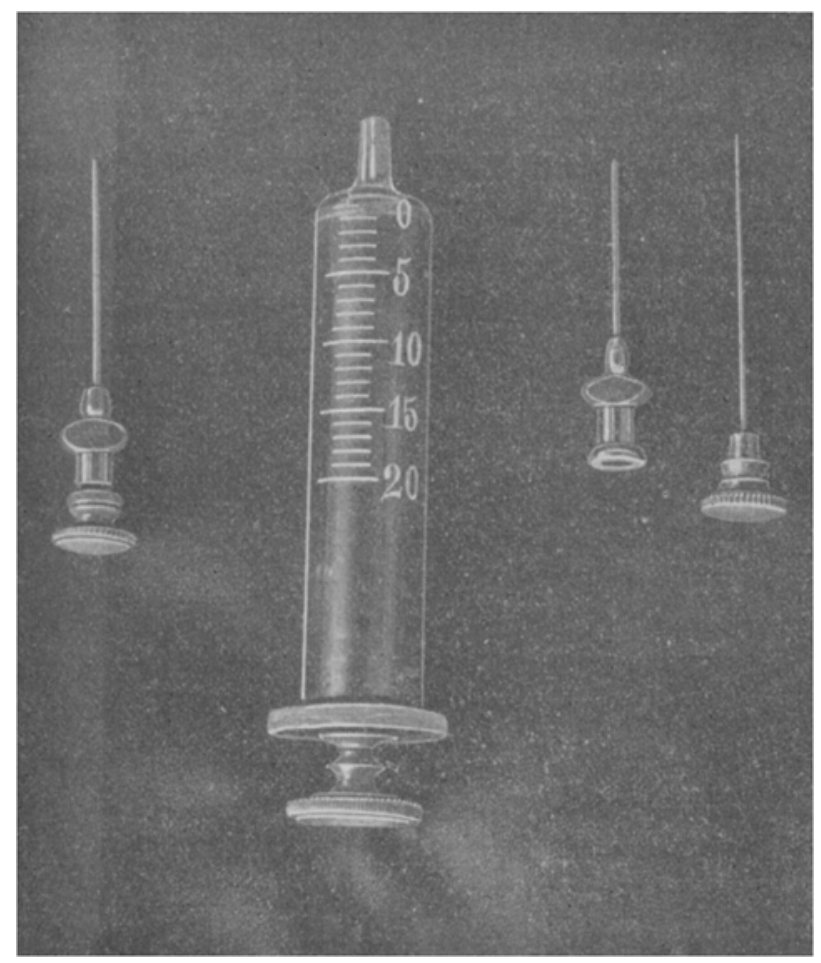

Eine ganze Reihe von Vorversuchen hatte mir die Gewissheit gegeben, dass die Blutentnahme aus dem Herzen bei richtiger Ausführung mit einem exact gearbeiteten, gut gehaltenen Instrumentarium eine sichere, aseptische und ungefährliche Methode darstellt. Natürlich kann gelegentlich auch einmal ein sehr unruhiges Thier einen pericardialen Bluterguss davontragen und daran zu Grunde gehen. Doch gehören solche Ereignisse zu 
den Seltenheiten. Ich habe bis zu 14 Herzpunctionen an einem Kaninchen vorgenommen, ohne das Thier in erkennbarer Weise zu schädigen. Man muss nur mit sicher geführtem Stich in das Herz hineinkommen. Dazu gehört aber eine absolut scharfe Troicartnadel. Mit stumpfer Nadel sticht man das Herz an, durchbohrt aber nicht die Herzwand, sondern schiebt bei weiterem Vordringen das angestochene Herz in die Tiefe des Thorax. Aber auch, wenn man ganz scharfe Nadeln zur Verfügung hat, kann doch die Herzpunction missglücken, nämlich, wenn bei schweren Infectionen in Folge starken Sinkens des Blutdrucks die Herzwand so weich und nachgiebig geworden ist, dass sie selbst der scharfen Nadel ausweicht und wegen des mangelhaften Tonus gewissermaassen eingebeult wird.

Vor Ausführung der Herzpunction wurde stets die entsprechende Thoraxgegend sauber rasirt, mit Aether sorgfältig abgerieben, und nun der Troicart in den Intercostalraum, wo die deutlichste Herzpulsation zu fühlen war, krältig eingestochen. Je nachdem ich ins linke oder rechte Herz hineingelangt war, bekam ich natürlich dunkles oder hellrothes Blut, und zwar in einer beliebig grossen Menge. $\mathrm{Zu}$ diesem $\mathrm{Zwecke}$ wurde die Troicartnadel entfernt, während dje Canüle sicher fixirt gehalten wurde, die leicht gehende und genau passende Spritze aufgesetzt, und nun das Blut angesogen. Oft genug pumpte das Herz mit eigener Kraft unter Anheben des Kolbens das Blut in die Spritze hinein. Nach genügender Füllung der Spritze wurde die Troicartcanüle mit einem energischen Zug entfernt.

Es lag mir zunächst daran, für die Resorptionsprüfungen ein Bacterium in die Kaninchenbauchhöhle zu bringen, das die Versuchsthiere nicht schwer krank macht oder gar tödtet, das für gewöhnlich im Kaninchenkörper nicht vorkommt, das aus dem Blute leicht gezüchtet und schon makroskopisch auf der Platte identificirt und von etwaigen Verunreinigungen sicher unterschieden werden kann.

Alle diese Eigensehaften besitzt das Bacterium prodigiosum ${ }^{1}$ ).

1) Bacterium prodigiosum, sowie das für die späteren Versuche velwandte Bacterium coli haemolyticum wählte ich auf den Rath des Geh. Med.Raths Prof. Dr. Fischer, Director des hygienischen Instituts in Kiel. Bei den nächsten Versuchsgruppen (XI. bis XIV. Versuchsgruppe) wurde ich in zuvorkommendster Weise von dem Privatdocenten am hygienischen Institut Dr. Reiner Müller mit Rath und That" unterstützt. Beiden Herren danke ich auch an dieser Stelle für ihr bereitwilliges Entgegenkommen. 
Nach der peritonealen Prodigiosusinjection wurden zu verschiedenen Zeitpunkten, die bei Versuchs- und Controlthieren einander möglichst entsprachen, Blutproben entrommen, mit flüssiggemachtem Agar vermischt, in Petrischalen ausgegossen und im Brutofen bei $37^{\circ}$ C. gehalten. Nach Ablauf von mindestens 24 Stunden erfolgte zum ersten Mal eine Controle der Blutagarcultur auf das erzielte Prodigiosuswachsthum, indem die einzelnen Colonien ausgezählt wurden. War das Wachsthum sehr reichlich, so wurde der Boden der Petrischale in möglichst gleiche Quadranten eingetheilt, je nach der Menge und Vertheilung der Colonien 1 oder 2 Quadranten genau gezählt, und dann durch Multiplication die Gesammtzahl der angegangenen Colonien berechnet. Die Culturen wurden dann noch mehrere Tage hindurch beobachtet. Die auf wiederholte Untersuchungen der Culturen sich bezjehenden Eintragungen sind der besseren Uebersicht halber nur dann in der Arbeit erwähnt, wenn beträchtliche Abweichnngen von den nach mindestens 24 stündigem Wachsthum gefundenen Zahlen und vor Allem Verschiebungen in den Verhältnisszahlen vorhanden waren.

\section{Versuchsgruppe.}

Am 4. III 1909 wird zwei fast gleich grossen Kaninchen die Prodigiosuscultur in die eröffnete Bauchböhle eingespritzt, dem ersten nach vorausgeschickter intraperitonealer Campherölinjection, dem zweiten obne Oelbehandlung des Peritoneums.

No. 34. Männliches Kaninchen, schwarz, $1885 \mathrm{~g}$ schwer. $8 \mathrm{ccm}$ 10 proc. Campheröls und unmittelbar darauf $2 \mathrm{ccm}$ einer 24 stündigen Prodigiosusbouilloncultur intraperitoneal injicirt (9 Uhr 24 Min. a. m.). Wie vorher angenommen, leidet das Thier nicht unter der Peritonealbehandlung mit der erprobten Campheröldosis und unter der abdominalen Prodigiosusinjection. Es läuft munter umher und frisst bald nach dem Erwachen aus der Narkose. Zur vergleichenden Resorptionsprüfung dienen 3 Blutentnahmen, ca $1 / 2$ Stunde, ca. 1 Stunde und gut 11/2 Stunden nach der abdominalen Prodigiosusinjection. Nach 24 stïndigem Wachsthum im Brutofen bei $37^{\circ} \mathrm{C}$. ergaben die Blutproben:

1. ca. $1 / 2$ Std: post inject. Prod. $\left.\begin{array}{c}1 \mathrm{ccm} \text { Jugularisblut, } \\ \text { auf } 2 \mathrm{ccm} \text { berechnet }\end{array}\right\}=4176 \mathrm{Col}$. 2. ca. $\left.1 " n \quad " \quad, \quad \begin{array}{c}1^{1 / 2} \mathrm{ccm} \text { Ohrvenenblut } \\ \text { auf } 2 \mathrm{ccm} \text { berechnet }\end{array}\right\}=1472 \mathrm{Col}$. 3. $\operatorname{gut} 1 \frac{1 / 2}{2}, " \quad, \quad$ ca. 2 ccm Ohrvenenblut $=252 \mathrm{CoI}$.

Gut 24 Stunden post injectionem Prod. durch Herzpunction gewonnenes hellrothes Blut $(3 \mathrm{ccm})$ liess kein Prodigiosuswachsthum mehr erkennen. Die Blutagarplatte blieb steril.

Am 8. III. 1909, also 4 Tage post inject. Prod. Relaparotomie: Durch einen kleinen Peritonealschlitz werden 2 mit Watte umwickelte sterile Entnahmestäbchen in die Bauchhöhle eingeführt, das eine nach unten, das andere nach oben. Der entnommene Bauchinhalt wird auf 
Agarplatten ausgestrichen, sodann die ganze Watte der Stäbchen in Nährbouillon versenkt.

Weder auf den Agarplatten noch in der Bouillon sind Prodigiosuskeime angegangen; die Nährböden sind sämmtlich steril geblieben.

Es ist also der Prodigiosus nicht bur aus dem Blute, sondern auch aus der Bauchhöhle nach kurzer Zeit verschwunden, bezw. culturell nicht mehr nachweisbar. (Siehe über das weitere Verhalten des Thieres XXIX. Versuchsgruppe, No. 72.)

No. 35. Controlthier. Männliches Kaninchen, schwarz, $1735 \mathrm{~g}$ schwer. Ohne vorherige Oelinjection werden lediglich $2 \mathrm{ccm}$ derselben 24 stündigen Prodigiosusbouilloncultur intraperitoneal eingespritzt, wobei eine minimale Menge der Culturflüssigkeit vorbeifliesst und in die Bauchwunde gelangt (9 Uhr 33 Min. a. m.). Nach der Einspritzung kein Zeichen von Erkrankung.

Zum Vergleich mit No. 34 erfolgen 4 Blutentnahmen aus der Obrvene, ca. $1 / 2$ Stunde, gut 1 Stunde, 11/4 Stunden und gut $1 \frac{3}{4}$ Stunden nach der abdominalen Prodigiosusinjection.

Nach 24 stündigem Wachsthum im Brutofen bei $37^{\circ} \mathrm{C}$. ergaben die Blutproben:

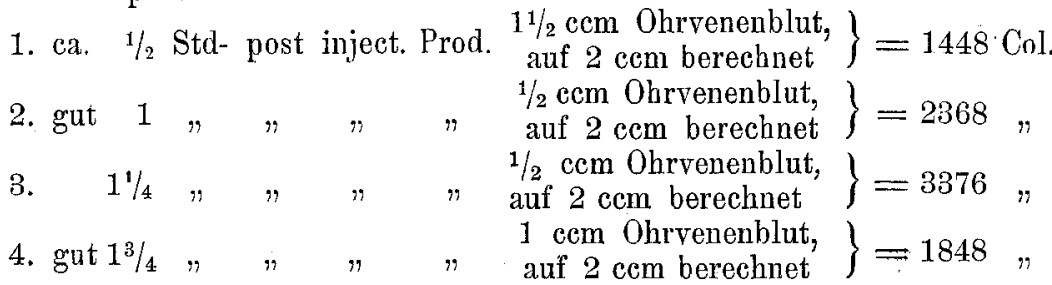

Gut. 24 Stunden post inject. Prod. durch Herzpunction gewonnenes hellrothes Blut (2 ccm) lässt kein Prodigiosuswachsthum mehr erkennen.

Am 8. III. 1909, also 4 Tage post inj. Prod. Relaparotomie: In derselben Weise wie bei No. 34 vorgenommene Abimpfungen aus den unteren und oberen Bauchhöhlenabschnitten liefern kein Prodigiosuswachsthum, weder auf Agar noch in Bouillon.

Also auch bei diesem Thier ist der Prodigiosus nicht nur aus dem Blute, sondern auch aus der Bauchhöhle schnell verschwunden.

- Ueber das weitere Verhalten dieses Kaninchens siehe XXIX. Versuchsgruppe, No. 73. -

Der Prodigiosus hat sich bei beiden Kaninchen dieser Versuchsgruppe als unschädlich erwiesen. Beide Thiere reagirten auf die abdominale Prodigiosusinjection nicht mit irgendwelchen Krankheitssymptomen. Als besonders wichtiges Ergebniss muss hervorgehoben werden, dass bei dem Versuchsthier trotz der Oelbehandlung des Peritoneums eine beträchtliche Prodigiosusresorption aus der Bauchhöhle stattgefunden hat. Die Zahl der $1 / 2$ Stunde nach vollendeter Injection resorbirten Keime übertraf sogar bei dem geölten Versuchsthier No. 34 (4176 Col.) die des nicht peritoneal behandelten Controlthieres No. 35 (1448 Col.) fast um das Dreifache. 
Bei beiden Thieren waren nach 24 Stunden keine Prodigiosuskeime mehr aus dem Blute zu züchten, und bei der nach $4 \times 24$ Stunden ausgeführten Relaparotomie zeigte sich bei beiden Thieren der Bauchhöhleninhalt frei von entwickelungsfähigen Prodigiosuskeimen.

Ein der XI. Versuchsgruppe analoges Prodigiosusexperiment betrifft

\section{die XII. Versuchsgruppe.}

Am 8. III. 1909 werden einem unmittelbar vorher peritoneal geölten und einem nicht geölten Kaninchen gleiche Mengen der gleichen Prodigiosuscultur in das eröffnete Peritonealeavum injicirt.

No. 36. Männliches Kaninchen, grau, $2650 \mathrm{~g}$ schwer. $8 \mathrm{ccm}$ 10 proc. Campheröls und im Anschluss daran 2 cem einer 24 stündigen Prodigiosusbouilloneultur gelangen, obne dass die Bauchwunde von dem Oel oder der Culturflüssigkeit berührt wird, in die Abdominalhöhle hinein (9 Uhr 19 Min. a. m.). Bald nach der Operation sitzt das aus der leichten Aethernarkose erwachte Thier aufrecht da und verhält sich, als sei ihm nichts geschehen.

Zur vergleichenden Resorptionsprüfung dienen 3 Blutentnahmen durch Herzpunction, nach gut 1 Stunde, nach gut 2 Stunden und nach 8 Stunden.

Nach 24 stündigem Wachsthum im Brutofen bei $37^{\circ}$ C. ergaben die Blutproben:
1. 1 Std. 4 Min. p. inject. Prod.
$\left.\begin{array}{c}1,9 \mathrm{ccm} \text { hellrothes Herz- } \\ \text { blut, auf } 2 \mathrm{cem} \text { berechnet }\end{array}\right\}=1861 \mathrm{Col}$.
2. 2 $0,3 \mathrm{ccm}$ dunkelroth. Herz-
3. 8 , blut, auf $2 \mathrm{ccm}$ berechnet $\}=1466$ " $\left.\begin{array}{c}1,7 \mathrm{ccm} \text { dunkelroth. Herz- } \\ \text { blut, auf } 2 \mathrm{ccm} \text { berechnet }\end{array}\right\}=1378$ "

Bald nach der letzten Blatentnahme stirbt das Thier. Die beị dieser Herzpunction verwendete Troikartnadel war nicht mehr genügend scharf und hatte in Folge dessen die Herzwand so verletzt, dass ein nicht unbeträchtlicher Bluterguss in den Perieardialraum und in das vordere Mediastinum entstand. In der Bauchhölle zeigt sich das Oel gleich. mässig vertheilt, alle Abdominalorgane von einer feinen Oelschicht bedeckt.

Aus der Bauchhöhle und aus der Lunge werden reichlich Prodigiosuskeime gezüchtet, weniger reichlich ans Leber und MiIz.

No. 37. Con trolthier. Weibliches Kaninchen, dunkelgrau, $2200 \mathrm{~g}$ schwer. Ohne vorherige Oelinjection werden ledighlich $2 \mathrm{ccm}$ derselben 24 stündigen Prodigiosusbouilloncultur in die Bauchhöhle eingespritzt, was ohne Verunreinigung der Bauchwunde gelingt: 9 Uhr 35 Min. a. $\mathrm{m}$.

Zum Vergleich mit No. 36 erfolgen 3 Blutentnahmen durch Herzpunction nach gut 1 Stunde, nach gut 2 Stunden und nach 8 Stunden.

Nach 24 stündigem Wachsthum im Brutofen bei $37^{\circ} \mathrm{C}$. ergaben die Blutproben:

1. 1 Std. 6 Min. p. inject. Prod.

2. $2 " 2$ " $" n \quad n$

3. 8 n $\left.\begin{array}{l}1,9 \mathrm{ccm} \text { hellrothes Herz- } \\ \text { blut, anf } 2 \mathrm{ccm} \text { berechnet }\end{array}\right\}=1305 \mathrm{Col}$.

$2 \mathrm{ccm}$ hellrothes Herzblut $=1384$ " $\left.\begin{array}{l}0,35 \mathrm{ccm} \text { dunkelroth. Herz- } \\ \text { blut, auf } 2 \mathrm{ccm} \text { berechnet }\end{array}\right\}=1965$, 
Keine Krankheitserscheinungen. Das Thier läuft munter umher und frisst sofort nach Beendigung des Versuches.

Am 11. III. 1909, also 3 Tage post injectionem Prod. Relaparotomie. Abimpfen aus den oberen und unteren Bauchhöhlenabschnitten mit je einem watteumwickelten Entnahmestäbchen. Die davon ange. legten Agar- und Bouilloneulturen bleiben steril.

- Ueber das weitere Verhalten des Thieres siehe XVII.Versuchsgruppe, No.46; XIX. Versuchsgruppe, No.50 und XXVI.Versuchsgruppe, No.64. -

Auch aus dieser Versuchsgruppe geht deutlich hervor, dass die der abdominalen Bakterieninjection unmittelbar vorausgeschickte Campherölbehandlung des Bauchfells die Aufnahme der injicirten Keime in die allgemeine Circulation nicht zu verhüten, auch nicht zu verringern im Stande ist. Vielmehr betrug die Resorptionszahl der Prodigiosuskeime nach gut 1 Stunde bei dem geölten Versuchsthier No. $361 / 2 \mathrm{mal}$ so viel $(1861 \mathrm{Col}$.) als bei dem nicht geölten Controlthier No. 37 (1305 Col.). Dass die Bakterienresorption aus der Bauchhöhle trotz der Oelinjection eine sehr erhebliche war, beweisen also die zahlenmässig festgestellten, auf der Blatagarplatte angegangenen Prodigiosuscolonien und der starke Gehalt der Lungen an Prodigiuskeimen bei dem geölten Thier, das leider an den Folgen einer fehlerhaft, nämlich mit zu stumpfer Troikartnadel ausgeführten Herzpunetion zu Grunde gegangen ist.

Bei dem nicht geölten Controlthier war schon nach $3 \times 24$ Stunden der Prodigiosus nicht mehr in der Abdominalhöhle nachzuweisen.

\section{Als XIII. Versuch}

schob ich am 10. III. 1909 zwischen die Prodigiosusversucbsgruppen ein Experiment mit einer Schrägagarcultur von Paratyphus B ein.

No. 38. Zum Versuchsthier wird das schwarze, weibliche Kaninchen gewählt, das als Controlthier am 23. XI. 1908 eine peritoneale Coliinjection mit einem wenig virulenten Stamm leicht überwunden und nach überstandener Infection an Gewicht bedeutend zugenommen hatte (cf. II. Versuchsgruppe, No. 5). Zwei Normalösen einer 24 Stunden alten Paratyphuscultur werden in $5 \mathrm{ccm}$ physiologiseher Kochsalzlösung suspendirt, darin gleichmässig vertheilt und die Hälfte der Bakterienemulsion (also 1 Oese) in die Bauchhöhle des Versuchsthieres injicirt: 5 Uhr 15 Min. p. m. Ueber die peritoneale Paratyphusresorption orientiren 3 Blutentnahmen aus dem Herzen, nach $1 / 4$, nach $1 / 2$ und nach 1 Stunde.

Nach 24 stïndigem Wachsthum im Brutofen bei $37^{\circ} \mathrm{C}$. ergaben die Blutproben:

1. 13 Min. p. inj. Paratyph. $2 \mathrm{ccm}$ Herzblut $=52$ Col. (nach 48 Std. 61 Col.)

2. $30 " n " n=2 "=51 "(" 48 \eta 55 ")$

3. $60 " n " . \quad " 2,3 " n=1 "$ " $"$ " $" 48 "$ idem). 
1 Tropfen des nach 60 Min. entnommenen Herzblutes wurde auf Malachitgrünagar ausgestrichen. Auf dieser Platte ging keine Colonie an, weder nach 24 Stunden noch später.

Eine nach 2 Tagen dem Herzen entnommene 4. Blutprobe $(2,3 \mathrm{ccm}$ dunkles Herzblut) erwies sich als steril.

Ueber das weitere Verhalten dieses Kaninchens siehe XXVIII. Versuchsgruppe No, 69.

Bei diesem vor $3 \frac{1}{2}$ Monaten mit Coli peritoneal inficirten Kaninchen frappirte die sehr geringe Paratyphusresorption aus der Bauchhöhle und die ungewöhnlich geringfügige Reaction auf diese Infection.

Mit den 3 nächsten Versuchsgruppen (XIV, XV und XVI) wollte ich mir darüber Gewissheit verschaffen, ob die genaue Zählung der aus den Blutprobèn angegangenen Colonien immer wieder zu dem Resultat führt, dass die peritoneale Keimresorption durch eine der abdominalen Bakterieninjection unmittelbar vorausgeschickte Oelbehandlung des Bauchfells nicht verringert, sondern gesteigert wird.

\section{Versuchsgruppe.}

Am 11. III. 1909 werden wie bei den Versuchsgruppen XI und XII einem unmittelbar vorher peritoneal geölten und einem nicht geölten Kaninchen gleiche Mengen der gleichen Prodigiosuscultur in das eröfnete Abdominalcavum gebracht.

No. 39. Weibliches Kaninchen, grau, $3200 \mathrm{~g}$ schwer. $8 \mathrm{ccm}$ 10 proc. Kampferöls und gleich darauf $2 \mathrm{ccm}$ einer 24 stündigen Prodigiosusbouill oncultur gelangen ohne Verunreinigung der Bauchwunde in das Cavum peritonei: 3 Uhr 31 Min. p. m.

Bei der 4 Uhr 11 Min. p. m. ausgeführten Herzpunetion bewegt sich das Thier stark. Die Herzwand wird dabei gröber verletzt; das Thier stirbt $5 / 4$ Stunden p. inj. Prod. an pericardialem und mediastinalem Bluterguss.

Nach gut 24 stündigem Wachsthum im Brutofen bei $37^{\circ} \mathrm{C}$. ergab die Blutprobe:

40 Min. p. inj. Prod. $\left.\begin{array}{c}1,8 \mathrm{ccm} \text { hellrothes Herzblut, } \\ \text { auf } 2 \mathrm{ccm} \text { berechnet }\end{array}\right\}=2566 \mathrm{CoI}$.

No. 40. Controlthier. Männliches Kaninchen, weiss, $3110 \mathrm{~g}$ schwer. Ohne vorherige Oelinjection werden lediglich 2 ccm derselber 24 stündigen Prodigiosusbouilloncultur in die eröffnete Bauchhöhle eingespritzt; keine Verunreinigung der Bauchwunde: 3 Uhr 46 Min. p. m. Zum Vergleich mit No. 39 1 Blutentnahme aus dem Herzen 4 Ubr 50 Min. p. m. Der operative Eingriff, die Prodigiosusinjection und die Herzpunction haben keinen nachtheiligen Einfluss auf den Allgemeinzustand des Thieres.

Nach 24 stündigem Aufenthalt im Brutofen bei $370 \mathrm{C}$. ergab die Blutprobe:

1 Std. 4 Min. p. inj. Prod. $1,8 \mathrm{ccm}$ hellrothes Herzblut $=0 \mathrm{Col}$. 
Die Platte ist vollständig steril geblieben und bleibt auch weiterhin steril.

Ueber das spätere Verhalten des Thieres siehe XVLII. Versucbsgruppe, No. 47 und XXV. Versuchsgruppe, No. 62.

Wieder hatte bei dem Versuchsthier trotz der Oelbehandlung des Peritoneums eine starke Bakterienresorption aus der Bauchhöhle stattgefunden, bei dem Controlthier dagegen gar keine, obwohl sicher fehlerfrei gearbeitet worden war. Dieses Vorkommniss erinnerte mich an Glimm's 41. Versuch l. c., S. 280 und 281 und erschien mir deshalb bedeutsam, weil daraus ersichtlich wird, dass es Thiere giebt, bei denen ohne bekannte vorherige Beeinflussung des Bauchfells eine peritoneale Resorption von Bakterien nicht zu Stande kommt.

\section{Versuchsgruppe.}

Am 12. III. 1909 wird genau wie in der vorigen Versuchsgruppe an einem unmittelbar vor der abdominalen Prodigiosusinjection peritoneal geölten und an einem nicht geölten Thier experimentirt.

No. 41. Weibliches Kaninchen, grauweiss, $1460 \mathrm{~g}$ schwer. $8 \mathrm{ccm}$ 10 proc. Campheröls und gleich darauf $11 / 2 \mathrm{ccm} 14$ stündiger Prodigiosusbouilloncultur werden obne Verunreinigung der Bauchwunde in den Peritonealraum injicirt: 8 Uhr 50 Min. a. m. Keine Zeichen von Erkrankung.

Zur vergleichenden Resorptionsprüfung dienen 4 Blutentnahmen aus dem Herzen nach $1 / 2$ Stunde, nach gut 1 Stunde, nach $1 \frac{3 / 4}{4}$ Stunden und nach $4^{1 / 2}$ Stunden.

Nach 24 stündigem Wachsthum im Brutofen bei $37^{\circ} \mathrm{C}$. ergaben die Blutproben:
1. 30 Min. p. inject. Prod.
$\left.\begin{array}{l}2,2 \mathrm{~cm} \text { dunkelroth. Herz- } \\ \text { blut, auf } 2 \mathrm{ccm} \text { berechnet }\end{array}\right\}=2327 \mathrm{Col}$.
2. 1. Std. 2 Hin., $\left.\begin{array}{l}1,9 \mathrm{ccm} \text { bellrothes Herz- } \\ \text { blut, auf } 2 \mathrm{ccm} \text { berechnet }\end{array}\right\}=2650$,
3. 1 " 45 " " " $\left.\begin{array}{l}2,1 \text { cem hellrothes Herz- } \\ \text { blut, auf } 2 \mathrm{ccm} \text { berechnet }\end{array}\right\}=860$,
4. 4 "30" " " " $0,3 \mathrm{ccm}$ dunkelroth. Herz- blut, auf $2 \mathrm{cem}$ berechnet $\}=\mathrm{ca} .20$,

Ueber das weitere Verhalten des Thieres siehe XXVIII. Versuchsgruppe, No. 70.

No. 42. Controlthier. Männliches Kaninchen, weiss, $1400 \mathrm{~g}$ schwer. Ohne vorherige Oelinjection werden lediglich $11 / 2 \mathrm{ccm}$ derselben 14 stündigen Prodigiosusbouilloncultur intraperitoneal eingespritzt; keine Verunreinigung der Bauchwunde: 9 Uhr 5 Min. a. m. Das Thier erkrankt nicht.

Zum Vergleich mit No. 414 Blutentnahmen durch Herzpunction, nach $1 / 2$ Stunde, nach gut 1 Stunde, nach fast 2 Stunden und nach $4^{1 / 2}$ Stunden.

Nach 24 stündigem Wachsthum im Brutofen bei $37^{\circ} \mathrm{C}$. ergaben die 4 Blutproben: 
1. 35 Min. p. inject. Prod. $\left.\begin{array}{l}1,8 \mathrm{ccm} \text { hellrothes Herz- } \\ \text { blut, auf } 2 \mathrm{ccm} \text { berechnet }\end{array}\right\}=1018 \mathrm{Col}$.

2. 1 Std. 4 " " " $2 \mathrm{ccm}$ hellrothes Herblut $\}=\begin{gathered}\mathrm{ca} . \\ 4000\end{gathered}$

3. 1 " $55 " n \quad " \quad$ " $\left.\begin{array}{l}1,2 \mathrm{ccm} \text { dunkelinoth. Herz- } \\ \text { blut, auf } 2 \mathrm{ccm} \text { berechnet }\end{array}\right\}=153 "$

4. 4 "30 " " " ", $\left.\begin{array}{l}1,7 \text { ccm dunkelroth. Herz- } \\ \text { blut, auf } 2 \text { ccm berechnet }\end{array}\right\}=180$,

Ueber das weitere Verhalten des Thieres siehe XVIII. Versuchsgruppe, No. 48 und XXVIII. Versuchsgruppe, No. 71.

Auch in dieser XV. Versuchsgruppe sind bei dem peritoneal geölten Versuchsthier No. 41 nach 1/2 Stunde mehr aus der Bauchhöhle resorbirte Prodigiosuskeime angegangen (2327 Col.) als bei dem zugehörigen nicht geölten Controlthier No. 42 (1018 Col.). Bei beiden Thieren hatte schon im Verlauf der 2. Stunde nach der Injection die abdominale Bakterienresorption bedeutend nachgelassen.

\section{Versuchsgruppe.}

Am 16. III. 1909 wird ein der XIV. und XV. Versuchsgruppe analoges. Prodigiosusexperiment angestellt an einem soeben geölten und einem nicht geölten Kaninchen.

No. 43. Weibliches Kaninchen, grau, $1610 \mathrm{~g}$ schwer. Ohne Narkose werden $8 \mathrm{ccm} 10$ proc. Campheröls und $2 \mathrm{ccm}$ einer 24 stündigen Prodigiosusbouilloncultur gleich nacheinander unter sorgfältiger Vermeidung einer Bauchwundverunreinigung in das eröffnete Cavum peritonei gebracht: 9 Uhr 15 Min. a. m. Keinerlei Krankheitserscheinungen. Es gelingt am lebenden Thier nur 1 Blutentnahme aus dem Herzen nach gut einer. Stunde. "Weitere. Herzpunctionen führen nicht zum Ziele. In Folge dieser mehrfachen missglückenden Versuche und der damit verbundenen Contusionen der Herzwand stirbt das Thier 12 Uhr $30 \mathrm{Min}$. mittags. Aus dem unmittelbar post mortem freigelegten Herzen wird noch einmal 1 Blutentnabme gemacht.

Das Campheröl im Abdomen ziemlich gleichmässig vertheilt, auf den Därmen weisslicher, flockiger Belag. Abimpfungen aus Leber, Milz und Lunge auf Agar und in Bouillon.

Nach 30 stündigem Wachsthum im Brutofen bei $37^{\circ}$ C. ergaben die Blutproben:

1. 1. Std. 7 Min. p. inject. Prod. $2 \mathrm{ccm}$ hellrothes Herzblut $=6764 \mathrm{Col}$.

2. Kurz post mortem, 3 Std. 24 Min. p. inject. Prod. $2 \mathrm{ccm}$

Blut aus dem linken Ventrikel bei noch pulsirend. Herzen $=2946 "$

Aus Leber, Milz und Lungen werden mässig reichliche Prodigiosuscolonien gezüchtet.

No. 44. Controlthier. Männliches Kaninchen, weiss, $1430 \mathrm{~g}$ schwer. Ohne Narkose werden lediglich $2 \mathrm{ccm}$ derselben 24 stündigen Prodigiosusbouilloncultur ohne Bauchwundverunreinigung in die eröffnete Bauchhöhle eingespritzt: 9 Uhr 31 Min. a. m. Auch dieses Thier macht nach dem Eingriff keinen kranken Eindruck. Es gelingt nur 1 Blutentuahme nach 1 Stunde aus dem Herzen. Bei ẉei- 
teren vergeblichen Herzpunctionsversuchen wird das Thier sehr elend and stirbt ca. 2 Stunden nach der Bakterieninjection, offenbar an den Läsionen der Herzwand durch ungenügend scharfe Troikartnadel ${ }^{1}$ ). Unmittelbar post mortem Blutentnahme aus der Cava inferior. Alle Abdominalorgane mit Campheröl bedeckt. Kein stärkerer Bluterguss in den Herzbeutel, bezw. in das Mediastinum ant. Abimpfungen aus Leber; Milz und Lunge auf Agar und in Bouillon.

Nach 30 stündigem Wachsthum im Brutofen bei $37^{\circ} \mathrm{C}$. ergaben die Blutproben:

1. 1 Std. 8 Min. p: inject. Prod. $\left.\begin{array}{l}1,2 \mathrm{cem} \text { hellrothes Herz- } \\ \text { blut, auf } 2 \mathrm{ccm} \text { berechnet }\end{array}\right\}=6176 \mathrm{Col}$. 2. Kurz post mortem, gut 2 Std. p. inject. Prod. $2 \mathrm{cem}$

Cavablut $=206 "$

Aus Leber, Milz und Lunge wurden mässig reichliche Prodjgiosuskeime gezüchtet.

Die Keimzahl der gut 1 Stunde nach der abdominalen Prodigiosusinjection dem Herzen entnommenen Blutprobe übertraf auch diesmal bei dem Versuchsthier No. 43 die des Controlthieres No. 44, wenn auch nicht sehr bedeutend (um ca. 600 Keime).

Nach Abschluss dieser Versuchsgruppen hatte ich ein genügend reichliches und einwandsfreies Material gesammelt zum Beweise, dass die Bakterienresorption aus der Bauchhöhle (Bacterium prodigiosum) keine Verminderung, sondern eine Vermehrung erfährt, wenn dem Thier unmittelbar vor der abdominalen Bakterieninjection die erprobte Campheröldosis intraperitoneal eingespritzt wird. In 5 Versuchsgruppen (XI, XII, XIV, XV u. XVI) erfolgte bei dem unmittelbar vor der Prodigiosusinjection geölten Thier regelmässig eine reichliche Bakterienresorption, die fast immer die des Controlthieres nicht unwesentlich übertraf. Der durch dieses Material erbrachte Beweis erschien mir um so zwingender, als das Ergebniss der zahlenmässig festgelegten Bakterienresorption aus der Bauchhöhle bei unmittelbar vor der Bakterieninjection geölten und bei nicht geölten Thierèn sich vollkommen deckte mit den rein klinischen Erfahrungen und den Resultaten der nur im Groben angestellten Resorptionsprüfungen bei meinen früheren Experimenten mit abdominaler Coliinfection. Bei diesen hatte sich durchweg das nicht geölte Controlthier besser befunden und war schneller über die Infection hinweggekommen als das unmittelbar vor der abdominalen Coli-

1) Diese Herzpunctionsversuche überzeugten mich von der Wichtigkeit und Nothwendigkeit, für jedes neue Experiment ganz frisch geschliffene und absolut scharfe Troikartnadeln zu verwenden, da beide Thiere lediglich dem Experimentiren mit zu stumpfem Instrument zum Opfer gefallen sind. 
infection geölte Versuchsthier (cf. VIII., IX. u. X. Versuchsgruppe: 3 Controlthiere im Vergleich zu 7 Versuchsthieren). Durch die zahlenmässige Feststellung der Bakterienresorption war es verständlich und erklärlich geworden, dass ein mit Oel peritoneal behandeltes Thier die unmittelbar folgende abdominale Infection gar nicht leichter überwinden kann, als das nicht geölte Controlthier, da eben eine Aufhebung oder auch nur nennenswerthe Verminderung der Bakterienresorption durch die gleichzeitige Oelung nicht erreicht wird, im Gegentheil die Zahl der resorbirten Bakterien wäehst.

Die bisher beschriebenen 16 Gruppen von Versuchen am Kaninchen hatten den Beweis geliefert:

1. Dass die intraperitoneale Injection von $8 \mathrm{ccm}$ 10 proc. Campheröls und die dadurch hervorgerufene Bauchfellreizung unschädlich ist und

2. dass die Bakterienresorption aus der Bauchhöhle (Bacterium coli und Bacterium prodigiosum) durch eine der abdominalen Bakterieninjection unmittelbar vorausgehende Behandlung des Peritoneums nicht vermindert, sondern sogar gesteigert wird.

A usserdem aber hatten die Versuche meine Aufmerksamkeit auf eine Reihe unvermutheter Erscheinungen gelenkt. Es musste auffallen, dass in Versuchsgruppe VIII die 11 Tage vor der abdominalen Coliinfection mit der unschädlichen Campheröldosis behandelten Thiere No. 24 u. 25 unter der Infection sehr wenig litten, weniger als das entsprechende Controlthier No. 22, ganz zu schweigen von den unmittelbar vorher geölten Thieren dieser Gruppe No. 21 u. 23. Ferner war in Versuch XIII Kaninchen No. 38 einer abdominalen Paratyphusinfection bei minimaler Keimresorption aus der Bauchhöhle nicht erlegen, hatte im Gegentheil auf die Infection ungewöhnlich schwach reagirt. Dieses Thier hatte $3 \frac{1}{2}$. Monate früher eine leichte peritoneale Coliinfection mit mässigen Krankheitserscheinungen durchgemacht. Endlich hatte das Controlthier in Versuchsgruppe XIV, Kaninchen No. 40, gar keine peritoneale Prodigiosusresorption gezeigt, während bei dem dazu gehörigen unmittelbar vor der abdominalen Prodigiosusinjection geölten Kaninchen No. 39 eine sehr lebhafte Keimresorption zu verzeichnen war.

Weshalb war bei den beiden 11 Tage vor der abdomi: 
nalen Colieinspritzung geölten Kaninchen No. 24 u. 25 die Infection so leicht verlaufen? Weshalb überstand das $3^{1} / 2$ Monate vorher peritoneal mit Coli inficirte Thier No. 38 die abdominale Paratyphusinfection so überraschend leicht? Weshalb resorbirte das als Controlthier dienende Kaninchen No. 40 überhaupt keine Bakterien aus der Bauchhöhle? Sollten sich vielleicht diese verschiedenen Beobachtungen combiniren und auf eine gemeinsame Ursache zurückführen lassen? Diese Erwägungen veranlassten mich, nach der Einwirkung einer Vorbehandlung des Bauchfells auf die peritoneale Bakterienresorption $\mathrm{zu}$ forschen.

\section{Versuchsgruppe.}

Am 17. III. 1909 wird einem Kaninchen, dem schon vor 24 Stunden die erprobte Campheröldosis intraperitoneal injicirt war, die Prodigiosuscultur in die Bauchhöhle gebracht, und ebenso einem anderen Kaninchen, das als Controlthier in Versuchsgruppe XII, No. 37 am 8. III. 1909 , also vor 9 Tagen schon einmal eine abdominale Prodigiosusinjection erhalten und damals eine starke Keimresorption aus der Bauchhöhle gezeigt hatte.

No. 45. Weibliches Kaninehen, hellgrau, $2000 \mathrm{~g}$ schwer. Am 16. III. 1909 ohne Narkose Einbringung von $8 \mathrm{ccm} 10$ proc. Campheröls in die eröffnete Bauchhöhle: 9 Uhr a. m.

Am 17. III. 1909, gut 24 Stunden nach der intraperitonealen Campheröleinspritzung in leichter Aethernarkose unter sorgfältigem Schutz der unterhalb der gestrigen Operationsstelle angelegten neuen Bauchwunde abdominale Injection von $2 \mathrm{ccm}$ einer 24 stündigen Pro. digiosusbouilloncultur: 9 Uhr 27 Min. a. m. 3 Blutentnahmen dureh Herzpunction nach ca. $3 / 4$ Stunden, nach gut $11 / 2$ Stunden und nach 3 Stunden.

Nach 24 stündigem Wachsthum im Brutofen bei $37^{\circ} \mathrm{C}$. ergaben die Blutproben:

1. 41 Min. p. inject. Prod. $2 \mathrm{ccm}$ dunkelrothes Herzblut $=32 \mathrm{Col}$.

2. 1 Std. $36 " n "$ " $" 2$ hellrothes $"=1$ "

$3.3 "$ " " " $" 2 "$ " " $"=4 "$

Eine weitere (4.) Herzpunction am 19. III. 1909, also zwei Tage p. inj. Prod. ergiebt aus $2 \mathrm{ccm}$ hellrothen Herzblutes kein Prodigiosuswachsthum auf der Blutagarplatte in einer Beobachtungszeit von 48 Stunden.

Ueber das weitere Schicksal des Thieres siehe XIX. Versuchsgruppe, No. 49 und XXVI. Versuchsgruppe, No. 63.

No. 46. Das mittelgrosse dunkelgraue weibliche Kaninchen, bei dem als Controlthier schon vor 9 Tagen ein Prodigiosusresorptionsversuch angestellt war (XII. Versuchsgruppe, No. 37), erhält heute von Neuem in leichter Aethernarkose eine Einspritzung von $2 \mathrm{ccm}$ der auch für No. 45 verwendeten 24 stündigen Prodigiosusbouilloncultur in das eröffnete Peritonealcavum: 9 Uhr 46 Min. a. m. Schon vor sechs Tagen hatte eine controlirende Relaparotomie kein wachsthumsfähiges Prodigiosusmaterial mehr in der Bauchhöhle ermittelt. 
4 Blutentnahmen durch Herzpunction: 1 kurz vor der abdominalen Prodigiosusinjection mit Rücksicht auf den früheren Prodigiosusversuch und 3 nach der erneuten Prodigiosusinjection, und zwar nach ca. $3 / 4$ Stunde, nach gut 11/2 Stunden und nach 3 Stunden.

Nach 24 stündigem Wachsthum im Brutofen bei $37^{\circ} \mathrm{C}$. ergaben die 4 Blutproben:

1. $3 / 4$ Std. ante inject. Prod. 2 ccm hellroth. Herzblut $=0$ Col. 2. 41 Min. post " " 2 "dunkelroth. " $=34$ "

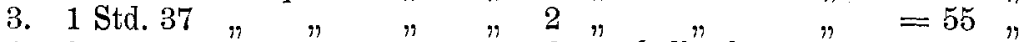
4. 3 " " "ca.2" hellrothes " $"=16 "$

Eine nochmalige (5.) Herzpunction am 19. III. 1909, also 2 Tage p. inj. Prod. liefert aus $2 \mathrm{ccm}$ hellrothen Herzblutes kein Prodigiosuswachsthum auf der Blutagarplatte in einer Beobachtungszeit von mehr als 48 Stunden.

Ueber das weitere Verhalten des Thieres siehe XIX. Versuchsgruppe, No. 50 und XXVI. Versuchsgruppe, No. 64.

Die Vorbehandlung des Peritoneums hatte nach dem Ausfall dieser beiden Versuche ein ganz anderes Resultat als die peritoneale Oelbehandlung $\mathrm{k} u \mathrm{rz}$ vor der abdominalen Bakterieninjection. Sowohl die der abdominalen Prodigiosusinjection um 24 Stunden vorausgeschickte intraperitoneale Campheröleinspritzung als auch der vor 9 Tagen angestellte Prodigiosusversuch hatten eine eklatante Hemmung der Prodigiosusresorption aus der Bauchhöhle zur Folge. Das Resultat erschien um so wichtiger, als bei dem mit Prodigiosus peritoneal vorbehandelten Thier damals eine sehr starke Prodigiosusresorption sich zahlenmässig batte nachweisen lassen (cf. Kaninchen No. 37).

Sollte es eine regelmässige Erscheinung sein, dass bei dem mit Prodigiosus abdominal vorbehandelten Thier eine Hemmung der peritonealen Prodigiosusresorption eintritt?

\section{Versuchsgruppe.}

Am 20. III. 1909 wird 2 mit Prodigiosus vorbehandelten Thieren, die bei früheren Prodigiosusversuchen als Controlthiere gedient hatten, von neuem eine Prodigiosusbouilloncultur in die wieder eröffnete Bauchhöhle gebracht. Um auszuschliessen, dass etwa die zu diesem Versuche verwandte Prodigiosusbonilloncultur die Schuld trägt an einem geringen oder fehlenden Wachsthum aus den Blutproben, werden vor der abdominalen Prodigiosusinjection 3 Oesen der Versuchscultur auf Agar ausgestrichen. Diese liefern ein üppiges Prodigiosuswachsthum auf der Controlplatte.

No. 47. Das grosse weisse männliche Kaninchen, das in Versuchsgruppe XIV, No. 40 als Controlthier vor 9 Tagen ohne Oelbehandlung und ohne irgendeine bekannte Beeinflussung des Peritoneums auf eine abdominale Prodigiosusinjection hin gar keine Keimresorption aus der Bauchhöhle gezeigt hatte, erhält beute von Neuem in leichter Aethernarkose eine Injection von $2 \mathrm{ecm}$ einer 24 stündigen Pro: 
digiosusbouilloncultur in das wieder eröffnete Cavum peritonei. Am Tage vorher aus dem Herzen entnommenes Blut (2 $\mathrm{ccm}$ bellroth) war als prodigiosusfrei befunden worden (innerhalb von 48 Stunden kein Wachsthum auf der Agarplatte). Aus dem oberhalb der ersten Laparotomienarbe wiedereröffneten Peritonealraum entleeren sich einige Cubikcentimeter röthlichen Serums von dünnsirupöser Consistenz. Proben aus der Bauchböhle, aus den unteren und oberen Abscbnitten, verimpft auf Agar und in Bouillon, ergeben kein Prodigiosuswachsthum. Also vor der ernenten abdominalen Prodigiosusinjection Blut und Bauchhöhle sicher frei von Prodigiosus.

9 Uhr 1 Min. a. $\mathrm{m}$. abdominale Prodigiosusinjection ohne Verunreinigung der Bauchwunde beendet.

3 Blutentnahmen durch Herzpunction, wach 1 Stunde, nach 2 Stunden und nach 3 Stunden.

Nach 24 stündigem Wachsthum im Brutofen bei $37^{\circ} \mathrm{C}$. ergaben die 3 Blutproben:

1. 1 Std. 2 Min. p. inject. Prod. $2 \mathrm{ccm}$ hellrothes Herzblut $=17 \mathrm{Col}$.

$2.2 " 6 " n " n 2 ", "=0 "$

3. $3 " 5 ", " n 2 ", "=0 "$

Ueber das weitere Schicksal dieses Thieres siehe XXV. Versuchsgruppe No. 62 .

No. 48. Das kleine weisse mänuliche Kaninchen, das in.Versuchsgruppe $X V$, No. 42 als Controlthier vor 8 Tagen auf eine abdominale Prodigiosusinjection hin eine reichliche Bakterienresorption gezeigt batte, erhält heute ebenso wie No. 47 vou nenem in leichter Aethernarkose eine Injection von $2 \mathrm{ccm} 24$ stündiger Prodigiosusbouilloncultur in das wiedereröffnete Cavum peritonei. Auch bei diesem Thier war aus einer tags zuvor dem Herzen entnommenen Blutprobe (2 ccm bellrotb) innerhalb von 48 Stunden keine einzige Prodigiosuscolonie angegangen. Ebenso wie bei No. 47 entleerte sich aus dem wiedereröffneten Peritonealraum reichlich röthliches dickflüssiges Serum. Die Bauchhöhlenprobe auf etwa noch vorhandene Prodigiosuskeime fiel wie bei No. 47 negativ aus (Agar und Bonillon). Also war auch bei diesem Thier vor der erneuten abdominalen Prodigiosusinjection Blut und Bauchhöhle sicher keimfrei.

9 Uhr 26 Min. a. m. abdominale Prodigiosusinjection ohne Verunreinigung der Bauchwunde beendet.

3 Blutentnahmen durch Herzpunction, nach 1 Stunde, nach 2 Stunden und nach 3 Stunden.

Nach 24 stündigem Wachsthum im Brutofen bei $37^{\circ} \mathrm{C}$. ergaben die 3 Blutproben:

1. 1 St. 2 Min. p. inject. Prod. $2 \mathrm{ccm}$ hellrothes Herzblut $=13 \mathrm{Col}$. 2. $2,4 \quad " \quad " \quad$ " $\quad 1,9, \quad n=3 n$ 3. $3 " 5 " n ", " 2 ", \quad "=0 "$

Ueber das weitere Verhalten des Thieres siehe XXVIII. Versuchsgruppe No. 71.

Beide Thiere dieser Versuchsgruppe, beide mit Prodigiosus vor 9 bezw. 8 Tagen peritoneal vorbehandelt, hatten nur minimalste Mengen wachsthumskräftiger Prodigiosuskeime aus dem Peritonealcavam in die allgemeine Circulation 
resorbirt, noch weniger als das 9 Tage vorher mit Prodigiosus vorbehandelte Thier No. 46 der vorigen Versuchsgruppe.

Besonders beachtenswerth ist bei den beiden letztenThieren die auf die Prodigiosusinjection hin erfolgte reactive Entzündung -des Peritoneums, die sich kenntlich machte durch das bei der Relaparotomie aus dem Peritonealcavum hervorquellende, bei beiden Thieren prodigiosusfreie und überhaupt sterile Exsudat. Von den beiden Thieren hatte das eine, No. 47, schon bei der ersten abdominalen Prodigiosususinjection als No. 40 in Versuchsgruppe XIV keine Keimresorption aus der Bauchhöhle erkennen lassen.

Eine weitere Versuchsgruppe sollte die Wirkung der ProdigiosusVorbehandlung des Peritoneums auf ihre Allgemeingültigkeit hin prüfen.

\section{Versuchsgruppe.}

Am 22. III. 1909 wird nochmals an 2 mit Prodigiosus vorbehandelten Thieren ein Prodigiosusversuch angestellt. Die zur Verwendung gelangende Prodigiosusbouilloneultur wird wieder durch Anlegung: einer Controlcultur unmittelbar vor Beginn des Versuches auf ihre Wachsthumsfähigkeit geprüft. 4 Oesen der Versuchscultur, auf Agar ausgestrichen, bewirken ein reichliches Prodigiosuswachstum auf der Controlplatte.

No. 49. Dem Kaninchen No. 45 der Versuchsgruppe XVII, das am 17. III. 1909 , also vor 5 Tagen nach vortägiger Campherölbehandlung des Peritoneums auf eine abdominale Prodigiosusinjection hin nur minimalste Keimresorption aus dem Peritonealcavum gezeigt hatte, werden heute nochmals $2 \mathrm{~cm}$ einer 24 stündigen Prodigiosusbouilloncultur unter sorgsamem Sebutz der Bauchwunde in die links von der Medianlinie eröffnete Bauchhöhle eingespritzt. Die Blutbahn war schon am 19. III. 1909 als prodigiosusfrei befunden worden. Die Bauchhöhlenprobe mit 2 watteumwickelten Stäbchen unmittelbar vor der erneuten Prodigiosusinjection fiel auf Agar und in Bonillon bei mehrtägiger Beobachtungszeit der angelegten Cultur negativ aus.

Die erneute abdominale Prodigiosusinjection beendet 9 Uhr 15 Min. a.m.

3 Blutentnabmen aus dem Herzen, nach $1 / 2$, nach $1 \frac{1 / 2}{2}$ und nach $3^{1 / 2}$ Stunden.

Nach 30 stündigem Wachsthum im Brutofen bei $37^{\circ} \mathrm{C}$. ergaben die 3 Blutproben:

1. 36 Min. p. inject. Prod. $2 \mathrm{~cm}$ hellrothes Herzblut $=0$ Col.

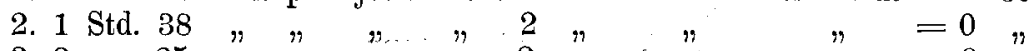
$3.3 " 25 ", "$ " " " " $" 2 "$ " " $"$

Ueber das weitere Schicksal dieses Thieres siehe XXVI. Versuchsgruppe, No. 63.

No. 50. Dem Kaninchen No. 46 der Versuchsgruppe XVII, das am 8. III. 1909, also vor 14 Tagen, und am 17. III. 1909, also vor 5 Tagen, je eine intraperitoneale Prodigiosusinjection, das erste Mal mit darauf folgender starker, das zweite Mal mit minimaler Keimresorption erhalten hatte, werden heute zum dritten Male $2 \mathrm{ccm}$ 
einer 24 stündigen Prodigiosusbouilloncultur unter sicherem Schutz der Bauchwunde in die rechts von der Medianlinie eröffnete Bauchböhle eingespritzt.' - Das vor 3 Tagen geprüfte Herzblut war prodigiosusfrei befunden. Der mit 2 watteumwickelten Stäbchen entnommene Bauchhöhleninhalt unmittelbar vor der 3. Prodigiosusinjection brachte auf der Agarplatte einige wenige Prodigiosuscolonien zur Entwicklung. Auch die als Controlnährboden benutzte Bouillon zeigte Prodigiosuswachsthum.

Die abdominale Prodigiosusinjection beendet 9 Ubr 40 Min. a. m.

3 Blutentnahmen aus dem Herzen, nach $1 / 2$, nach fast $13 / 4$ und nach $3 \frac{1}{4}$ Stunden.

Nach 30 stündigem Wachsthum im Brutofen bei $37^{\circ} \mathrm{C}$. ergaben die 3 Blutproben:

1. 37 Min. p. inject. Prod. $2 \mathrm{~cm}$ hellrothes Herzblut $=0 \mathrm{Col}$.

2. 1 Std. $40, n " n " n=0$ " $"$

$3.3 " 11 " n " n=0 " n$

Ueber das weitere Schicksal dieses Thieres siehe XXVI. Versuchsgruppe, No. 64 .

Bei beiden peritoneal vorbehandelten Thieren (No. 49 vor 6 Tagen mit Campheröl, vor 5 Tagen mit Prodigiosus; No. 50 vor 14 und 9 Tagen, also 2 mal mit Prodigiosus) war diesmal gar keine Keimresorption aus der Bauchhöhle nachzuweisen.

Mit den Resultaten der Versuchsgruppen XVII-XIX hielt ich es für bewiesen, dass bei einem mit Prodigiosus, bezw. mit Campheröl vorbehandelten Kaninchen kein oder nur ein minimaler Uebertritt von Keimen aus der Bauchhöhle in die allgemeine Circulation erfolgt, und dass die in das Peritonealcavum hineingelangten Keime binnen kurzem an Ort und Stelle zu Grunde gehen.

Ob eine 24 stündige Vorbehandlung des Bauchfells mit Campheröl zur Aufhebung der peritonealen Keimresorption wirklich genügt, sollte die nächste Versuchsgruppe entscheiden. Das beigegebene Controlthier sollte nicht nur ein Indicator für die peritoneale Keimresorption bei unterlassener Vorbehandlung des Peritoneums sein, sondern gleichzeitig die Frage nach der Schnelligkeit der Keimresorption aus der Bauchhöhle beantworten.

\section{Versuchsgruppe.}

Am 23. III. 1909 wird einem tags zuvor peritoneal geölten Kaninchen und einem nicht vorbehandelten Controlthier die Prodigiosusversuchscultur abdominal injicirt. schwer.

No. 51. Männliches Kaninchen, grau mit weissen Abzeichen, $2830 \mathrm{~g}$

Am 22. 1II. 1909, 1/29 Uhr a. m. in leichter Aethernarkose Einbringung von $8 \mathrm{ccm} 10$ proc. Campheröls in die median unterhalb der Bauchmitte eröffnete Ảbdominalhöhle. 
Am 23. III. 1909, 251/2 Stunden später mittels erneuter Laparotomie (Mitte der Oberbauchgegend) in nochmaliger Aethernarkose Injection von $2 \mathrm{ccm}$ einer 14 stündigen Prodigiosusbouilloncultur ohne Verunreinigung der Bauchwunde. Bakterieninjection beendet: 10 Uhr a. m.

4 Blutentnahmen durch Herzpunction, nach 1 Stunde, nach $1^{3 / 4}$ Stunden, $2^{3} / 4$ Stunden und nach gut 3 Stunden.

Nach 30 stündigem Wachsthum im Brutofen bei $37^{\circ} \mathrm{C}$. ergaben die 4 Blutproben:

1. 1 Std. 2 Min. p. inject. Prod. $2 \mathrm{ccm}$ hellrothes Herzblut $=0$ Col.

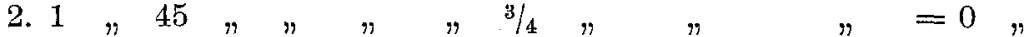

$3.2 " 47 " . " \quad " \quad " \quad 2 \quad " \quad " \quad " \quad "=0 "$

$4.3 " 5 ", " n " 2 ", "=0 "$

Ueber das weitere Verhalten des Thieres siehe XXVII. Versuchsgruppe, No. 66.

No. 52. Controlthier. Hännliches Kaninchen, grau, $2320 \mathrm{~g}$ schwer. Ohne jede Vorbehandlung des Peritoneums werden lediglich $2 \mathrm{ccm}$ derselben 14 stündigen Prodigiosusbouilloncultur unter sicherem Schutz der Bauch wunde intraperitoneal injicirt: 10 Uhr22 Min. a.m.

Zur Feststellung der Schnelligkeit der peritonealen Bakterienresorption 3 Blutentnahmen durch Herzpunction sogleich nach Schluss der Bauchwunde, nach 7 Min. und nach 15 Min., ferner 2 weitere Blutentnahmen aus dem Herzen zum Vergleich mit dem Versuchsthier No. 51 nach $1 \frac{1 / 4}{4}$ Stunden und gut $2^{1 / 2}$ Stunden; im ganzen also 5 Herzpunctionen.

Nach 30 stündigem Wachsthum im Brutofen bei $37^{\circ} \mathrm{C}$. ergaben die 5 Blutproben:

1. $4 \frac{1}{2}$ Min. p. inject. Prod. 2 ecm hellrothes Herzblut $=1250 \mathrm{Col}$.

2. $7 " n " n " 2 n "=3506 "$

$3.15 ", " n \quad " 2 " \quad " \quad "=4780 "$

4. 1 St. $14 \quad " \quad " \quad " \quad, 2$ " $\quad " \quad$ " $721 "$

$5.2,33 ", " \#, \quad " \quad " \quad=311 "$

Ueber das weitere Verhalten des Thieres siehe XXVII. Versuchsgruppe, No. 67.

Mit dieser XX. Versuchsgruppe wurde es klar, dass eine am Tage vor der abdominalen Prodigiosusinjection ausgeführte Vorbehandlung des Peritoneums mit Campheröl das Ziel der Aufhebung einer Keimresorption aus der Bauchhöhle erreicht, also zu demselben Resultate führt, wie eine vorausgegangene peritoneale Prodigiosusinjection. Da in Versuchsgruppe VIII die beiden Kaninchen No. 24 und No. 25 nach einer 11 Tage vorher erfolgten Campherölbehandlung des Peritoneums die peritoneale Coliinfection auffallend leicht überstanden hatten, so musste man nach den jetzigen Erfahrungen rückwärts schliessen, dass damals mit grösster Wahrscheinlichkeit keine Keimresorption aus der Bauchhöhle erfolgt und deshalb die gesetzte Infection so milde verlaufen war. Danach würde sich die aufgehobene bezw. stark gehemmte Keimresorption nicht allein auf Prodigiosus, sondern 
auch auf Bacterium coli, also wahrscheinlich überhaupt auf irgendwelche in die Bauchhöhle gebrachte Bakterien erstrecken. Es schien mir dieser Wahrscheinlichkeitsschluss um so berechtigter, als in Versuch XIII bei Kaninchen No. 38 nach einer 31/2 Monate zurückliegenden peritonealen Coliinfection auffallend wenig Paratyphusbakterien in die allgemeine Circulation gelangt waren. Endlich lag die Vermuthung nahe, dass das in Versuchsgruppe XIV als Controlthier fungirende, also nicht vorbehandelte Kaninchen N0.40, das trotz nicht vorhergegangener bewusster Vorbehandlung des Bauchfells keine peritoneale Prodigiosusresorption gezeigt hatte, doch über eine derartige Veränderung des Peritoneums verfügte, die einer Campherölbezw. Bakterienvorbehandlung des Bauchfells entsprach: Und in der That ist es sehr wohl denkbar, dass solche Verhältnisse am Kaninchenperitoneum geschaffen werden durch bakteriell entzündliche Processe, wie sie häufig im Gefolge von Lebererkrankungen des Kaninchens vorkommen. Auf Grund aller dieser Erfahrungen und Erwägungen gelangte ich zu der Anschauung, dass entzündliche Vorgänge mannigfacher Art, sei es auf der Basis eines rein chemischen Reizes, sei es in Folge einer bakteriellen Einwirkung, das Peritoneum in einen solchen Zustand versetzen, der nicht nur für wenige Tage, sondern sogar für längere Zeit eine Hemmung oder völlige Aufhebung der Bakterienresorption aus der Bauchhöhle zur Folge hat.

Der letzte Prodigiosusresorptionsversuch an dem Controlthier No. 52 hatte mir auch Aufschluss gegeben über die enorme Sehnelligkeit, mit welcher der Uebertritt von Bakterien aus der Bauchhöhle in die allgemeine Circulation bei einem nicht veränderten Peritoneum vor sich geht. Obwohl ich sofort nach der schnellstens ausgeführten Bauchnaht, schon $4^{1} / 2$ Minuten nach der abdominalen Prodigiosusinjection, die unter sicherem Ausschluss der Bauchwunde als Resorptionspforte geschehen war, dem Herzen Blut entnahm, liess sich bereits eine sehr beträchtliche Menge von Prodigiosuskeimen im Kreislauf nachweisen. Aus $2 \mathrm{ecm}$ dieses Herzblutes wurden 1250 in der Cultur angegangene Prodigiosuscolonien gezählt.

Wenn nun meine Anschauung zu Recht bestand, dass jede reactive Entzündung des Peritoneums, mag sie durch einen abakteriellen oder bakteriellen Reiz hervorgerufen sein, die Keimresorption aus der Bauchböhle hemmt oder aufhebt, so musste Glimm's Annahme, dass in die Bauchhöhle injicirtes Oel durch 
Verlegung der abführenden Lymphwege, also durch eine specifische Wirkung, die peritoneale Bakterienresorption hindere, als hinfällig erscheinen. Um die Unrichtigkeit der Glimm'schen Vorstellung über die Bakterienresorptionshemmung möglichst klar zu stellẹn, verwendete ich jetzt als Peritonitis erzeugende Substanz Crotonöl, das schon in minimalster Dosis sehr stark reizt, ohne in dieser geringen Menge als mechanisches Verstopfungsmittel der Lymphbahnen in Frage kommen zu können. - Bei dem nicht vorbehandelten Controlthier wurden die Beobachtungen über die Schnelligkeit der peritonealen Keimresorption fortgesetzt.

\section{Versuchsgruppe.}

Am 27. III. 1909 wird einem tags zuvor mit Crotonöl vorbeh andelten Kaninchen und einem nicht vorbehandelten Controlthier die Prodigiosusversuchscultur abdominal injicirt.

No. 53. Weibliches Kaninchen, weiss, $2600 \mathrm{~g}$ schwer. Am 26. III. 1909, 9 Uhr a. m. in leichter Aethernarkose Einspritzung von drei Tropfen Crotonöl, suspendirt und gleichmässig vertheilt in $10 \mathrm{ccm}$ steriler physiologischer Kochsalzlösung, in die entsprechend der mittleren Bauchgegend eröffnete Peritonealhöhle.

Die Crotonölinjection wird gut überstanden.

Am 27. III. 1909, genau 24 Stunden später, nach erneuter Laparotomie oberhalb der gestern angelegten Wunde peritoneale Injection von $2 \mathrm{ccm}$ eimer 20 stündigen Prodigiosusbouilloncultur ohne Verunreinigung der durchschnittenen Bauchdecken. Vor der Prodigiosuseinspritzung abgeimpfter Bauchhöhleninhalt liefert kein Bakterienwachsthum auf den Controlnährböden, weder auf Agar noch in Bouillon. Prodigiosusinjection beendet $9 \mathrm{Uhr} 13 \mathrm{Min}$. a. m.

3 Blutentnahmen aus dem Herzen, nach $3 / 4$ Stunden, nach annähernd 1 Stunde und nach $1^{1 / 2}$ Stunden.

Nach 36 stündigem Wachsthum im Brutofen bei $37^{\circ} \mathrm{C}$. ergaben die 3 Blutproben:

1. 45 Min. p. inject. Prod. 2 cem hellrothes Herzblut $=1 \mathrm{Col}$.

$2 . \quad 52, " \quad " \quad, \quad " 1,9 \quad "=0 "$

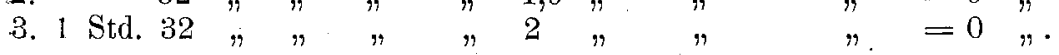

No. 54. Controlthier. Weibliches Kaninchen, grau, $2850 \mathrm{~g}$ schwer. Dem nicht peritoneal vorbehandelten Thier werden nach kleinem Bauchschnitt in der Medianlinie der Oberbauchgegend $2 \mathrm{ccm}$ derselben 20 stündigen Prodigiosusbouilloncultur unter sicherem Schutz der Bauchwunde abdominal injicirt: 9 Uhr 37 Min. a. m. Um möglichst schnell nach Einbringung der Bakterien in die Bauchhöhle Herzblut entnehmen zu können, wurde der Troikart schon vor der peritonealen Prodigiosusinjection in das Herz eingestochen, sodann die Versuchscultur abdominal injicirt, das Peritoneum durch Naht geschlossen und nun sofort nach Herauszieben der Troikartnadel das Herzblut mit der Spritze angesogen.

2 Blutentnahmen nach wenigen Minuten zur Prüfung der Schnelligkeit der Bakterienresorption und 2 Entnahmen von Herzblutproben zum 
Vergleich mit dem Versuchsthier No. 53, nach annähernd 1 Stunde und nach $13 / 4$ Stunden.

Nach 36 stündigem Wachsthum im Brutofen bei $37^{\circ} \mathrm{C}$. ergaben die 4 Blutproben:

1. $1 \frac{1}{2}$ Min. p. inj. Prod. $2 \mathrm{ccm}$ hellroth. Herzblut $=1 \mathrm{Col}$.

2. $3 \frac{1}{2} "$ " " $\left.\quad \frac{1,6}{\text { auf } 2 \text { cem berechnet }}\right\}=$ ca. 875 ,

3. $51, " n " 2 \mathrm{ccm}$ hellroth. Herzblut $=123 n$

4. 1 Std. $45 ", " n " 2 ", \quad " \quad=17 "$.

Wie nach den bisherigen Versuchsergebnissen erwartet werden durfte, war durch die Vorbehandlung des Peritoneums mit Crotonöl 24 Stunden vor der abdominalen Prodigiosusinjection in der That die Keimresorption aus der Bauchhöhle aufgehoben, während bei dem nicht vorbehandelten Controlthier aus den Herzblutproben ein nicht ganz unbedeutendes Prodigiosuswachsthum erzielt wurde. Schon $1 \frac{1}{2}$ Minuten nach Einbringen der Prodigiosuscultur in die Bauchhöhle zeigte sich das Herzblut prodigiosushaltig und nach 2 weiteren Minuten, also $3 \frac{1}{2}$ Minuten post injectionem war die Resorptionsgrösse rapid gewachsen. Bei Kaninchen No. 53 hatte also die peritoneale Vorbehandlung mit 3 Tropfen des stark reizenden Crotonöls ebenso zur Aufhebung der Prodigiosusresorption aus der Bauchhöhle geführt, wie in früheren Versuchen die $8 \mathrm{ccm} 10$ proc. Campheröls. Dass unter solchen Versuchsbedingungen von einer Verstopfung der abführenden Lymphbahnen keine Rede sein konnte, versteht sich von selbst.

Wenn es aber gelingt, durch einen chemischen Bauchfellreiz die abdominelle Bakterienresorption auszuschalten, so musste man, falls dieser peritoneale Reizzustand wirklich die Ursache der aufgehobenen Bakterienresorption war, auf dem Wege einer genügend starken mechanischen peritonealen Reizung zu dem gleichen Resultat gelangen. Dieser Probe diente die nächste Versuchsgruppe. Als mechanisches Reizmittel wurde feines Glaspulver gewählt.

\section{XXIr. Versuchsgruppe.}

Am 1. IV. 1909 wird einem tags zuvor mit Glaspulveraufschwemmung peritoneal vorbehandelten Kaninchen und einem nicht vorbehandelten Controlthier die Prodigiosusversuchscultur abdominal injicirt. Das Cortrolthier sollte nicht nur das Vergleichsobject bezüglich der Bakterienresorptionsgrösse darstellen, sondern auch weiteren Aufschluss über die Schnelligkeit der peritonealen Bakterienresorption geben.

No. 55. Weibliches Kaninchen, weiss mit schwarzen Abzeichen, $1860 \mathrm{~g}$ schwer. Am 31. III. 1909 Morgens werden $2 \mathrm{ccm}$ sterilen sehr fein pulverisirten Glases in $10 \mathrm{ccm}$ steriler physiologischer Koch- 
salzlösung aufgeschwemmt und dem leicht mit Aether narkotisirten Thier in die eröffnete Peritonealhöhle gebracht. Nach dem Eingriff keine Krankheitserscheinungen.

Am 1. IV. 1909, genau 24 Stunden später, erneute Laparotomie oberhalb der gestrigen Wande und Injection von $2 \mathrm{ccm}$ einer 24 stündigen Prodigi osusbouilloncultur in das Peritonealcavum ohne Verunreinigung der durchtrennten Bauchdecken: 9 Uhr 35 Min. a. m. 2 Blutentnahmen aus dem Herzen, nach knapp ${ }^{1} / 2$ Stunde und nach 1 Stunde.

Nach 30 stündigem Wachsthum im Brutofen bei $37^{\circ} \mathrm{C}$. ergaben die 2 Blutproben:

1. 23 Min. p. inject. Prod. $2 \mathrm{ccm}$ hellrothes Herzblut $=98 \mathrm{Col}$.

2.1 Std. $3 " n ", " 2 "=2 "$

No. 56. Controlthier. MänulichesKaninchen, weiss mit schwarzen Abzeichen, $2120 \mathrm{~g}$ schwer. Dem nicht vorbehandelten Thier werden in leichter Aethernarkose nach Eröffnung der Bauchböhle in der Medianlinie der Oberbauchgegend $2 \mathrm{ccm}$ derselben 24 stündigen Prodigiosusbouilloncultur unter sorgfältigem Schutz der Bauchwunde gegen Verunreinigung intraperitoneal injicirt: $9 \mathrm{Uhr} 50 \mathrm{Min}$. a $\mathrm{m}$. Um die Schnelligkeit der Bakterienresorption zu prüfen, war der zur Blutentnahme bestimmte Troikart wie bei No. 54 schon vor der peritonealen Prodigiosuseinspritzang im Herzen situirt, so dass unmittelbar nach Schluss des Peritoneums, schon ganz kurze Zeit nach der peritonealen Bakterieninjection, durch einfaches Herausziehen der Troikartnadel das Ansaugen der nöthigen Herzblutmenge mit der Spritze ermöglicht werden konnte. 2 Blutentnahmen aus dem Herzen nach wenigen Minuten und 1 nach knapp 1/2 Stunde.

Nach 30 stündigem Wachsthum im Brutofen bei $37^{\circ} \mathrm{C}$. ergaben die 3 Blutproben:

1. $2^{3 / 4}$ Min. p. inject. Prod. $2 \mathrm{ccm}$ hellrothes Herzblut $=86 \mathrm{Col}$.

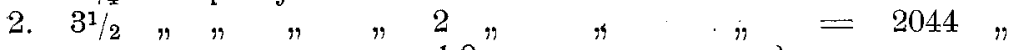

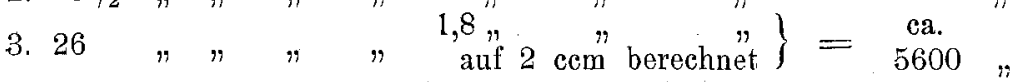

Auch die rein mechanische Reizung des Peritoneums war demnach im Stande gewesen, die Bakterienresorption, wenn auch nicht ganz aufzuheben, so doch sehr stark hemmend zu beeinflussen, was besonders deutlich hervortritt, sobald man die wenigen bei Versuchsthier No. 55 resorbirten Keime mit den hohen Resorptionsziffern des Controlthieres No. 56 vergleicht.

Für die enorme Schnelligkeit der Bakterienresorption seitens eines unveränderten Kaninchenperitoneums lieferte das Controlthier wiederum einen eklatanten Beweis. Aus der $2 \frac{3}{4}$ Minuten nach der peritonealen Prodigiosusinjection entnommenen Herzblutprobe wurden schon 86 Keime gezüchtet, and in der nächisten Minute war diese Zahl etwa um das 24 fache, auf 2044 Keime angestiegen.

Die Prodigiosusresorptionsversuche am vorbehandelten Kaninchenbauchfell (XVII. bis XXII. Versuchsgruppe) hatten ganz unzweideutig bewiesen, dass eine Hemmung 
bezw. Aufhebung der Keimresorption aus der Bauchhöhle durch Einwirkung der verschiedensten Reizmittel auf das Peritoneum erreicht werden kann. Nicht nur die erprobte Campheröldosis, sondern auch kleinste Mengen des stark reizenden Crotonöls, rein mechanisch wirkendes Glaspulver und Bakterienculturen (Prodigiosus), alle diese Reizmittel chemischer, mechanischer und bakterieller Art verursachten die peritoneale Bakterienresorptionshemmung, wenn sie früh genug in den Bauchfellraum gebracht wurden und genügend Zeit hatten, das Peritoneum. in einen Reizzustand zu versetzen. Mit diesem Resultat ist die Anschauung, dass abdominal injicirte ölige Substanzen durch Verstopfung der aus dem Cavum peritonei abführenden Lymphstrassen; also durch eine specifische Leistung die peritoneale Bakterienresorption hemmen, nicht vereinbar und deshalb als unrichtig zo bezeichnen. Nicht eine Verstopfung der Lymphwege, sondern der durch alle möglichen Reize erzielbare reactive Entzändungsustand des Bauchfells ist als die Ursache der Hemmung resp. Aufhebung der peritonealen Bakterienresorption anzusehen; und zwar bildet die mit dem reactiven Entzündungszustand einhergebende Peritonealveränderung das. Hemmniss für die Bakterienresorption. Je energischer die beabsichtigte reactive Entzündung des Peritoneums sich gestaltet, um so sicherer und vollständiger lässt sich verhindern, dass die bei bereits ausgebildeter Peritonitis ins Cavum peritonei gebrachten Bakterienmassen durch Resorption dem allgemeinen Kreislauf zugeführt werden. Es kommt viel weniger darauf an, wodurch die reactive Peritonitis veranlasst wird, als vielmehr auf die Reizintensität und auf die Reizdauer. Als geeignet muss ein solches. Reizmittel gelten, das schnell und gleichmässig im Abdomen vertheilt wird, eine gewisse Zeit in der Bauchhöhle verbleibt und dadurch in seiner Wirkung genügend nachhaltig ist. Physiologische Kochsalzlösung oder eine blosse Laparotomie wirken nicht intensiv genug und viel zu vorübergehend auf das Peritoneum ein, um als Hemmungsmittel für die Bakterienresorption in Frage kommen zu können. Es würde aber auch unzweckmässig sein, ein sehr starkes Reizmittel in grossen Quantitäten abdominal zu injiciren. Zwar würde dadurch die Bakterienresorption aus der Bauchhöhle mit. grosser Sicherheit aufgehoben werden, aber gleichzeitig daraus eine unnöthige Belästigung und eine schwere Schädigung des Allgemeinzustandes durch heftige Schmerzen, stärkste Blutüberfüllung des 
Abdomens und mangelhafte Nahrungsaufnahme entstehen. Ein ausgezeichnetes Mittel zur Erzielung der Bakterienresorptionshemmung ist das Campheröl in mässiger Menge. Es wird, wie wir haben feststellen können, sehr schnell überall im Peritonealcavum verbreitet, reizt stark genug, ohne dabei das Allgemeinbefinden in nennenswerther Weise zu stören, und entfaltet eine genügend lange Reizwirkung, da es nicht sofort wieder aus der Bauchhöhle verschwindet, wie z. B. eine wässerige Salzlösung. Damit will ich natürich nicht leugnen, dass eventuell noch geeignetere Reizmittel zur Vorbehandlung des Peritoneums gefunden werden könnten.

In vollem Einklange mit den Ergebnissen meiner Bakterienresorptionsversuche stehen die Erfahrungen, die ich bei den Vorstudien der peritonealen Oelresorption gemacht hatte. Auch dort hatte sich gezeigt, dass mit steigender Peritonealreizung die Resorptionsgrösse des Oeles abnimmt. Es scheinen demnach überhaupt die corpusculären Elemente bei bestehender Peritonitis im Abdomen aufgehalten und festgehalten zu werden. Dies zu betonen, halte ich für recht wichtig. Es ergiebt sich nämlich schon daraus ein Hinweis, dass bei den peritoneal vorbehandelten Thieren die Herzblutproben nisht deshalb keimfrei oder keimarm ausfielen, weil etwa resorbirte Bakterien in den Blutculturen nicht angegangen wären, sondern weil in Wirklichkeit keine oder eine nur unbedeutende Resorption der abdominal injicirten Bakterien stattgefunden hatte.

Als besonders interessante Beobachtung verdient nochmals hervorgehoben zu werden, dass die Bakterienresorptionshemmung keineswegs eine schnell vorübergehende Erscheinung ist, sondern dass der Zustand des Nichtresorbirens von Bakterien seitens des Peritoneums tagelang und sogar wochenlang anhalten kann.

Hatte ich so auf dem Wege zahlreicher bakteriologischer Untersuchungen des Herzblutes den Beweis für die Möglichkeit erbracht, durch geeignete Vorbehandlung des Peritoneums die Bakterienresorption aus der Bauchhöhle sicher zu verhindern und dadurch den Kampf des Körpers mit den in das Peritonealcavum injicirten Bakterien im wesentlichen auf die Bauchhöhle zu beschränken, so war es nunmehr nöthig zu zeigen, dass diese Aufhebnng der Bakterienresorption aus der Bauchhöhle nicht nur eine Erscheinung von rein theoretischem Interesse ist, sondern einen grossen 
praktischen Werth hat, indem sie für die sonst durch Bakteriämie aufs schwerste bedrohten Thiere eine Lebenssicherung und sogar in den meisten Fällen für die sonst dem sicheren Tode verfallenen Thiere eine Lebensrettung bedeutet. $\mathrm{Zu}$ diesem $\mathrm{Z}$ wecke machte ich jetzt intraperitoneale Injectionen von hochvirulenten Bakterien bei vorbehandelten und nicht vorbehandelten Kaninchen. Dem Rathe von Geheimrath Fischer folgend, wählte ich für diese Versuche hochvirulente Coliculturen, und zwar Coli haemolyticum, das an Virulenz für das Kaninchen etwa der Virulenz der hämolytischen Streptokokken für den Menschen gleich kommt und mit fast absoluter Sicherbeit selbst grosse Kaninchen binnen wenigen Stunden odor im Verlaufe einiger Tage tödtet.

Zunächst. worde in den folgenden beiden Versuchsgruppen der ausgewählte Stamm von Coli haemolyticum auf seine vermuthete hohe Virulenz geprüft, und dabei nochmals die Probe auf die früher schon erwiesene ungünstige Einwirkung einer der intraperitonealen Bakterieninjection.unmittelbar vorausgeschickten Oelung des Peritoneums gemacht (vergl. S. 598 u. 599). Auch der Schnelligkeit der Bakterienresorption aus der Bauchhöhle wurde weiterhin Beachtung gesihenkt.

\section{Versuchsgruppe.}

Am 26. III. 1909 werden einem unmittelbar vor der peritonealen Infection geölten Kaninchen und einem nicht geölten Controlthier gleiche Mengen derselben Colicultur abdominal injicirt.

No. 57. Weibliches Kaninchen, grau, $2530 \mathrm{~g}$ schwer. Dem leicht mit Aether narkotisirten, nicht vorbehandelten gesunden Versuchsthier wurden nach Laparotomie in der Medianlivie der mittleren Oberbauchgegend $8 \mathrm{ecm} 10$ proc. Campheröls und im unmittelbaren Anschluss daran $2 \mathrm{ecm}$ einer 24 stündigen Bouilloncultur von Bact. coli haemolyticum ohne Verunreinigung der Bauchwunde in die Peritonealhöhle injicirt: 9 Uhr 59 Min. a. m.

Kurze Zeit nach der peritonealen Coliinfection macht das Thier einen sehr elenden Eindruck. Ein Versuch, durch Herzpunction von dem schon schwerkranken Thier Blut zu gewinnen, misslingt. Weitere Herzpunctionsversuche werden unterlassen, um nicht durch Schädigung der Herzwand die Beurtheilung des Infectionsablaufes zu compliciren. $1^{3 / 4}$ Stunden p. inject. Coli haemol. ist das Thier moribund und wird in diesem Zustande durch Nackenschlag getödtet, damit eine möglichst frühzeitig entnommene Herzblutprobe zur Cultur Verwendung finden kann. Eröffnen des Tborax. Das noch pulsirende Herz ist in seiner Wandung intact; Kein Bluterguss, weder in der Pericardialhöble noch im Mediastinum. Es klärt sich sofort auf, weshalb die Herzpunction mit dem auf seine Schärfe controlirten, frisch geschliffenen Troicart 
versagte. Das Herz war nämlich so wenig bluthaltig, so weich und schlaff, der Turgor der Wand offenbar in Folge der schweren foudroyanten Infection so gering, dass es selbst der haarscharfen Nadel auswich und eingedrückt wurde. Aus dem freigelegten, sich noch in regelmässigen Intervallen contrahirenden Herzen wird nun unter aseptischen Cautelen Blut mit der Spritze angesogen, and zwar aus dem rechten Ventrikel; ferner Controlimpfungen aus Lunge, Leber und Milz vorgenommen.

Nach 24 stündigem Wachsthum im Brutofen bei $37^{\circ} \mathrm{C}$. ergaben die Culturen:

1. Die einzige mögliche Blutentnahme aus dem noch thätigen Herzen des im moribunden Zustande getödteten Thieres:

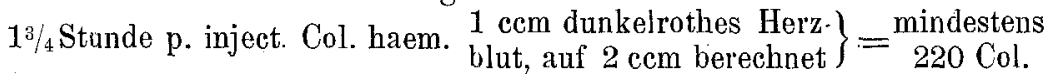

2. Die Organimpfungen (Lunge, Leber, Milz) unmittelbar p. exit.: auf Agar und in Bouillon deutliches Coliwachsthum, am reichlichsten aus der Milz.

No. 58. Controlthier: Weibliches Kaninchen, weissschwarz, $2050 \mathrm{~g}$ schwer. In leichter Aethernarkose werden $\mathrm{dem}$ bisher nicht zu Versuchszwecken verwendeten und nicht vorbehandelten Thier lediglich $2 \mathrm{ccm}$ derselben 24 stündigen Bouilloncultur von Bact. col. haemol. unter sorgfältigem Schutz der Bauchwunde intraperitoneal injicirt. Schon vor Beginn der Infection war der zur Blutentnahme dienende Troicart ins Herz gestochen worden, um so schnell wie nur angängig nach abgeschlossener Infection Herzblut zu erhalten. Abdominale Coliinjection beendet: $10 \mathrm{Uhr} 22 \mathrm{Min}$. a. m. 2 Blutentnahmen aus dem Herzen zur Bestimmung der Schnelligkeit der Bakterienresorption und 1 Bluten tnahme nach $5 / 4$ Stunden zum Vergleich mit dem Versuchsthier.

Nach 24 stündigem Wachsthum im Brutofen bei $37^{\circ} \mathrm{C}$. ergaben die Blutproben:

1. 35 Secunden p. inj. Col. haem. 2 com hellrothes Herzblut $=0$ Col.

2. $4^{1 / 2}$ Minuten $" n " n " 2 n " n=64 n$

3. 1Std. 11 Min. " " " " " $" 2 " 2 " \quad " \quad " \quad=260 "$

Das Thier ist nach der Infection deutlich krank, sitzt ruhig da, frisst nicht. Es wird von Tag zu Tag elender und magert sichtlich ab. Am 30. III. 09 Mittags, also gut 4 Tage post infect. nochmalige Bluteñtnahme aus dem Herzen des schwerkranken Thieres: $1 \mathrm{ccm}$ hellrothes Herzblut. Aus dieser Blutprobe erfolgt ein sehr reichliches Wachsthum von Coli haemol. auf der Agarplatte. Die aus der Bauchhöhle resorbirten Colibakterien haben sich im Blute sehr stark vermehrt; es besteht eine ausgesprochene Colisepsis. Der schweren Colibakteriämie erliegt das Thier am 1. IV. 09, also 5 Tage nach Beginn der peritonealen Infection. Aus der Bauchböhle, aus den Bauchhöhlenorganen (Leber und Milz), aus dem Herzblut und besonders aus allen Theilen der Lunge werden Unmengen von hämolytischen Colibakterien gezüchtet.

Bei der für die beschriebene Versuchsgruppe verwendeten Colicultur handelte es sich demnach wirklich um einen hochvirulenten Stamm. Beide Thiere sind an Colisepsis gestorben. Das unmittelbar vor der peritonealen Coli- 
infection geölte Versuchsthier erkrankte, obwohl es das kräftigere Kaninchen war, schneller und schwerer als das nicht geölte Controlthier. Es war schon nach $13 / 4$ Stunden moribund, während das Controlthier 5 Tage lebte. Bei dem geölten Thier war der Blutdruck bald nach der Infection so gesunken, dass eine Blutentnahme durch Herzpunction unmöglich wurde; bei dem nicht geölten Thier gelang die Herzpunction gut. Die Zahl der aus der Bauchhöhle resorbirten und aus den Herzblutproben angegangenen Keime fiel für beide Kaninchen fast gleich aus.

Durch Einstechen des Troicarts in das Herz vor der peritonealen Coliinfection war es mir bei dem Controlthier geglückt, so. früh (schon 35 Secunden post infect.) Herzblut zu gewinnen, dass resorbirte Keime darin noch nicht nachweisbar waren. 41/2. Minuten nach der abdominalen Coliinfection gingen entsprechend den früheren Resultaten der Prodigiosusresorptionsversuche reichlich Keime aus der Herzblutprobe an.

Die Virulenzprüfung des Coli haemolyticum-Stammes wurde in der nächsten Versuchsgruppe wiederholt. Die Schnelligkeit der peritonealen Coliresorption wurde weiter genau beachtet.

\section{Versuchsgruppe.}

Am 30. III. 1909 werden einem unmittelbar vorber mit Crotonöl peritoneal vorbehandelten Kaninchen und einem nicht geölten controlthier gleiche Mengen derselben Colicultur abdominal injicirt.

No. 59. Weibliches Kaninchen, hellgrau, $3160 \mathrm{~g}$ schwer. 3 Tropfen 01. crotonis werden in $10 \mathrm{ccm}$ steriler physiologischer Kochsalzlösung durch kräftiges Schütteln möglichst fein und gleichmässig vertheilt, diese Emulsion dem leiebt mit Aether narkotisirten Thier in das geöffnete Cavum peritonei gebracht und gleich danach $2 \mathrm{ccm}$ einer $24 \mathrm{stün-}$ digen Bouilloncultur von Bact. coli haemol. injicirt, ohne dass die Bouilloncultur mit der Bauchwunde in Berührung. kommt: 9 Uhr 40 Min a. $\mathrm{m}$.

Bald nach der Coliinfection ist das Thier schwerkrank, wird nach $3 / 4$ Stunden sehr elend, immer matter und hinfälliger, kann sich nach $5 / 4$ Stunden nicht mehr aufrecht halten, fällt auf die Seite, athmet sehr beschleunigt und stirbt $1 \mathrm{Stunde} 58 \mathrm{Min}$. nach. Beginn der Infection.

Zwei erfolgreiche Herzpunctionen vor dem Tode, 1/2 Stunde und 1 Stunde post infect., und 2 Blutentnahmen aus dem sogleich post exit., also 2 Stunden post infect., freigelegten noch pulsirenden Herzen. Ausserdem Controlimpfungen aus Leber, Lunge und Milz (Ausstriche von den watteumwickelten Entnahmestäbchen auf Agarplatten und Versenken der von den Entnahmestäbchen entfernten Watte in Bouillon).

Nach 26 stündigem Wachsthum im Brutofen bei $37^{\circ} \mathrm{C}$. ergaben die Herzblut- bezw. Organproben: 
1. 25 Min. p. inj. Col. haem. $2 \mathrm{ccm}$ hellroth. Herzblut = ca. $18000 \mathrm{Col}$.

2. 61 " " " " $\quad \begin{aligned} & 1 \mathrm{ccm} \text { hellroth. Herzblut; } \\ & \text { auf } 2 \text { ecm berechnet }\end{aligned}=$ " 24000 "

3. 2 Min. p. exit., 2 Std. p. inj. Col. haem. 2 ccm Blut aus dem rechten Ventrikel des noch pulsirenden Herzens $=\left\{\begin{array}{c}\infty \text { Col., geschätzt auf } \\ \text { ca. } 50000 \mathrm{Col} .\end{array}\right.$

4. 4 Min. p. exit., 2 Std. p. inj. Col. haem. $2 \mathrm{ccm}$ Blut aus dem rechten

Ventrikel des noch pulsirenden Herzens $=\infty$ Col., genau so, wie bei der unmittelbar vorhergegangenen Blutentnahme.

Aus den Organabstrichen, besonders aus der Lunge, erfolgt auf Agar und in Bouillon ein sehr üppiges Coliwachsthum.

No. 60. Controlthier. Weibliches Kaninchen, dunkelgrau, $2860 \mathrm{~g}$ schwer. Dem nicht vorbehandelten Thier werden in leichter Aethernarkose lediglich $2 \mathrm{ccm}$ derselben 24 stündigen B ouilloncultur von Bact. coli haem. unter sorfältigem Vermeiden einer Verunreinigung der Balıchwunde in den eröffneten Peritonealsack eingespritzt: $9 \mathrm{Uhr} 55$ Min. a. m.

Das Thier ist bald nach der Infection deutlich krank, aber weniger als das Versuchsthier No. 59. Nach ca. 2 Stunden wird es sehr elend und fällt wiederholt um. Die Athmung bleibt mässig frequent. Allmählich erholt sich das Thier etwas, richtet sich wieder auf, lässt aber den Kopf hängen. Dann tritt wieder eine Verschlechterung des Zustandes ein, Exitus $51 / 2$ Stunden post infectionem. 3 Blutentnahmen aus dem Herzen vor dem Tode, wenige Minuten, 1/4 und 1//4 Stunden nach der intraperitonealen Coliinjection und 1 Blutentnahme post exitum aus dem rechten Ventrikel des Herzens. Ausserdem Abimpfungen aus Lunge, Bauchhöhle, Leber und Milz auf Agar und in Bouillon.

Nach 26 stündigem Wachsthum im Brutofen bei $37^{\circ} \mathrm{C}$. ergaben die Blut- bezw. Organgroben:

1. $2^{1 / 2}$ Min. p. inj. Col. haem. 1,6 cem dunkel-

$$
\text { 2. } 18, " n, ", \begin{array}{r}
\text { rothes Herzblut } \\
2 \text { cem hellroth. }
\end{array} \quad \text { Col. }
$$

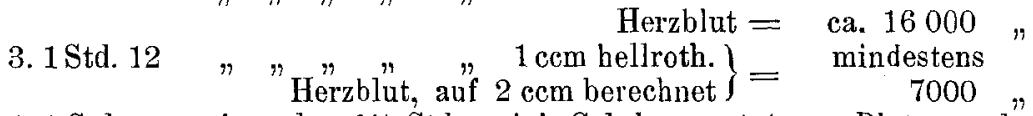

4. 1 Std. p. exit., also $6 \frac{1 / 2}{2}$ Std. p. inj. Col. haem. $1,4 \mathrm{ccm}$ Blut aus dem rechten Ventrikel des Herzens, auf $2 \mathrm{ccm}$ berechnet $=$ ca. $12000 \mathrm{Col}$.

Aus der Bauchhöhle "und aus allen geprüften Organen, besonders ans der Lunge, wird ein ausserordentlich intensives Coliwachsthum erzielt.

Das unmittelbar vor der abdominalen Colinfection mit 3 Tropfen Crotonöl peritoneal behandelte Versuchsthier No. 59 ist wieder unter acuteren und schwereren Erscheinungen von Colisepsis erkrankt und früher gestorben (nach knapp 2 Stunden) als das entsprechende, wiederum kleinere Controlthier No. 60. (Tod nach $5^{1} / 2$ Stunden).

Wie ist nun die ron mir festgestellte Thatsache zu 
erklären, dass ein Kaninchen, wenn ihm kurz vor der peritonealen Infection 0 el in die Bauchböhle injicirt wird, unter dem Infectionsprocess mehr leidet und an demselben in kürzerer Zeit za Grunde geht, als wenn das Peritoneum unbehandeJt bleibt?

Die gegentheilige Ansicht Glimm's, der den peritonealen Olivenölinjectionen selbst noch kurz nach der abdominalen Bakterieninjection einen Nutzen für die Versuchsthiere zugesprochen hat (cf. 1. c., S. 281, 43.-46. Versuch, im Ganzen 4 Kaninchen, dabei keine Controlthiere), muss ich nach meinen Erfahrungen mit $9 \mathrm{Ver}^{-}$ suchsthieren (No. 21, 23, 26, 27, 30,31,32, 57 und 59) und 5 Controlthieren (No. 22, 28, 33; 58 und 60), je einem Controlthier für die 5 Versuchsgruppen (VIII, IX, X, XXIII and XXIV) für widerlegt halten. Da nun die zablenmässig controlirte Bakterienresorption aus der Bauchhöhle (Bacterium prodigiosum und Bacterium coli haemolyticum) fast immer bei dem soeben geölten Versuchsthier grösser ausgefallen ist, als bei dem entsprechenden nicht peritoneal behandelten Controlthier (cf. XI., XII., XIV., XV., XVI., XXIII. und XXIV. Versuchsgruppe), so lässt sich das schwerere Erkranken und das schnellere Sterben der kurz vor der abdominalen Infection geölten Thiere gegenüber den peritoneal nicht behandelten Kaninchen ungezwungen auf die wahrscheinlich durch den eben erst gesetzten Peritonealreiz hervorgerufene Steigerung der Bakterienresorptionsgrösse zurückführen. Dies ist eine interessante Parallele zu den Milchzucker-Resorptionsversuchen Glimm's, der ja eine beschleunigte Resorption seitens des frisch inficirten Peritoneums für wasserlösliche Substanzen mit aller Sicherheit nachgewiesen hat. Nach meinen Versuchsergebnissen würde sich die Resorptionsbeschleunigung bei acuter Peritonitis nicht nur auf den Blutweg, sondern auch auf den Lymphweg erstrecken. Von einer Reizbehandlung des Bauchfells, die zeitlich mit der peritonealen Infection zusammenfällt, darf man demnach keinen Nutzen erwarten. In Folge der vermehrten Bakterienresorption müssen die Chancen für das peritoneal inficirte Thier nur ungünstiger werden.

Nachdem auch die beiden Kaninchen der XXIV. Versuchsgruppe, im Ganzen also 4 ausgewachsene, gesunde Thiere hintereinander der peritonealen Infection mit dem auf seine Virulenz zu prüfenden Coli haemolyticum-Stamm schnell erlegen waren, konnte an der hohen Virulenz des für die weiteren Versuche zur 
Verfügung stehenden Bakterienmaterials nicht gezweifelt werden.

Wie verhalten sich nun die in geeigneter Weise peritoneal rorbehandelten Thiere gegenüber der so delètär wirkenden Infection mit dem als hochvirulent erkannten Coli haemolyticum-Stamm? Ueberstehen gut und genügend lange peritoneal vorbehandelte Kaninchen auf Grund der gehemmten, bezw. aufgehobenen Bakterienresorption, die für nieht vorbehandelte Kaninchen verhängnissvolle und fast sicher letale Infection? Das war die brennende Frage geworden, die jetzt in den weiteren Versuchsgruppen ihre Lösung finden musste.

\section{Versuchsgruppe.}

Am 2. IV. 1909 werden einem tags zuvor mit Campheröl peritoneal vorbehandelten und einem schon 2 mal, vor 13 und vor 22 Tagen, mit intraperitonealer Prodigiosusinjection vorbebandelten Kaninchen gleiche Mengen der als hochvirulent erprobten Colicultur abdominal injicirt.

No. 61. Weibliches. Kaninchen, weiss, $2950 \mathrm{~g}$ schwer. Am 1. IV. 19099 Uhr a. m. werden dem leicht mit Aether narkotisirten Thier $8 \mathrm{ccm}$ sterilen 10 proc. Campheröls per laparotomiam in die Peritonealhöhle gebracht.

Nach 24 Stunden erneute Laparotomie oberhalb der gestrigen Wunde, wiederum in leichter Aethernarkose und Injection von $2 \mathrm{ccm}$ einer 24 stündigen Bouilloncultur von Bact. coli haemolyt. unter sorgfältiger Vermeidung einer bakteriellen Bauchwundverunreinigung: 9 Uhr 46 Min. a. m. Das Thier befindet sich nach der Infection gut, was besonders im Vergleich $\mathrm{zu}$ den Thieren der beiden vorigen Versuchsgruppen ins Auge fällt. Leider stirbt das Thier, nachdem nur 1 Blutentnahme aus dem Herzen gut gelungen ist, in Folge eines grossen pericardialen und mediastinalen Blutergusses, der sich im Anschluss an wiederholte vergebliche Herzpunctionsversuche entwickelt hat: 2 Stunden 11 Min. post infectionem.

2 Blutentnahmen aus dem Herzen, $3 / 4$ Stunden post infectionem und ca. $1 / 2$ Stunde post exit. In der Bauchhöhle kein Erguss; Peritoneum stark hyperämisch, hier und da weisse Flöckchen und Krümelehen, die aus emulgirtem $\mathrm{Oel}$, Leukocyten und Fibrinfädchen besteben. Controlimpfungen aus Bauchhöhle und Lunge.

Nach 36 stündigem Wachsthum im Brutofen bei $37^{\circ} \mathrm{C}$. ergaben die Blut- bezw. Organproben:

1. $42 \mathrm{Min}$. p. inj. Col. haem. $2 \mathrm{ccm}$ hellrothes Herzblut $=12 \mathrm{Col}$.

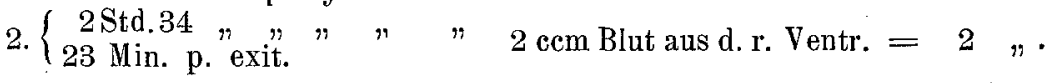

Aus der Lunge entnommenes Material hat weder auf Agar noch in Bouillon Coliwachsthum geliefert. Die Nährböden blieben während einer mehrtägigen Beobachtung steril. Dagegen liess sich aus der Bauchhöhle eine üppige Cultur von Coli haemolyticum züchten. 
Diese Culturergebnisse bestätigen die Annahme, dass das bis $z u$ den vergeblichen Herzpunetionen kaum krank erscheinende Thier nicht an Colisepsis, sondern an dem pericardialen Bluterguss gestorben ist. Wenn auch einige wenige Colikeime aus der Bauchhöhle resorbirt waren: so ist doch der Unterschied in der Resorptionszahl gegenüber den 4 Thieren der XXIII. und XXIV. Versuchsgruppe ein so deutlicher, dass eine günstige Wirkung der prophylaktischen Oelbehandlung des Peritoneums wohl ausser $\mathrm{Zweifel} \mathrm{steht.} \mathrm{Besonders} \mathrm{möchte} \mathrm{ich} \mathrm{noch} \mathrm{darauf}$ hinweisen, dass die Zahl der im Blute gefundenen Colikeime von der ersten Blutentnahme aus dem Herzen $(3 / 4$ Stunden post infectionem) bis zur Herzpunction post exitum $(21 / 2$ Stunden post infectionem) nicht zugenommen hatte, sondern die an sich schon sehr geringe Keimzahl 12 auf 2 Keime heruntergegangen war, und dass aus der Lunge keine Colikeime gezüchtet wurden.

No. 62. Dem grossen, weissen, männlichen Kaninchen, das ror 22 Tagen (cf. XIV. Versuchsgruppe No. 40) und vor 13 Tagen (cf. XVIII. Versuchsgruppe No. 47) je eine intraperitoneale Injection von $2 \mathrm{ccm}$ einer 24 stündigen Prodigiosusbouilloncultur erhalten und damals keine, bezw. eine minimale Keimresorption aus der Bauchhöhle gezeigt hatte, werden heute in leichter Aethernarkose $2 \mathrm{ccm}$ derselben 24 stündigen Bouilloncultur von Bact. coli haemol., wie bei dem mit Campheröl vorbehandelten Thier No. 61 in die links von der Medianlinie der Oberbauchgegend eröffnete Peritonealhöhle unter sorgsamem Schutz der Bauchwunde gegen Verunreinigung mit Colibakterien eingespritzt: 10 Uhr 7 Min. a. m.

Wenn auch das Thier nach der abdominalen Coliinfection krank ist, so erholt es sich doch binnen wenigen Stunden, erscheint schon am Abend des Infectionstages munter und frisst. In den nächsten Tagen verhält es sich wie ein gesundes Kaninchen.

2 Blutentnahmen durch Herzpunction, ca. 1/4 Stunde und ca. 1 Stunde post infectionem.

Nach 36 stündigem Wachsthum im Brutofen bei $37^{\circ} \mathrm{C}$. ergaben die beiden Blutproben:

1. 10 Min. p. inj. Col. haem. $2 \mathrm{ccm}$ hellrothes Herzblut $=10 \mathrm{Col}$.

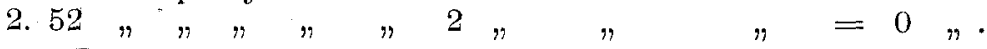

8 Tage post infect, also am 10. IV. 1909 wurde bei dem gesunden Thier eine Controllaparotomie gemacht, und aus der Bauchhöhle, aus den oberen und unteren Abschnitten, mit je einem watteumwickelten Stäbchen eine Abimpfung vorgenommen. Ausstreichen des Impfmaterials auf Agarplatten und Versenken der Watte der Entnahmestäbchen in Bouillon. Die Culturen wurden mehrere Tage beobachtet und liessen während der Beobachtungszeit kein Coliwachsthum erkennen.

Während 4 nicht vorbehandelte Thiere auf die intraperitoneale Injection von $2 \mathrm{cem}$ einer 24 stündigen Bouilloncultur von Coli haemolyticum hin unter reichlicher Resorption von Colibakterien 
aufs schwerste erkrankt und an Colisepsis gestorben waren, hatte bei beiden vorbehandelten Thieren (das eine mit Campheröl, das andere mit Prodigiosus) nur ein minimalster Uebertritt von Colibakterien in die allgemeine Circulation stattgefunden. Die beiden Thiere machten nach der Infection einen nur leichtkranken Eindruck, und, während No. 61 an dem pericardialen Bluterguss zu Grunde ging, überstand No. 62 die schwere Infection auffallend leicht und vernichtete die grossen Massen intraperitoneal injicirter Colibakterien schnell, so dass 8 Tage post infectionem kein einziger Colikeim mehr aus der Bauchhöhle gezüchtet werden konnte.

Wie nach den bisherigen Erfahrungen und vor allem nach den Ergebnissen der Prodigiosusresorptionsversuche vorauszusehen war, hatte die Vorbehandlung des Bauchfells (Campheröl- und Prodigiosusinjectionen) in Wirklichkeit die peritoneale Bakterienresorption stark gehemmt; und in dieser Resorptionshemmung, resp. in der durch sie bedingten Verhütung der allgemeinen Colisepsis lag der Schutz des Thieres gegen schwerste Erkrankung mit einem fast sicher letalen Ausgange begründet.

Jetzt war an einer grösseren Reihe von Kaninchen zu prüfen, ob sich die prophylaktische Bauchfellbehandlung auch fernerhin bei schweren Bauchhöhleninfectionen als Schutzmittel gegen Sepsis bewährt.

\section{Versuchsgruppe.}

Am 3. IV. 1909 werden einem mit Campheröl und später mit zweimaliger Prodigiosusinjection peritoneal vorbehandelten Kaninchen, einem 3 mal mit intraperitonealer Prodigiosusinjection vorbehandelten Kaninchen und einem nicht vorhehandelten Controlthier gleiche llengen derselben Colicultur abdominal injicirt.

No. 63. Dem mittelgrossen, heligrauen, weiblichen Kaninchen, das vor 18 Tagen (XVII. Versuchsgruppe, No. 45) eine intraperitoneale Injection von $8 \mathrm{ccm} 10$ proc. Campheröls und tags darauf und nochmals 6 Tage später (XIX. Versuchsgruppe, No. 49) je eine intraperitoneale Injection von $2 \mathrm{ccm}$ einer 24 stündigen Prodigiosusbouilloncultur erhalten und auf die erste Prodigiosusinjection nur minimale, auf die zweite Prodigiosusinjection hin gar keine Keimresorption aus dem Peritonealcarum gezeigt hatte, werden heute in leichter Aethernarkose $2 \mathrm{ccm}$ einer 24 stündigen Bouilloncultur v on Bact. coli haemolyt. in die rechts von der Medianlinie des Mittelbauches eröffnete Peritonealhöhle unter sicherer Vermeidung einer bakteriellen Bauchwundverunreinigung eingespritzt: 10 Uhr 3 Min. a. m.

Schon nach 2 Stunden hat sich das Thier von dem Eingriff ganz èrholt, springt vergnügt umher und frisst. Auch später werden an dem Thier keine Krankheitssymptome bemerkt. 
1 Blutentnahme aus dem Herzen 1 Stunde 12 Min. post infectionem: $2 \mathrm{ccm}$ hellrothes Blut.

Nach 48 stündigem Wachsthum im Brutofen bei $37^{\circ} \mathrm{C}$. ist auf der ganzen Blutagarplatte keine Colicolonie angegangen.

Am 10. IV. 1909, also 7 Tage post infect., Controllaparotomie zwecks Abimpfung mit 2 watteumwickelten Stäbchen aus den oberen und unteren Partien der Bauchhöhle. Weder auf Agar noch in Bouillon wird in mehrtägiger Beobachtungszeit ein Coliwachsthum constatirt.

No. 64. Das mittelgrosse, dunkelgraue, weibliche Kaninchen, dem schon $3 \mathrm{mal}$, vor 26 Tagen (XII. Versuchsgruppe, No. 37), vor 17 Tagen (XVII. Versuchsgruppe, No. 46) und vor 12 Tagen (XIX. Versuchsgruppe, No. 50) je 2 ccm einer 24 stündigen Prodigiosusbouilloncultur intraperitoneal injicirt worden waren, und das nach der ersten abdominalen Prodigiosusinjection eine sehr reichliche, nach der zweiten eine geringe und nach der dritten gar keine Keimresorption aus der Bauchhöhle gezeigt hatte, erhält heute in leichter Aethernarkose $2 \mathrm{ccm}$ derselben Coli haemolyticum-Bouilloncultur wie No. 63 intraperitoneal injicirt, bei sorgfältigem Schutz der Bauchwuude gegen Verunreinigung mit Coli: 9 Uhr 40 Min. a. $\mathrm{m}$.

An dem Thier merkt man kein Kranksein. Nach wenigen Stunden tummelt es sich wie ein gesundes Kaninchen, frisst und bleibt auch weiterhin gesund.

1 Blutentnahme aus dem Herzen 1 Stunde 11 Min. post infectionem: $2 \mathrm{ccm}$ hellrothes Blut.

Nach 48 stündigem Wachsthum im Brutofen bei $37^{\circ} \mathrm{C}$. ist auf der ganzen Blutagarplatte keine Colicolonie angegangen.

Am 10. IV. 1909, also 7 Tage post infectionem Controllaparotomie, um zu prüfen, ob noch entwicklungsfähige Colibakterien in der Bauchhöhle nachzuweisen sind. Das mit watteumwickelten Stäbchen aus dem Peritonealcavum entnommene Material wird auf Agar und in Bouillon verimpft; es liefert in einer mehrtägigen Beobachtungszeit kein Wachsthum: Auf der Agarplatte keine einzige Colonie; die Bouillon bleibt ganz klar und ohne Bodensatz.

No. 65. Controlthier. Männliches Kaninchen, grau, $1460 \mathrm{~g}$ schwer. Ohne jede Vorbehandlung des Peritoneums werden dem leicht mit Aether narkotisirten Thier lediglich $1,8 \mathrm{ccm}$ der für No. 63 und No. 64 verwendeten 24 stündigen Bouilloncultur von Bact. coli haemolyt. unter sicherer Vermeidung einer Bauchwundverunreinigung intraperitoneal injicirt.

Nach der Infection sitzt das Thier traurig da und macht, im krassen Gegensatz zu den beiden peritoneal vorbehandelten Thieren, einen schwerkranken Eindruck. Eine Herzpunction gelingt wegen Schlaffheit der Herzwandung nicht. Allmählich erholt sich das Thier etwas, ist aber immer deutlich krank, magert bei sehr geringer Nahrungsaufnahme sichtlich ab, wiegt schliesslich nur noch $1070 \mathrm{~g}$ und stirbt am 10. IV. 1909, also 7 Tage nach der peritonealen Coliinfection.

Die sofort ausgeführte Section ergiebt eine diffuse fibrinös-eitrige Peritonitis mit sehr reichlichem Exsudat, wie man es bei länger dauernder Peritonitis des Menschen zu sehen gewohnt ist. Unter aseptischen Cautelen Blutentnahme aus dem rechten Ventrikel des noch schwach pulsirenden Herzens, ferner Abimpfungen aus der Bauchhöhle, aus der Leber, Milz und Lunge. 
Nach 30 stïndigem Wachsthum im Brutofen bei $37^{\circ} \mathrm{C}$. sind aus dem Herzblut $(1 \mathrm{ccm})$ unzählige, dicht gedrängte Colonien von Coli haemolyticum gewachsen. Ebenso ist aus der Lunge, ans der Leber, $\mathrm{Milz}$ und aus der Bauchhöhle ein sehr üppiges Wachsthum von Coli haemolyticum in Reincultur erfolgt.

Während die gut vorbehandelten Thiere dieser XXVI. Versuchsgruppe No. 63 und 64 nach der abdominalen Infection mit dem schwerinfectiösen Colivirus kaum ein Kranksein erkennen liessen, keine Bakterienresorption aus der Bauchhöhle zeigten und innerhalb von 7 Tagen die Unmengen hoch virulenter Colibakterien in der Bauchhöhle völlig vernichtet hatten, erkrankte das nicht vorbehandelte Controlthier schwer an Colisepsis und ging allmählich an der schweren Allgemeininfection zu Grunde. Die bakteriologische Untersuchung unmittelbar post exitum ergab eine Durchseuchung des ganzen Körpers mit dem zur Infection gewählten Coli haemolyticum und eine typisehe fibrinös-eiterige Peritonitis, die sich bei der relativ langen Dauer des Infectionsprocesses ( 7 Tage) hatte entwickeln können.

Ob der verblüffende Unterschied in dem Verhalten der vorbehandelten und nicht vorbehandelten Kaninchen gegenüber der peritonealen Infection mit dem hochvirulenten Colistamm regelmässig zu constatiren ist, sollten weitere Versuche lehren.

\section{Versuchsgruppe.}

Am 6. IV. 1909 werden einem mit Campheröl und mit 1 maliger Prodigiosusinjection peritoneal vorbehandelten Kaninchen, einem nur mit 1 maliger intraperitonealer Prodigiosusinjection vorbehandelten Kaninchen und einem nicht vorbehandelten Controlthier gleiche Mengen derselben Colicultur abdominal injicirt.

No. 66. Das mittelgrosse, weiss gezeichnete, graue mämnliche Kaninchen, dem als No. 51 der Versuchsgruppe $X X$ vor 15 Tagen $8 \mathrm{ccm} 10$ proc. Campheröls und tags darauf $2 \mathrm{ccm}$ einer 14 stündigen Prodigiosusbouilloncultur intraperitoneal injicirt, und in dessen Herzblut nach der Prodigiosusinjection keine Keime gefunden worden waren, erhält heute in leichter Aethernarkose unter sicherem Schutz der Bauchwunde gegen bakterielle Verunreinigung eine Injection von $1,8 \mathrm{ccm}$ einer 20 stündigen Bouilloncultur von Bact. coli haemolyt. in die eröffnete Bauchhöhle: 9 Uhr 37 Min. a. m.

Dem Thier merkt man kein Kranksein an. Es fühlt sich sichtlich ganz wohl, schnuppert umber und frisst schon nach wenigen Stunden. 2 Blutentuahmen aus dem Herzen, nach ca. 1 Stunde und nach fast 8 Stunden werden gut vertragen.

Nach 30 stündigem Wachsthum im Brutofen bei $37^{\circ} \mathrm{C}$. ergaben die beiden Blutproben:

1. - 58 Min. p. inject. Col. haem. 2 ccm hellrothes Herzblut $=0 \mathrm{Col}$.

2. 7 Std. $54 " n ", " n "=0$ " $"$ 
Controllaparotomie des gesunden Thieres zwecks bakteriologischer Untersuchung des Bauchhöhleninhaltes am 10. IV. 09, also 4 Tage post infect., ohne Narkose. Bei mehrtägiger Beobachtung der angelegten Culturen ergiebt sich weder auf Agar noch in Bouillon Coliwachsthum: Auf der Agarplatte ist keine einzige Colonie angegangen, die Bouillon ist völlig klar geblieben.

No. 67. Dem mittelgrossen, grauen, männlichen Kaninchen, das vor 14 Tagen in Versuchsgruppe XX als Controlthier No. 52 anf die intraperitoneale Injection von $2 \mathrm{ccm}$ einer 14 stündigen Prodigiosusbouilloncultur hin eine reichliche Resorption von Prodigiosuskeimen aus der Bauchhöhle hatte erkenuen lassen, werden heute wie dem Versuchsthier No. 66 in leichter Aethernarkose 1,8 ccm der 20 stündigen Bouilloneultur von Coli haemolyticum ohne Verunreinigung der Bauchwunde mit Colibakterien in die eröffnete Bauchböhle eingespritzt: 9 Uhr 57 Min. a. m.

Auch diesem Thier merkt man nach der peritonealen Coliinfection kaum ein Kranksein an. Herausgenommen aus dem Korb, schnuppert das vor kurzem operirte und inficirte Thier umher und knabbert an hingeworfenen Rübenstückchen.

2 glatte Herzpunctionen zwecks Blutentnahme, nach ca. 1 Stunde und nach $7^{3 / 4}$ Stunden, werden ohne jede Störung vertragen.

Nach 30 stündigem Wachsthum im Brutofen bei $37^{\circ} \mathrm{C}$. ergaben die beiden Blutproben:

1. -57 Min. p. inj. Col. haem. $2 \mathrm{ccm}$ hellrothes Herzblut $=0 \mathrm{Col}$. 2. 7 Std. 48 $2 " n=0$,

Eine bakteriologische "Untersuchung des Bauchhöhleninhaltes am 10. IV. 09, also 4 Tage post infect. (Controllaparotomie ohne Narkose) zeigt weder auf der Agarplatte noch in der Bouillon Coliwachsthum. Die steril bleibende Agarplatte und die klar bleibende Nährbouillon werden mehrere Tage hindurch controlirt.

No. 68. Controlthier. Weibliches Kaninchen, schwarz, $2710 \mathrm{~g}$ schwer. Dem leicht mit Aether narkotisirten Thier, das nicht peritoneal vorbehandelt ist, werden $1,8 \mathrm{ccm}$ derselben 20 stündigen Bouilloncultur von Coli haemolyticum, ohne dass auch nur ein Tropfen der Culturflüssigkeit vorbeifliesst, in die median etwas unterhalb. der Mitte des Bauches eröffnete Peritonealhöhle injicirt: 10 Uhr 11 Min. a. m.

Bald nach der peritonealen Infection ist das Thier schwerkrank, sitzt traurig da, lässt den Kopf hängen, kann sich bald nicht mehr aufrecht halten, fällt um und stirbt 5 Stunden post infectionem.

1 Blutentnahme aus dem Herzen des lebenden Thieres, ca. 1 Stunde post infect. und 1 post exit. Ausserdem Abimpfungen aus Bauchhöhle, Leber, Milz und Lunge auf Agar und in Bouillon. Die Bauchorgane sind hyperämisch. Im Peritonealcavum wenige Cubikcentimeter seröshämorrhagischen Exsudates. Keine Blutung ins Mediastinum; Herzbeutel frei von Blut.

Nach 30 stündigem Wachsthum im Brutofen bei $37^{\circ} \mathrm{C}$. ergaben die angelegten Culturen:

1. 58 Min. p. inject. Col. haem. $2 \mathrm{ccm}$ hellrothes Herzblut $=$ reichliche Colicolonien, daneben diffuses rasenartiges Wachsthum mit ausgesprochen hämolytischem Hofe.

2. post exit, 1,8 ccm z. T. geronnenes Blut aus dem rechten Ventrikel $=$ sehr reichliches Coliwachsthum, theils difius rasenförmig, theils in einzelnen Colonien. 
Aus der Bauchhöhle, aus der Leber, Milz und Lunge werden sehr reichliche Mengen von Colibakterien gezüchtet.

Die Versuchsgruppe XXVII hatte also zu demselben Ergebniss geführt, wie die vorhergegangenen. Auch hier frappirte der Unterschied in dem Befinden der peritoneal vorbehandelten Versuchsthiere und des nicht vorbehandelten Controlthieres nach der abdominalen Infection mit der deletär wirkenden Coli haemolyticumCultur. Die vorbehandelten Thiere befanden sich so wohl, als ob ihnen eine indifferente Flüssigkeit in die Peritonealhöhle injicirt sei, während das nicht vorbehandelte Thier in kurzer Zeit (5 Stunden) an foudroyanter Colisepsis starb. Wiederum entsprachen sich Keimfreiheit des untersuchten Herzblutes und Fehlen von stärkeren Krankheitssymptomen bei den vorbehandelten Thieren einerseits, sehr ausgesprochene Colibakteriämie und Zeichen schwerster Allgemeininfection beim nicht vorbehandelten Controlthier andererseits. Es kann anch hier keinem $Z_{\text {weifel unterliegen, dass die peritoneale }}$ Campheröl- bezw. Prodigiosusvorbehandlung den Schutz gegen die Bakterienresorption und damit gegen die Allgemeininfection geliefert hat.

Bei beiden vorbehandelten Thieren waren durch die 4 Tage post infect. vorgenommene Controllaparotomie lebensfähige Colibakterien nicht mehr in der Bauchhöhle nachweisbar.

Die mit der Coli haemolyticum-Versuchscultur abdominal inficirten, nicht peritoneal vorbehandelten Controlthiere (No. 58, 60, 65 und 68) waren bisher alle an Colisepsis gestorben, noch schneller die beiden unmittelbar vor der abdominalen Coliinfection mit intraperitonealer Injection von $8 \mathrm{~cm} 10$ proc. Campheröls, bezw. einer Emulsion ron 3 Tropfen Crotonöl behandelten Kaninchen. Die gut vorbehandelten Thiere dagegen (6 Kaninchen) hatten kaum Krankheitserscheinungen gezeigt und die Reincultur des hochvirulenten Colivirus in der Bauchhöhle auffallend schnell unschädlich gemacht. Der Grad der Erkrankung hielt sich immer genau parallel der Höhe der peritonealen Bakterienresorption, bezw. der Zahl der aus dem Herzblut angegangenen Colicolonien.

Um zu erkennen, ob es sich bei diesen Beobachtungen um eine gesetzmässige Erscheinung handelt, nutzte ich das noch vorhandene Material an peritoneal vorbehandelten Thieren für weitere Versuche aus. 


\section{Versuchsgruppe.}

Am 7. IV. 1909 werden einem ror $4 \frac{1}{2}$ Monaten mit einem wenig virulenten Colistamm und vor 4 Wochen mit Paratyphus peritoneal vorbehandelten Kaninchen, ferner einem vor 26 Tagen mit intraperitonealer Campheröl- und gleichzeitiger Prodigiosusinjection vorbehandelten Kaninchen und einem vor 26 und 18 Tagen, also 2 mal mit intraperitonealer Prodigiosusinjection vorbehandelten Kaninchen gleiche Mengen derselben hochvirulenten Cultur von Coli haemolyticum abdominal injicirt.

No. 69. Das schwarze, weibliche Kaninchen, das als No. 5 der II. Versuchsgruppe am 23. XI. 08 eine peritoneale Infection mit $5 \mathrm{ccm}$ einer wenig virulenten 20 stündigen Bouilloncultur von Bacterium coli gut überstanden hatte, und das als No. 38, Versuch XIII am 10. IIl. 09 auf eine peritoneale Paratyphusinfection (1 Normalöse suspendirt in $5 \mathrm{ccm}$ physiologischer Kochsalzlösung) sehr wenig reagirt, sogar $1 \frac{1}{2}$ Pfund an Gewicht zugenommen hatte, erhält heute in leichter Aethernarkose eine Einspritzung von $1,9 \mathrm{ccm}$ einer 20 stündigen Bouilloncultur von Coli haemolyticum in die eröffnete Bauchhöhle unter sicherer Verhütung einer Bauchwundverunreinigung: 9 Uhr 53 Min. a. m.

Das Thier macht nach der peritonealen Coliinfection zu keiner Zeit. einen nennenswerth kranken Eindruck, springt bald munter herum und frisst schon mach wenigen Stunden.

1 Blutentnahme aus dem Herzen, 1 Stunde 14 Min. post infect: $2 \mathrm{ccm}$ hellrothes Blut, ergiebt nach 30 stündigem Wachsthum im Brutofen bei $37^{\circ} \mathrm{C}$. $=1$ Colicolonie. Eine 2. Blutentnahme von gut $2 \mathrm{ccm}$ hellrothen Blutes aus dem Herzen 25 Stumden post infect. liefert auf der Agarplatte innerhalb mehrerer Tage gar kein Coliwachsthum.

Kurz vor dieser 2. Herzpunction, also 1 Tag post infect. wird ohue Narkose eine Controllaparotomie ausgeführt und aus den unteren und oberen Bauchböhlenparthien mit watteumwickelten Entnahmestäbchen abgeimpft. Sowohl auf der Agarplatte wie in der Bouillon geht eine Reincultur von Coli haemolyticum an. Das Fehlen einer Colibakteriämie, während es gleichzeitig in der Bauchhöhle wimmelt von hochvirulenten Colibakterien, am Beginn des 2. Tages post infect. zeigt ganz klar, dass der Colinfectionsprocess vollkommen auf das Cavum peritonei beschränkt geblieben ist. Die 24 Stunden hatten für das Thier noch nicht genügt, um das schwerinfectiöse Colivirus im Peritonealraum zu vernichten und zu eliminiren. Trotzdem waren Krankheitssymptome nicht vorbanden. Nach weiteren 2 mal 24 Stunden, also 3 Tage post infect. wird die Bauchhöhle noch einmal ohne Narkose eröffnet und auf ihren Keimgehalt geprüft. Diesmal wird ein. Wachsthum auf der Agarplatte nicht mehr erzielt, während sich die Nährbouillon noch in Folge von Colientwickelung trübt.

No. 70. Dem kleinen grauweissen, weiblichen Kaninchen, jetzt $1620 \mathrm{~g}$ (früher $1460 \mathrm{~g}$ ) schwer, das als No. 41 der Versuchsgruppe XV am 12. III. 09 (vor $26 \mathrm{Tagen}$ ) eine intraperitoneale Injection von $8 \mathrm{ccm} 10$ proc. Campheröls und gleich darauf von $11 / 2 \mathrm{ccm}$ einer 14 stündigen Prodigiosusbouilloncultur erhalten hatte, werden heute in leichter Aethernarkose 1,8 ccm derselben 20 stündigen Bouilloncultur von Coli haemolyticum wie bei No. 69 ohne Verunreinigung der Bauchwunde in die eröffnete Bauchhöhle eingespritzt: 10 Uhr 18 Min. a. m. 
Auch dieses Thier leidet unter der peritonealen Infection mit dem hochvirulenten Colivirus so gut wie garnicht, befindet sich bald völlig wohl und frisst schon am Infectionstage wie ein gesundes Kaninchen.

1 Blutentnahme aus dem Herzen, 1 Stunde 15 Min. post infect : $2 \mathrm{ccm}$ hellrothes Blut ergiebt nach 30 stündigem Wachsthum im Brutofen bei $37^{\circ} \mathrm{C}$. kein Coliwachsthum anf der Blutagarplatte.

Aus der am Tage post infect. (nach gut 24 Stunden) ohne Narkose wiedereröffneten Bauchhöhle lassen sich reichlich Colibakterien, sowohl auf der Agarplatte wie in Bouillon in Reincultur züchten. $3 \mathrm{mal} 24 \mathrm{Stunden}$ post infect., also am 10. IV. 09 werden bei erneuter ohne Narkose vorgenommener Controllaparotomie auch noch entwickelungsfähige Colibakterien gefunden. Doch gingen diese Colibakterien nicht mehr auf Agar, sondern nur nnch in Bouillon an, genau so wie bei dem Parallelthier No. 69.

No. 71. Das kleine, weisse, männliche Kaninchen, jetzt $1420 \mathrm{~g}$ (früher $1400 \mathrm{~g}$ ) schwer, dem als No. 42 der Versuchsgruppe XV am 12. III. 09 (vor $26 \mathrm{Tagen}$ ) $1 \frac{1 / 2}{\mathrm{ecm}}$ einer 14 stündigen Prodigiosus bouilloneultur und als No. 48 der Versuchsgruppe XVIII am 20. III. 09 (vor 18 Tagen) noch einmal $2 \mathrm{ccm}$ einer 24 stündigen Prodigiosus. bouilloncultur intraperitoneal injicirt worden waren, erhält heute in leichter Aethernarkose 1,8 ccm derselben 20 stündigen Bruilloncultur von Coli haemolyticum wie No. 69 und No. 70, ohne dass die Bauchwunde mit der Versuchscultur in Berührung kommt, in die eröffnete Bauchhöhile eingespritzt: $10 \mathrm{Uhr} 49$ Min. a. m.

Das Thier erbolt sich nach dem Erwachen aus der Narkose sehr schnell, erscheint nicht krank, läuft munter umher und frisst schon kurze Zeit nach der Infection.

1 Blutentnahme aus dem Herzen, 1 Stunde 15 Min. post infect.: $2 \mathrm{ccm}$ hellrothes Blut, ergiebt nach 30 stündigem Wachsthum im Brutofen bei $37^{\circ} \mathrm{C}$.: 1 Colicolonie.

Eine weitere Blntentnahme aus dem Herzen (2 ccm hellrothes Blut) nach 25 Stunden, also am Tage nach der Infection liefert keine einzige Colonie auf der Blatagarplatte.

Die 24 Stunden nach der peritonealen Infection ohne Narkose ausgeführte Controll a parotomie erzielt ein reichliches Wachsthum von Colibakterien auf der Agarplatte und in Bouillon, während bei einer 2. Prüfung der Peritonealhöhle 3 mal 24 Stunden post infect. wohl auch noch Colibakterien nachzuweisen sind, aber nur noch in Bouillon, nicht auf Agar.

Die drei auf verschiedene Weise, theils mit Coli und später Paratyphus, theils mit Campheröl und Prodigiosus, theils mit 2 maliger Prodigiosusinjection und zwar verschieden lange vor der Infection peritoneal vorbehandelten Thiere verhielten sich ganz übereinstimmend nach der abdominalen Injection der hochvirulenten Colicultur wie gesunde Thiere, als sei ihnen eine ganz unschädliche Substanz in den Peritonealraum gebracht. Bei allen 3 Kaninchen hatte eine Coliresorption aus der Bauchhöhle nicht stattgefunden, der Infectionsprocess war streng auf die Bauchhöhle begrenzt, und, was besonderes Interesse bot, 
die in der Bauchhöhle befindlichen Colibakterien waren nach 1 mal 24 Stunden noch in Bouillon und auf Agar entwickelungsfähig, hatten aber nach 3 mal 24 Stunden jedesmal ihre Wachsthumsfähigkeit auf Agar eingebüsst, während in Bouillon noch eine Trübung durch Colientwickelung auftrat. Vergleicht man die Resultate dieser Controlprüfungen der inficirten Bauchhöhle mit den bisherigen Ergebnissen der Bauchhöhlenuntersuchungen nach peritonealer Infection, so kommt man zu dem Schluss, dass. virulentes Colimaterial, in die Bauchhöhle des Kaninchens gebracht, wohl in der Regel im Verlaufe des 4. Tages post infect. seine Entwickelungsfähigkeit verliert und vom 5 . Tage ab nicht mehr, weder auf Agar noch in Bouillon, zu züchten ist.

Jn der

\section{Versuchsgruppe}

wird zur Bauchhöhleninfection peritoneal vorbehandelter Thiere noch ein anderes für Kaninchen starkvirulentes Bacterium verwandt, nämlich Paratyphus B., entsprechend dem XIII. Versuch No. 38. Am 16. IV. 09 erhält ein mit intraperitonealer Campheröl- und gleichzeitiger Prodigiosusinjection vorbehandeltes Kaninchen und das damalige nur mit intraperitonealer Prodigiosusinjection vorbehandelte Controlthier gleiche Mengen derselben Paratyphuscultur abdominal injicirt. Zum Versuch dient eine 24 stündige Schrägagarcultur von Paratyphus. Von dieser Cultur werden 5 Normalösen in $10 \mathrm{ccm}$ physiologiseher Kochsalzlösung aufgeschwemmt und darin möglichst gleichmässig vertheilt.

No. 72. Dem kleinen, schwarzen, männlichen Kaninchen, dem als: No. 34, Versuchsgruppe XI am 4. III, 09 (vor $43 \mathrm{Tagen}$ ) $8 \mathrm{ccm}$ 10 proc. Campheröls and unmittelbar darauf $2 \mathrm{ecm}$ einer 24 stündigen Prodigiosusbouilloncultur abdominal injicirt worden waren, werden heute $2 \mathrm{ccm}$ (1 Oese) der frisch hergestellten Paratyphusaufschwemmung ohne Narkose in die Bauchhöhle eingespritzt: 5 Uhr 23 Min. p. m.

2 Blutentnahmen aus dem Herzen, nach 20 Minuten und nach 1 Stunde. Bald nach der Einspritzung springt das Thier munter umher und hat unter der Infection nicht zu leiden.

Nach mehrtägigem Wachsthum im Brutofen bei $37^{\circ} \mathrm{C}$. ergaben die beiden Herzblutproben:

1. 20 Min. p.inj. Paratyph. B 2,3 ccm hellrothes’ Blut = $\begin{gathered}\text { ganz spärliche } \\ \text { Paratyphuscol. }\end{gathered}$

2. $60 " \quad " \quad " 2,3, \quad " \quad$ " $=\begin{gathered}\text { wenige } \\ \text { Paratyphuscol. }\end{gathered}$

No. 73. Das kleine, schwarze, männliche Kaninchen, das als Controlthier No. 35 der Versuchsgruppe XI am 4. III. 09 (vor 48 Tagen). $2 \mathrm{ccm}$ einer 24 stündigen Prodigiosusbouilloncultur peritoneal eingespritzt erhalten hatte, bekommt heute, genau wie No. 72, obne Narkose eine abdominale Injection von $2 \mathrm{ccm}(\mathbf{1}$ Oese) der frisch hergestellten Paratyphusaufschwemmung: 5 Uhr 32 Min. p. m. 
2 Blutentuabmen aus dem Herzen, nach 21 Minuten und nach 1 Stunde. Auch an diesem Thier werden nach der abdominalen Paratyphusinfection nennenswerthe Krankheitssy mptome nicht wahrgenommen.

Nach mehrtägiger Beobachtung der im Brutofen bei $37^{\circ} \mathrm{C}$. gehaltenen Blutagarculturen zeigen sich:

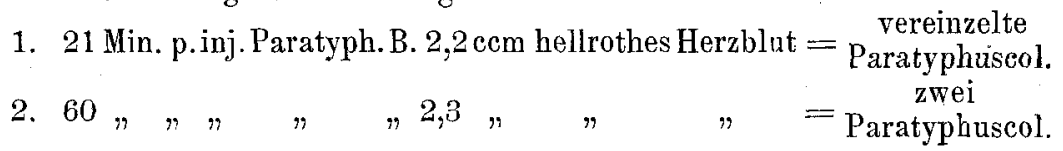

Nachdem die Paratyphusresorptionsversuche an den peritoneal vorbehandelten Thieren dieselben günstigen Resultate geliefert hatten, wie die Versuche mit dem hochvirulenten Bact. coli haemol., nahm ich als bewiesen an, dass ein vorbehandeltes Kaninchenperitoneum die verschiedensten lnfectionsprocesse in der Bauchhöhle zu localisiren im Stande ist, und dass das localisirte Infectionsmaterial mit leichter Mühe binnen wenigen Tagen durch die in Folge der Vorbehandlung angehäuften baktericiden Kräfte im Peritonealcavum unschädlich gemacht wird.

Wie lange vor der peritonealen Infection muss nun aber auf das Bauchfell eingewirkt werden, wenn die Beschränkung des Infectionsprocesses auf die Bauchböhle und damit der das Thier rettende Schutz gegen Allgemeininfection erreicht werden soll?

Dass ein unmittelbar vor der peritonealen Infection angebrachter Bauchfellreiz nicht nützt, sondern im Gegentheil die Bakterienresorption beschleunigt und der Allgemeininfection Vorschub leistet, habe ich schon als sichere Thatsache festgestellt und zu erklären versucht (cf. S. 616). Eine der peritonealen Bakterieninjection um 24 Stunden vorausgeschickte Reizbehandlung des Bauchfells hatte den gewünschten Erfolg der Bakterienresorptionshemmung erzielt (cf. No. 45, 51, 53, 55, 61). Wie steht es nun mit der dazwischen liegenden Zeit, wie namentlich mit einer Bauchfellreizung, die der abdominalen Bakterieninjection nur wenige Stunden vorausgeht?

Auf diese Frage sollte die

\section{Versuchsgruppe}

die Antwort geben: Am 13. IV. 1909 wird einem nicht vorbehandelten Kaninchen 1 Stunde nach der intraperitonealen Campheröleinspritzung die Prodigiosusversuchscultur, einem zweiten nicht vorbehandelten Kaninchen $1 \frac{1}{2}$ Stunden nach der intraperitonealen Campheröleinspritzung die Versuchscultur von Bact. coli haemo- 
ly.t, einem dritten nicht vorbehandelten Kaninchen zuerst eine Prodigiosuscultur und 2 Stunden später die Versuchscultur von Bact. coli haemolyt. und endlich einem frischen Controlthier obne vorhergehende Peritonealreizung lediglich die Versuchscultur von Bact. coli haemolyt. abdominal injicirt.

No. 74. Mänuliches Kaninchen, schwarzweiss, $1660 \mathrm{~g}$ schwer, nicht vorbehandelt. Dem leicht mit Aether narkotisirten Thier wird in der Mittellinie der mittleren Bauchgegend die Peritnnealhöble eröffnet, ein kurzer Gummischlauch in das Peritonealfenster eingebunden und $8 \mathrm{cem} 10$ proc. Campheröls durch den Schlauch in das Abdominalcavum injicirt: 9 Uhr 52 Min. a. $m$. Während 1 Stunde wird der in das Peritoneum eingebundene Schlauch verschlossen gehalten, nach Ablauf dieser Zeit wieder geöffnet, die stumpfe Canüle der mit der Prodigiosusbouilloncultur gefüllten Spritze durch den Schlauch hindurchgeführt, $2 \mathrm{ccm}$ der 16 stündigen Bakteriencultur obne Vermnreinigung der Bauchwunde in den Peritonealraum eingespritzt: $10 \mathrm{Uhr}$ 51 Min. a. m. und daun die Bauchdecken exact vernäht.

2 Blutentnahmen aus dem Herzen, gut $1 / 2$ Stunde und gut 3 Stunden nach der abdominalen Prodigiosusinjection.

Das Thier wird nach der peritonealen Campherölinjection von allgemeinen Körperkrämpfen befallen und ist in Folge der Krämpfe ermattet, erscheint aber sonst nicht krank und nimmt vorgesetzte Nahrung schon am Operationstage zu sich. Allmählich hören die Krämpfe ganz auf, das Thier wird wieder munterer und verhält sich nun wie ein gesundes Kaninchen.

Nach 30 stündigem Wachsthum im Brutofen bei $37^{\circ} \mathrm{C}$ ergaben die. beiden Herzblutproben:

1. 39 Min. p. inj. Prod. $2 \mathrm{ccm}$ hellrothes Herzblut $=$ ca. $2500 \mathrm{Col}$.

2. 3 Std. $7 " n " n=30 "$.

Bei diesem Thier batte also trotz der um 1 Stunde vorausgeschickten intraperitonealen Campherölinjection eine bedeutende Resorption von Prodigiosuskeimen stattgefunden, deren Unschädlichkeit aber eine schwerere Erkrankung nicht zu Stande kommen liess.

No. 75. Männliches Kaninchen, schwarzweiss, $1570 \mathrm{~g}$ schwer, nicht vorbehandelt. In derselben Weise wie bei No. 74 werden dem mit Aether narkotisirten Kaninchen $8 \mathrm{ccm} 10$ proc. Campheröls in die eröffnete Peritonealhöhle gebracht: 10 Uhr 9 Min. a. m., $1^{1 / 2}$ Stunden später durch den fest eingebundenen Verweilschlauch $2 \mathrm{ccm}$ einer 16 stündigen Bouilloncultur von Bact. coli haemolyt. unter sicherer Vermeidung einer Bauchwundverunreinigung abdominal injicirt: $11 \mathrm{Uhr}$ 38 Min. a. m., und dann die Bauchwunde sorgfältig vernäht.

1 Blutentnahme aus dem Herzen, gut 1 Stunde post infectionem. Das Thier erscheint gleich nach der Infection sehr hinfällig und matt, sitzt zusammengekauert mit gesträubten Haaren da und rührt dargebotenes Fressen nicht an.

Nach 30 stündigem Wachsthum im Brutofen bei $37^{\circ} \mathrm{C}$. ergiebt die Herzblutprobe:

1 Std. 8 Min. p. inj. Coli haem. gut $2 \mathrm{ccm}$ hellrothes Blut $=1018$ Colicol. (die ganze Platte ziemlich gleichmässig von den Colonien durchsetzt).

Auch in den nächsten Tagen ist das inficirte Kaninchen schwerkrank. Es verliert bedeutend an Körpergewicht und wiegt am 6. Tage 
post infectionem nur noch $1230 \mathrm{~g}$. Etwa vom 4 . Tage post infectionem ab macht das Thier trotz seines struppigen Aussehens einen etwas lebendigeren Eindruck. Es fängt wieder an zu fressen. Eine am 19. IV. 1909 (am 7. Tage post infectionem) wiederholte Herzpunction liefert aus 2,2 ccm hellrothen Blutes kein Coliwachsthum mehr.

Das aufs Schwerste erkrankte Thier hat also die gewöhnlich tödtende Infection glücklich überstanden. Nachdem es schon wieder völlig hergestellt war, erliegt es 10 Wochen post infectionem am 21. VI. 1909 einer Bissverletzung seitens eines anderen Kaninchens. In der Bauchhöhle finden sich keine Verwachsungen, das Peritoneum ist ganz glatt und spiegelnd, im Peritonealraum keine abnorm reichliche Flüssigkeit, nirgends Eiter.

No. 76. Männliches Kaninchen, weiss, $1440 \mathrm{~g}$ schwer. In leichter Aethernarkose Eröffnen der Bauchhöhle in der Medianlinie des Mittelbauches, Einbinden eines kurzen Gummischlauches in das Peritonealfenster und Einspritzen von $2 \mathrm{ccm}$ einer 16 stündigen Prodigiosusbouilloncultur in das Cavum peritonei: 10 Uhr 24 Min. a. m. Zwei Stunden nach der intraperitonealen Prodigiosuseinspritzung: $12 \mathrm{Uhr}$ 24 Min. mittags werden durch den inzwischen abgeschnürt gehaltenen und nun wieder geöffneten Verweilsschlauch $2 \mathrm{ccm}$ der auch für No. 75 verwandten 16 stündigen Bouilloncultur von $\mathrm{Bact.}$ coli haemolyt. ohne Verunreinigung der Bauchdecken in die Bauchhöhle injicirt und die Bauchwunde definitiv geschlossen.

1 Blutentnabme aus dem Herzen, gut 1/2 Stuude nach der Prodigiosusinjection, also vor der Infection mit Coli haem., führt leicht zum Ziele. Nach der Coliinfection ist das Thier in einem järmmerlichen $\mathrm{Zu}$ stande. Es sitzt ohne jedes Interesse für die Umgebung und für angebotene Lieblingsspeisen mit gesträubtem Haar zusammengekauert da. Eine 2. Herzpunction misslingt trotz gut geschliffener Troikartnadel wegen Schlafftheit des wenig gefüllten Herzens. Das ausserordentlich schwer inficirte Thier hält sich noch bis zum nächsten Tage, wird aber dann immer elender, ganz unsicher auf den Beinen, fällt auf die Seite und macht vergebliche Aufrichtungsversuche. In diesem moribunden $\mathrm{Zu}-$ stande wird es getötet, um aus dem noch pulsirenden Herzen Blut gewinnen zu können: 14. IV. $1909,3 / 48$ Uhr Abends, also gut 31 Stunden nach der Coliinfection. Sofort nach dem Tode Freilegen des Herzens und Blutentnahme aus dem noch arbeitenden rechten Ventrikel unter aseptischen Cautelen. Im Abdomen zeigt sich ausgesprochene Hyperämie, mässig reichlich trübe seröse Flüssigkeit, kein Eiter. Impfen aus der Banchböhle, aus der Leber, Milz und Lunge und Verimpfen des Materials auf Agar und in Bouillon.

Nach 30 stündigem Wachsthum im Brutofen bei $37^{\circ} \mathrm{C}$. ergaben die angelegten Culturen.

1. 38. Min. p. inj. Prod. 2 ccm hellrothes $=589$ Col.

2. unmittelbar post exitum, gut 31 Stunden p. inj. Col. haem. $2 \mathrm{ccm}$ Blut aus dem noch pulsirenden rechten Ventrikel $=$ sehr reich. liches Wachsthum von Col. haem.

Ebenso liefern die Impfproben aus der Bauchhöhle, der Leber, Milz und Lunge ein üppiges Coliwachsthum, sowohl in der Nährbouillon wie auf Agar. 
No. 77. Controlthier. Männliches Kaninchen, grau, $1520 \mathrm{~g}$ schwer. Dem leicht mit Aether narkotisirten Thier werden nach Eröffnung der Bauchhöhle in der Medianlinie des Mittelbauches ohne vorhergegangene Reizbehandlung des Bauchfells lediglich $2 \mathrm{ccm}$ der für No. 75 und 76 verwendeten 16 stündigen Bouilloncultur von Bact. coli haemolyt. unter sicherem Schutz der Bauchwunde gegen Coliverunreinigung in das Cavum peritonei eingespritzt: 11 Uhr 18 Min. a. $m$.

1 Blutentuahme aus dem Herzen, $5 / 4$ Stunden nach der Coliinfection. Das Thier ist anfangs sehr schwerkrank, sitzt theilnahmslos da und rührt dargereichtes Futter nicht an. Im Verlauf des folgenden Tages verschlimmert sich der Zustand noch mehr, so dass an einem Ueberstehen der schweren Allgemeinerkrankung gezweifelt wird. Vom 4. Tage $a b$ erholt sich das Thier etwas, wird munterer und beginnt wieder zu fressen. Es bleibt am Leben und verträgt eine am 19. IV. 09, gut 6 Tage post infect., nochmals ausgefübrte Herzpunction gut.

$\mathrm{Nach} 30$ stündjgem Wachsthum im Brutofen bei $37^{\circ} \mathrm{C}$. ergaben die Herzblutproben:

1. 1 Stunde 15 Min. p. inject. Col. haemol. $2 \mathrm{ccm}$ bellrothes Blut $=$ Sehr reichliche Colientwickelung: Die eine Hälfte der Blutagarplatte diffus überwachsen und durchwachsen, in der anderen Hälfte zahlreiche zerstreute Colonien.

2. Gut 6 Tage p. inject. Col. haemol. $2,5 \mathrm{ccm}$ hellrothes Blut $=$ Keine einzige Colicolonie.

Das Contolthier hat also die schwere Infection mit dem hochvirulenten Bact. coli haemol. trotz sehr ernster Sepsissymptome glücklich überstanden.

Die Versuchsthiere No. 74, 75 und 76 der Versuchsgruppe XXX lehrten, dass ein Intervall von 1-2 Stunden zwisehen Reizbehandlung und Infection des Peritoneums nicht genügt, um die Resorption der Bakterien aus der Bauchhöhle zu verhindern bezw. wesentlich zu hemmen, den Infectionsprocess auf die Bauchhöhle zu beschränken und der allgemeinen Sepsis vorzubeugen.

Als Ergänzung der Versuchsgruppe XXX wurden später noch einmal eine Reihe von Experimenten bei einem etwas grösseren Intervall zwischen Reizung und Infection des Peritoneums angestellt, um Klarbeit zu schaffen über das Minimum an Zeit, das für eine Erfolg versprechende künstlich erzeugte Peritonitis erforderlich ist. Diese Experimente gliedere ich, weil hierher gehörig, als nächste Versuchsgruppe an.

\section{Versuchsgruppe.}

Am 16. VI. 09 abdominale Infection von 4 bisher nicht zu Ver. suchszwecken benutzten Kaninchen mit der Coli haemolyticum-Cultur. 3 von diesen Coli - inficirten Thieren hatten 4-6 Stunden vorber eine intraperitoneale Campherölinjection erhalten, während das 4. als Controlthier diente. 
No. 78. Männliches Kaninchen, schwarzgrau, $1960 \mathrm{~g}$ schwer. 9 Uhr a. $\mathrm{m}$. werden dem mit Aether narkotisirten Thier $8 \mathrm{ccm} 10$ proc. Campheröls in die oben eröffnete Baucbhöhle gebracht und die Bauchwunde wieder geschlossen.

Genau nach 4 Stunden Relaparotomie des wieder narkotisirten Thieres in der Medianlinie des Mittelbauches und Einspritzen von $2 \mathrm{ccm}$ einer 24 stündigen Bouilloncultur von Bact. coli baemol. in das von neuem eröffnete Cavum peritonei unter sicherem Schutz der Bauchwunde gegen Infection: 1 Uhr 7 Minuten Mittags.

1 Blutentnahme aus dem Herzen, ca. $3 / 4$ Stunden post infect. Das Thier ist schwerkrank, sitzt ruhig da, frisst nicht und wird immer elender. Vom 3. Tage ab zeigt sich eine deutliche Besserung, die allmählich in eine völlige Gesundung übergeht. Nochmalige Herzpunction im Stadinm der Besserung (Beginn des 3. Tages post infect.).

Nach 24 stündigem Wachsthum im Brutofen bei $37^{\circ} \mathrm{C}$. ergaben die Herzblutproben:

1. 40 Minuten p. inj. Col. haem. $2 \mathrm{ccm}$ hellrothes Blut $=$ Sehr reichliches Coliwachsthum auf und in der Blutagarplatte mit typischer Hämolyse.

2. Am 3. Tage p. inject. Col. haem. $1 \mathrm{ccm}$ hellrothes Blut $=$ Wenig Colicolonien.

Trotz der peritonealen Campherölbebandlung ist das 4 Stunden später mit Bact. coli haemolyt. inficirte Thier an allgemeiner Sepsis schwer erkrankt, hat aber die septische Erkrankung überwunden.

No. 79. Männliches Kaninchen, hellgrau, $1620 \mathrm{~g}$ schwer. $9^{1 / 4}$ Uhr a. m. werden dem mit Aether narkotisirten Thier $8 \mathrm{ccm} 10$ proc. Campheröls in die oben eröffnete Bauchhöhle gebracht, die Bauchwunde dicht vernäht.

$4^{1 / 4}$ Stunden später Relaparotomie des nochmals leicht ätherisirten Thieres in der Medianlinie des Mittelbauches und langsames Einspritzen von $2 \mathrm{ccm}$ derselhen 24 stündigen Bouilloncultur von Bact. coli haemol., wie bei No. 78 unter sorgfältigem Schutz der Bauchwunde gegen Verunreinigung mit der Versuchscultur: 1 Uhr 33 Minuten Mittags.

1 Blutentnahme aus dem Herzen, $1 \frac{1}{2}$ Stunden post infect., gelingt trotz einer unmittelbar nach der Coliinfection einsetzenden sehr schweren Erkrankung. Das Thier taumelt hin und her, fällt schliesslich um, kann sich nicht mehr aufrichten und stirbt $3 \mathrm{Uhr} 30 \mathrm{Min}$. p. m., also 2 Stunden post infect.

Sogleich nach dem Tode wird aus dem rechten Ventrikel des freigelegten noch pulsirenden Herzens eine nochmalige Blutprobe entnommen. Abimpfen aus der Bauchhöhle, aus den Bauchhöhlenorganen und aus der Lunge und Uebertragen des Impfmaterials auf Agar und in Bouillon. Im Abdominalcavum ist das Oel ganz gleichmässig in dünner Schicht vertheilt. Keine makroskopischen Organveränderungen. Kein Bluterguss im Herzbeutel.

Nach 24 stïndigem Wachsthum im Brutofen bei $37^{\circ} \mathrm{C}$. ergaben die Culturen:

1. 1 Stunde 31 Min. p. inj. Col. haem. $2 \mathrm{ccm}$ hellrothes Herzblut = Die ganze Blutagarplatte überwachsen und durchwachsen von Colicolonien. 
2. 1 Stunde 57 Min. p. inj. Col. haem. $\{2 \mathrm{ccm}$ aus dem noch arbeitenunmittelbar post exitum $\}_{\text {den }}$ rechten Ventrikel = idem.

Aus dem abgeimpften Material der Bauchhöhle, der Brust- und Bauchorgane erfolgt ein sehr reichliches Wachsthum von Coli haemolyt., sowohl in der Nährbouillon wie auf der Aparplatte.

Trotz der um $4{ }^{1}{ }_{4}$ Stunden der abdominalen Coliinfection vorausgeschickten Campherölbehandlung des Peritoneums ist das Thier sehr schnell an Colisepsis zu Grunde gegangen.

No. 80. Männliches Kaninchen, schwarzweiss, $1240 \mathrm{~g}$ schwer. $9^{3} / 4$ Uhr a. m. werden dem leicht mit Aether narkotisirten Thier $8 \mathrm{ccm}$ 10 proc. Campheröls in die oben eröffnete Bauchböhle gebracht, die Bauchwunde sorgfältig vernäht.

6 Stunden nach der peritonealen Oelung Relaparotomie des wieder narkotisirten Thieres in der Medianlinie des Mittelbauches und Einspritzen von $2 \mathrm{ccm}$ der auch bei No. 78 und No. 79 verwendeten 24 stündigen Bouilloncultur von Bact. col. haemol. unter sicherem Schutz der Bauchwunde gegen Coliverunreinigung: 3 Uhr 40 Min. p. m.

1 Blutentnahme aus dem Herzen, ca. I Stunde post infect. Das Thier ist schwerkrank, wird immer elender und hinfälliger und stirbt gegen 8 Uhr Abends, also 4 Stunden post infect. Bald nach dem Tode werden Controlprüfungen des Herzblutes. der Lunge, der Bauchhöhle und der Bauchorgane vorgenommen. Gleichmässige Vertheilung des Campheröls in dem Peritonealraum. Makroskopisch keine erkennbaren Organveränderungen.

Nach ca. 17 stündigem Wachsthum im Brutofen bei $37^{\circ} \mathrm{C}$. ergaben die angelegten Culturen:

1. 55 Minuten p. inj. Col. haem. $2 \mathrm{ccm}$ dunkles Herzblut $=$ Sehr reichliche Colonien von hämolytischen Colibakterien.

Post exitum: Aus dem Herzblut, aus dem verimpften Material der Lunge, Bauchhöhle und der Bauchorgane ist ein üppiges Wachsthum von Colibakterien in der Nährbouillon und auf Agar erfolgt.

Das Thier ist also schnell der Colisepsis erlegen, obwohl die Campherölbehandlung des Peritoneums schon 6 Stunden vor der abdominalen Coliinfection eingesetzt hat.

No. 81. Controlthier. Männliches Kaninchen, hellgrau, $1620 \mathrm{~g}$ schwer. In leichter Aethernarkose Laparotomie in der Medianlinie der Oberbauchgegend und Injection von $2 \mathrm{ccm}$ der für diese Versuchsreihe angelegten 24 stündigen Bouilloncultur vou Bact. coli haemolyt. ohne vorhergegangene Behandlung des Bauchfells unter sorgfaltigstem Vermeiden einer Bauchwundverunreinigung: $10 \mathrm{Uhr} 5 \mathrm{Min}$. a. $\mathrm{m}$.

Während $3 / 4$ Stunden post infect. 1 Blutentnahme aus dem Herzen ganz glatt gelingt, bleiben später 2 weitere Herzpunctionsversuche mit frisch geschliffener Troikartnadel 12 Uhr Mittags und 3 Uhr Nachmittags erfolglos.

Das Thier leidet sehr unter der schweren Infection, wird immer elender, unsicher auf den Beinen und stirbt 1/26 Uhr p. m., 71/2 Stunden post infect. Bald nach dem Tode wird unter aseptischen Cautelen Material aus dem Herzen, Lunge, Bauchhöhle und Bauchorganen zur bakteriologischen Prüfung entnommen und auf Agar und in Bouillon 
verimpft. Makroskopisch keine Organveränderungen. Im vorderen Mediastinum minimalste Blutung, mit der der Tod des Thieres sicher nicht im Zusammenhang steht, zumal seit der letzten erfolglosen Herzpunction schon $2^{1 / 2}$ Stunden vergangen sind. Nach ca. 24 stündigem Wachsthum im Brutofen bei $37^{\circ} \mathrm{C}$. ergaben die angelegten Culturen: 1. 47 Minuten p. inj. Col. haem. $2 \mathrm{ccm}$ hellrothes Herzblut $=$ Sehr reichliche Colonien von hämolytischen Colibakterien.

2. Unmittelbar post exit.: Aus dem Herzblut, aus der Lunge, aus der Bauchhöhle and aus den Bauchorganen sind reichliche Mengen von Colibakterien gewachsen.

Zweifellos ist das Controlthier an der septischen Allgemeininfection zu Grunde gegangen.

Die damit abgeschlossenen Ergänzungsversuche zur Versuchsgruppe XXX berechtigten zu dem Schluss, dass eine Peritonealreizung, die der abdominalen Infection bis zu 6 Stunden vorausgeht, nicht hinreicht zur Aufhebung bezw. Hemmung der Bakterienresorption aus der Bauchhöhle und zur Verhütung der Allgemeininfection. Die kürzeste im Verlaufe der Untersuchungen gefandene Zeitspanne, in der ein wirksamer Peritonealschutz erzielt werden kann, beträgt etwa 24 Stunden.

In einer letzten Versuchsgruppe sollte noch geprüft werden, inwieweit die Laparotomie an sich als Peritonealreiz bei einer wirksamen Vorbehandlung des Peritoneums in Rechnung gezogen werden muss. Um die Reizwirkung der Laparotomie als solcher in ihrem etwaigen Einfluss auf die Bakterienresorptionshemmung richtig einschätzen zu können, wurde in

\section{Versuchsgruppe XXXII}

einem mit Campheröl peritoneal vorbehandelten und nach 24 Stunden mit Bact. coli haemolyt. abdominal inficirten Kaninchen ein lediglich laparotomirtes und nach 24 Stunden mit der gleichen Dosis derselben Colicultur abdominal inficirtes Thier gegenüber gestellt, und ebenso 2 Thiere, bei denen peritoneale Vorbehandlung mit Campheröl bezw. blosse Laparotomie der abdominalen Coliinfection um 7 Tage vorausgeschickt waren.

No. 82. Weibliches Kaninchen, weiss, $1850 \mathrm{~g}$ schwer. Am 19. IV. 1909 in leichter Aethernarkose Eröffnung der Bauchhöhle in der Medianlinie der Mittelbauchgegend, Einbringen von $8 \mathrm{ccm} 10$ proc. Campheröls in den Peritonealraum, Bauchwunde geschlossen.

A m 20. IV. 1909, 24 Stunden nach der intraperitonealen Campheröleinspritzung, Relaparotomie des wieder narkotisirten Thieres und Injection von $2 \mathrm{ccm}$ einer 16 stündigen Bouilloncultur von Bact. coli 
haemolyt. Dabei fliesst ein nicht unbeträchtlicher Theil der Culturflüssigkeit in die Bauchwunde, weil der Inbalt der Spritze wegen ungenügender Durchgängigkeit der Canüle zwischen beiden hindurchgepresst wird: 9 Uhr 29 Min. a. m.

1 Blutentnahme aus dem Herzen des schwer erkrankten Thieres selingt nur mülisam, ca. 3/4 Stunden post infect. Das Kaninchen erholt sich nicht, sitzt auch während des folgenden Tages theilnahmslos da. Unter zunehmender Verschlechterung des Zustandes stirbt das Thier in der Nacht vom 21.-22. IV, also ca. 40 Stunden post infect.

Nach 24 stündigem Wachsthum im Brutofen bei $37^{\circ} \mathrm{C}$. ergab die Hersblutcultur:

43 Min. p. inj. Coli haem. 1,5 ccm dunkles Blut $=\left\{\begin{array}{c}\text { sehr reichliche } \\ \text { Colicolonien. }\end{array}\right.$

Auch aus dem Herzblut des gestorbenen Thieres, sowie aus der Lunge, Bauchhöhle, Leber und Milz und aus der Bauchwunde werden grosse Mengen haemolytischer Colibakterien gezüchtet.

Dass dieses 24 Stunden vor der peritonealen Coliinfection geölte Thier trotz der Vorbereitung des Bauchfells an Colisepsis gestorben ist, findet seine Erklärung in der Verunreinigung der Bauchwunde mit der Versuchscultur. Es ist dies das einzige Kaninchen, bei dem nach einer derartigen Vorbehandlung des Peritoneums eine so reichliche Bakterienmenge in die Blutbahn gelangt ist und eine allgemeine Sepsis verursacht hat, und zugleich das einzige Thier, bei dem in Folge Nichtfunctionirens der Spritze eine Bauchwundverunreinigung mit der Versuchscultur sich ereignet hat.

No. 83. Männliches Kaninchen, gelb, $1940 \mathrm{~g}$ scbwer. Am 19. IV. 1909 in leichter Aethernarkose Eröffnung der Bauchhöhle. Auch wird der sonst zur Einbringung des Campheröls benutzte Gummischlauch in den Peritonealraum eingeführt, aber kein Oel injicirt, sondern nach der blossen Laparotomie und Wiederentfernung des Sçhlauches die Bauchwunde geschlossen.

Am 20. IV. 1909, 24 Stunden nach der Laparotomie, Wiedereröffnung der Bauchhöhle in nochmaliger Aethernarkose und intraperitoneale Injection von $2 \mathrm{ccm}$ derselben 16 stündigen Bouilloncultur von Bact. coli haemolyt. wie bei No. 82, ohne Verunreinigung der Bauchwunde: 9 Uhr 53 Min. a. m.

1 Herzpunction, 3/4 Stunden post infect., gelingt an dem schwerkranken Thier nur mit Mühe, doch ohne bemerkbare Schädigung desselben. Das schwer inficirte Kaninchen wird nach einer weiteren Stunde deutlich elender und stirbt $2^{3 / 4}$ Stunden post infect. Sofort nach dem Tode werden unter aseptischen Cautelen aus dem freigelegten Herzen 2 Blutproben zur bakteriologischen Untersuchung entnommen, und ausserdem aus der Lunge, Bauchhöhle und Leber gewonnenes Impfmaterial auf Agar und in Bouillon übertragen. Keine makroskopischen Organveränderungen. Herzbeutel und vorderes Mediastinum frei von Bluterguss.

Nach 24 stündigem Wachsthum im Brutofen bei $37^{\circ} \mathrm{C}$. ergaben die angelegten Culturen: 
1. 48 Min. p. inj. Coli haem. $2,4 \mathrm{ccm}$ hellrothes Herzblut $=$ sehr reichliche Colonien hämolytischer Colibakterien.

2. Unmittelbar post exit., $2^{3 / 4}$ Std. post infect.: Aus den beiden Herzblutproben (je $2 \mathrm{ccm}$ ) sind je ca. 1500 Colicolonien angegangen. Aus der Lunge, aus der Bauchböhle und aus der Leber werden grosse Mengen hämolytischer Colibakterien in Bouillon und auf Agar gezüchtet.

No. 84. Weibliches Kaninchen, grau, $1610 \mathrm{~g}$ schwer. A m 19. IV. 1909 wird bei dem mit Aether narkotisirten Thier das Abdomen geöfnet, mittelst Schlauch und Trichter $4 \mathrm{ccm} 10 \mathrm{proc}$. Campheröls in den Peritonealraum gebracht und die Bauchwunde vernäht.

Am 26. IV. 1909, also 7 Tage später, Relaparotomie wieder in Aethernarkose und Injection von $2 \mathrm{ccm}$ einer 22 stündigen Bouilloncultur von Bact. coli haemolyt: in die von Neuem geöffnete Perito. nealhöhle unter sicherem Schutz der Bauchwunde gegen Coliinfection: $11 \mathrm{Uhr} 25 \mathrm{Min}$. a. $\mathrm{m}$.

Das Thier macht keinen kranken Eindruck. 1 Blutentnahme aus dem Herzen, ea. 1 Stunde post infect., gelingt leicht. Dargebotene Nahrung wird genommen. Nach wenigen Stunden benimmt sich das Thier wie ein gesundes Kaninchen. Dies völlige Wohlbefinden hält auch weiterhin an.

Nach 24 stündigem Wachsthum im Brutofen bei $37^{\circ} \mathrm{C}$. ergiebt die Blutprobe:

53 Min. post inj. Coli haem. $2 \mathrm{ccm}$ hellrotbes Herzblut $=$ keine einzige Colicolonie.

Bei diesem längere Zeit (7 Tage) mit der Hälfte der gewöhnlich verwendeten Campheröldosis (statt $8 \mathrm{~cm}$ nur $4 \mathrm{ccm}$ ) peritoneal vorbehandelten Kaninchen war wiederum ein eclatanter Erfolg der prophylaktischen Bauchfellreizung zu verzeichnen, indem das Thier auf die abdominale Infection mit dem hochvirulenten Bakterienmaterial nicht viel anders reagirte, als auf die lnjection einer indifferenten Flüssigkeit. Das Thier kam nicht nur mit dem Leben davon, sondern liess kaum ein Kranksein erkennen.

No. 85. Männliches Kaninchen, weissgelb, $1720 \mathrm{~g}$ schwer. A m 19. IV. 1909 in leichter Aethernarkose Laparotomie und vorübergehende Einführung des sonst zur Campheröleinbringung benutzten. Gummischláuches in die eröffnete Peritonealhöhle, aber keine Oelinjection. Bis auf die Oelbehandlung des Bauchfells wurden demnach alle sonstigen Manipulationen vorgenommen, und sodann die Bauchwunde vernäht.

Am 26. IV. 1909, als 7 Tage später, Relaparotomie, wieder in Aethernarkose und Injection von $2 \mathrm{ccm}$ derselben wie für No. 84 verwendeten 22 stündigen Bonilloncultur von Bact. coli haemolyt. unter sorgsamem Vermeiden einer Bauchwundinfection: $11 \mathrm{Uhr}$ 42 Vin. a. m.

1 Blutentnahme aus dem Herzen des schwerkranken Thieres gelingt, ca. 1 Stunde post infect. Allmählich wird das Thier immer kränker, sitzt traurig und zusammengekauert mit gesträubten Haaren da, fällt 
schliesslich um, kamn sich nicht mehr aufrichten und stirbt $3 \mathrm{Uhr}$ 35 Min. p. m., ca. 4 Stunden post infect.

Unmittelbar nach dem Tode wird aus dem Herzen unter aseptischen Cautelen entnommenes Blut, ferner Impfmaterial aus der Lunge, Bauchhöhle, Leber und Milz auf Agar und in Bouillon verimpft. Makroskopisch keine Organveränderungen. Kein Bluterguss im Herzbeutel oder vorderen Mediastinum.

Nach 24 stündigem Wachsthum im Brutofen bei $37^{\circ} \mathrm{C}$. ergaben die angelegten Culturen:

1. 55 Min. p. inj. Col. haem. 2 cem hellrothes Herzblut $=$ unzählige Colonien von Coli haemolyt.

2. Unmittelbar post exit., ca. 4 Std. post infect. = Aus dem Herzbeutel sowohl, wie aus der Lunge, aus der Bauchhöhle und den Bauchhöhlenorganen sind sehr grosse Mengen von hämolytischen Colibakterien gewachsen.

Aus dieser letzten Versuchsgruppe ist besonders deutlich zu ersehen, dass die mit einer Laparotomie an sich verbundene Bauchfellreizung, einschliesslich vorübergehender mechanischer Manipulationen im Bauchfellraum, keineswegs im Stande ist, die peritoneale Bakterienresorption hemmend zu beeinflussen, geschweige denn ihr Halt zu bieten und der Bakteriämie vorzubeugen. Beide lediglich laparotomirten Thiere, das 24 Stunden und das 7 Tage vor der abdominalen Coliinfertion mit blossem Bauchschnitt behandelte Thier (No. 83 u. 85), starben binnen wenigen Stunden an Colisepsis, während das 7 Tage vor der abdominalen Coliinfection mit $4 \mathrm{ccm} 10$ proc. Campheröls peritoneal vorbehandelte Thier No. 84 einen glänzenden Beweis für die Wirksamkeit der Bauchfellvorbereitung lieferte. Dass man mit der prophylaktischen Behandlung des Peritoneums die Bakterienresorption aus einer Weichtheilwunde nicht verhüten kann, ist von vornherein selbstverständlich. Der versehentlichen Bauchwundverunreinigung mit hämolytischen Colibakterien fiel das 24 Stunden vor der abdominalen Coliinfection peritoneal geölte Thier No. 82 zum Opfer.

Ueberblicken wir noch einmal die Reihe der mit dem hochvirulenten Bacterium coli haemolyticum peritoneal inficirten Kaninchen, so müssen wir, um ein klares Bild zu bekommen, die nicht peritoneal vorbehandelten Kaninchen zusammen mit den nicht genügend lange vor der Coliinfection $(11 / 2-6$ Stunden) peritoneal vorbereiteten Thieren einerseits den längere Zeit vor der Coliinfection peritoneal vorbehandelten Kaninchen andererseits gegenüberstellen. 
Die erste Gruppe umfasst 6 Controlthiere (No. 58, 60, 65, 68, 77 u. 81), 2 nur laparotomirte, aber sonst nicht peritoneal behandeite Kaninchen (No. 83 u. 85), 2 Kaninchen mit der Coliinfection unmittelbar vorausgesehickter Campheröl- bezw. Crotonölbehandlung des. Peritoneums (№. 57 u. 59), 4 Kaninchen, denen $1 \frac{1}{2}, 4,4^{1 / 4}$ und 6 Stunden vor der Coliinfection die erprobte Campheröldosis in den Peritonealraum injicirt worden war (No. 75, 78,79 u. 80 ) und 1 Kaninchen, das 2 Stunden vor der Coliinfection eine intraperitoneale Prodigiosusinjection erhalten hatte (No. 76), im Ganzen also 15 Kaninchen. Bei allen diesen Thieren liess sich durch bakteriologische Prüfung des Herzblutes regelmässig eine beträchtliche Bakterienresorption aus der Bauchhöhle, bezw. Bakteriämie mit starker Vermehrung der resorbirten Bakterien nachweisen.

12 dieser 15 Thiere starben an Colisepsis (No. 57 nach $13 / 4$ Stunden moribund getödtet, 2 mal Tod nach 2 Stunden: No. 59 u. 79,1 mal nach $2^{3} / 4$ Stunden: No. 83,2 mal nach 4 Stunden: No. 80 u. $85,1 \mathrm{mal}$ nach 5 Stunden: No. $68,1 \mathrm{mal}$ nach $51 / 2$ Stunden: No. 60, $1 \mathrm{mal}$ nach $7 \frac{1}{2}$ Stunden: No. $81,1 \mathrm{mal}$ am 2. Tage moribund getödtet: No. 76, 1 mal Tod nach 5 Tagen: No. 58 und 1 mal nach 7 Tagen: No. 65). Am frühesten wurden die kurz vor der abdominalen Coliinfection geölten Kaninchen und die lediglich laparotomirten Thiere vom Tode betroffen, während die Controlthiere sich relativ länger hielten. Nur 3 dieser 15 Kaninchen blieben am Leben, nach Ueberwindung einer so schweren peritonealen Colisepsis, dass man jeden Augenblick den Tod des Thieres erwarten konnte. Es sind dies Controlthier No. 77 , bei dem nach anfänglich sehr ausgesprochener Bakteriämie am 7. Tage post infect. keine Colikeime mehr aus dem Herzblut gezüchtet werden konnten, ferner das $1 \frac{1}{2}$. Stunden vor der peritonealen Coliinfection geölte Kaninchen No. 75, das ebenfalls nach anfänglich sehr starker Bakteriämie am 7. Tage post infeet. ein colifreies Herzblut zeigte, und das 4 Stunden vor der peritonealen Coliinfection geölte Kaninchen No. 78, bei dem trotz zuerst constatirter Ueberschwemmung des Kreislaufes mit hämolytischen Colibakterien schon am 3. Tage post infect. nur noch wenige entwicklungsfähige Colikeime aus der Herzblutprobe angegangen waren.

An den nicht oder nicht genügend peritoneal vorbereiteten Thieren war die Durchseuchung des Körpers mit hämolytischen 
Colibakterien auch nach dem Tode stets nachweisbar, indem sich nicht nur aus der Bauchhöhle, sondern auch aus dem Herzblut und aus allen Organen, speciell aus der Lunge, grosse Mengen von stark virulenten Colibakterien züchten liessen.

Aus diesen Folgen der peritonealen Infection mit dem Bact. coli haemolyt. ist ersichtlich, ein wie schweres Gift der zu den Experimenten gewählte Colistamm für die Versuchsthiere darstellte. Je klarer wir uns diese enorme Giftigkeit des für die Resorptionsversuche benutzten Bact. coli haemolyt. vor Augen halten, um so evidenter tritt der Erfolg der prophylaktischen Behandlung des Peritoneums zu Tage.

11 peritoneal vorbehandelten Kaninchen wurde die gleiche Menge derselben Cultur des hochvirulenten Bact. coli haemolyt. unter völlig gleichen Versuchsbedingungen wie den nicht, bezw. ungenügend peritoneal vorbereiteten Thieren in die Bauchhöhle injicirt. Von diesen 11 Thieren starb nur 1 an Colisepsis (No. 82), ca. 40 Stunden post infect. Und dieser Tod an Colisepsis trotz peritonealer Vorbehandlung $(8 \mathrm{ccm} 10$ pros. Campheröls 24 Stunden ante infect.) erklärt sich leicht daraus, dass bei mangelhafter Durehgängigkieit der verwendeten Spritzencanüle die Colibakterien der Versuchscultur nicht nur in die vorbehandelte Peritonealhöhle, sondern in Folge Vorbeifliessens der Culturflüssigkeit auch in die Bauchwunde gelangt waren. Die Bauchwundresorption führte offenbar bei diesem Thiere zu der starken tödtlichen Bakteriämie. Aus der 43 Minuten post infect. durch Herzpunction gewonnenen Blutprobe gingen sehr reichliche Colonien hämolytischer Colibakterien an und, was besonderer Erwähnung bedarf, auch aus der Bauchwunde konnten grosse Mengen hämolytischer Colibakterien gezüchtet werden.

Am besten lässt sich mit diesem Tbier das Kaninchen No. 61 vergleichen, weil es genau ebenso, nämlich mit $8 \mathrm{ccm} 10$ proc. Campheröls 24 Stunden ante infect. peritoneal vorbehandelt war. Bei diesem Thier hatte aber keine Bauchwundverunreinigung mit den Colibakterien stattgefunden. Die 42 Minuten post infect. dem Herzen entnommene Blutprobe $(2 \mathrm{ccm})$ lieferte nur 12 Colicolonien, und als das Thier leider im Anschluss an wiéderholte vergebliche Herzpunctionsversuche $21 / 4$ Stunden post infect. an einem grossen pericardialen und mediastinalen Bluterguss starb, entwickelten sich aus dem nunmehr culturell geprüften Herzblut (2 ccm) nur noch 2 Colicolonien, während Impfmaterial aus der Lunge gar kein Coli- 
wachsthum ergab, weder auf Agar noch in Nährbouillon. Ganz entsprechend der minimalen Resorptionsziffer von Colibakterien und . im Gegenșatz zu den an Colisepsis erkrankten Thieren batte dieses Kaninchen bis zu dem Moment der Herzläsion keine nennenwerthen Krankheitserseheinungen gezejgt.

Die wenigen aus dem Blute gezüchteten Keime, das Sterilbleiben der Organcultur post exitum und das Verhalten des Thieres bis zu der verhängnissvollen, das grosse intra- und extrapericardiale Hämatom veranlassenden Herzpunction bewiesen, dass der Tod dieses Thieres in gar keinem Zusammenhang mit der peritonealen Coliinfection steht, dass er vielmehr seine alleinige Erklärung in der Herzverletzung und ihren Folgen findet.

Wie das an dem pericardialen und mediastinalen Bluterguss gestorbene Kaninohen №. 61, liessen auch die übrigen 9 peritoneal vorbehandelten Kaninchen nach der abdominalen Coliinfection keine oder nur auffallend geringe. Krankheitssymptome erkennen. Alle erholten sich sehr schnell nach dem Erwachen aus der leichten Aethernarkose und verhielten sich schon am Infectionstage in ibrem Interesse für die Umgebung und in ihrer Fresslust wie gesunde Thiere. Ein Uneingeweihter hätte nicht ahnen können, dass diesen Thieren ein so reichliches hochvirulentes Bakterienmaterial in die Bauchhöhle gebracht war. Die Culturen der gewöhnlich $3 / 4$ Stunden bis $5 / 4$ Stunden post infect. entnommenen Herzblutproben blieben in den allermeisten Fällen ganz steril. Nur 2 mal ging je 1 Colonie von Coli haemolyt. (No. 69 u. 71) und 1 mal aus einer 10 Minuten post infect. dem Herzen entnommenen Blutprobe 10 Colonien von Coli haemolyt. (No. 62) in der Agarblutcultur an.

Die Vorbehandlung des Peritoneums gesehah bei diesen 9 Kaninchen:

1 mal mit $4 \mathrm{ccm} 10$ proc. Campheröls $=7$ Tage a. inf. (No. 84). $1 "$ 1" 2 " einer Prodigiosusbouilloncultur $=14 " n$ (No.67). $1 " 8$ " 10 proc. Campheröls und gleichzeitig $11 / 2$ ecm einer Prodigiosusbouilloncultur $=26$ Tage a. inf. (No. 70).

$1,8,10$ proc. Campheröls und 1 Tag später mit $2 \mathrm{ccm}$ einer Prodigiosusbouilloncultur $=15$ bezw. 14 Tage a. inf. (No. 66).

1 " 8 " 10 proc. Campheröls und 1 Tag resp. 6 Tage später mit je $2 \mathrm{ccm}$ Prodigiosuscultur $=18$ bezw. $17 \mathrm{u}$. 12 Tage a. inf. (No. 63).

2 " 2 maliger Injection einer Prodigiosusbouilloncultur

$$
=\left\{\begin{array}{ccccc}
22 & \text { bezw. } 13 & \text { Tage a. inf. (No. 62) } \\
26 & n & 18 & \text { "N } & \text { (No. 71) } \\
41
\end{array}\right.
$$


1 mal mit 3 maliger Injection einer Prodigiosusbouilloncultur $=26$ bezw. 17 ind 12 Tage a. inf. (No. 64).

$1 "$ " einem wenig virulenten Colistamm und später mit einer Cnltur von Paratyphus $B .=4^{1} / 2$ Monate bezw. 4 Wochen a. inf. (No. 69).

Obwohl diese abdominal mit Bact. coli haemolyt. inficirten Thiere einen nach jeder Richtung hin gesunden Eindruck machten, beherbergten sie doch in ihrer Bauchhöhle das in Folge der peritonealen Vorbehandlung auf diese beschränkte und an einer allgemeinen Verbreitung im Körper gehinderte schwer infectiöse Bakterienmaterial. Dies in die Peritonealhöhle gebannte Bakterienvirus wurde von allen Thieren binnen wenigen Tagen unschädlich gemacht. Der bei den vorbehandelten Thieren in der Bauchböhle sich abspielende Vernichtungskampf des Kaninchenkörpers mit den hochvirulenten Colibakterien wurde bakteriologisch genau verfolgt.

11 mal wurde mittelst Relaparotomie eine Revision der Bauchhöhle auf ihren Keimgehalt angestellt, bei 5 Thieren je $1 \mathrm{mal}$ :

Controllaparotomie 1 mal 8 Tage p. inf. (No. 62) bei 3 Thieren je 2 mal:

$\begin{array}{lllllll}2 & 7 & 7 & & & & \\ 2 & " & 4 & & & & \end{array}$

Controllaparotomie nach 24 Stunden und nach Ablauf von 3 Tagen (No. 69, No. 70 und No. 71).

Diese bakteriologischen Untersuchungen der inficirten Bauchhöhle peritoneal vorbehandelter Kaninchen führten zu ganz übereinstimmenden Resultaten. Nach 24 Stunden wurden alle 3 Male noch reichliche in Bouillon und auf Agar wachsende hämolytische Colibakterien gefunden. Bei denselben 3 Thieren war nach Ablauf von 3 mal 24 Stunden aus dem Bauchhöhleninhalt zwar auch noch das Coli haemolyticum zu züchten, aber nur in Bouillon, nicht mehr auf Agar. Die anderen 5 Thiere zeigten 2 mal 4 Tage, 2 mal 7 Tage und 1 mal 8 Tage nach Einsetzen der peritonealen Infection überhaupt kein Coliwachsthum aus den Impfproben des Peritonealcavum mehr, weder auf Agar noch in Bouillon.

Hieraus geht unzweifelhaft hervor, dass eine geeignete Vorbehandlung des Peritoneums nicht nur die Bakterienresorption aus der Bauchhöhle aufhebt und die das Leben schwer bedrohende Bakteriämie verhütet, sondern auch in der Bauchhöhle eine Anhäufung und Concentrirung von baktericiden Kräften bewirkt, denen es leicht wird, den Kampf mit einer ungeheuren Menge hochviru- 
lenten Bakterienmaterials in kurzer Zeit erfolgreich durchzuführen. Aus den Resultaten der Controluntersuchungen des inficirten Cavam peritonei ist wohl zu folgern, dass im Allgemeinen bei gut peritoneal vorbehandelten Kaninchen die Vernichtung von intraperitoneal eingebrachtem hochvirulentem Bakterienvirus ca. 4 Tage in Anspruch nimmt, und dass in der Regel vom 5. Tage post infect. ab keine entwickelungsfähigen Keime mehr in der Bauchhöhle gefunden werden. Bei den nicht oder ungenügend peritoneal vorbereiteten an Colisepsis erkrankten Kaninchen erfolgt diese schnelle Vernichtung der Bauchhöhlenkeime natürlich nicht, wenn überhaupt die Thiere so lange am Leben bleiben und nicht schon innerhalb viel kürzerer Zeit der Seuche erliegen (No. 58 ง. 65).

Der experimentell am Kaninchen mit so regelmässigem und sicherem Erfolge erzeugte Schutz gegen peritoneale Infection mit hochvirulenten Colibakterien erwies sich auch gegenüber anderen bakteriellen Infectionen als durchaus wirksam, wie die Resorptionsversuche mit einer für Kaninchen als virulent erprobten Cultur von Paratyphus B. ergaben. Bei allen 3 in Betracht kommenden peritoneal vorbehandelten Thieren (No. $383^{1} / 2$ Monate ante infect. mit einer wenig virulenten Colicultur, No. 7243 Tage ante infect. mit $8 \mathrm{ccm}$ 10 proc. Campheröls und gleichzeitig mit $2 \mathrm{ccm}$ einer Prodigiosusbouilloncultur und No. 7343 Tage ante infect. mit $2 \mathrm{ccm}$ Prodigiosusbouilloncultur) wurden nur wenige wachsthumskräftige Paratyphuskeime, und nur innerhalb der 1 . Stunde post infect. in den Herzblutproben gefunden. Entsprechend der geringfügigen Keimresorption aus der inficirten Bauchhöhle reagierten die 3 Thiere sehr wenig auf die Paratyphusinfection und verhielten sich bald und dauernd wie gesunde Kaninchen.

Die Bauchhöhleninfectionen zeigten immer wieder von neuem, dass alles darauf ankommt, das Uebertreten grösserer Mengen virulenter Bakterien in den Blutkreislauf zu verhindern und damit der allgemeinen Sepsis vorzubeugen. Das gelang durch die Vorbehandlung des Peritoneums mit absoluter Sicherheit, und die ebenso sichere Folge der Aufhebung der Bakterienresorption aus der Bauchhöhle war dann das Fehlen merklicher Krankheitserscheinungen und das erstaunlich leichte Ueberstehen des schweren peritonealen Infectionsprocesses, immer im Gegensatz zu allen nicht oder ungenügend peritoneal vorbereiteten Thieren. 
Damit steht aber unbedingt fest, dass die durch Vorbehandlung des Peritoneums erreichbare Aufhebung bezw. Hemmung der Bakterienresorption aus der Bauchhöhlenicht nur eine theoretisch interessante 'Thatsache ist, sondern eine grosse praktische Bedeutung hat, indem sie lebensrettend wirkt.

Die Aufhebung der Bakterienresorption aus der Bauchhöhle muss also der Ausgangspunkt einer rationellen Therapie bei peritonealer Infection sein.

Dass sie nicht durch eine Oelverstopfung der aus dem Cavum peritonei abführenden Lymphbahnen zu Stande kommt, habe ich S. 610 ausführlich dargelegt. Nicht nur Oel in Menge von mehreren Cubikcentimetern, sondern auch wenige Tropfen eines stark reizenden Oels, und nicht nur ölige Substanzen, sondern auch mechaniche Reizmittel und Culturen von nicht oder wenig virulenten Bakterien erzielten das Resultat der Bakterienresorptionshemmung, um so sicherer und vollständiger, je intensiver und länger das Peritoneum durch eins dieser Mittel gereizt wurde. Die blosse Laparotomie mit schnell vorübergehendem Einführen von Fremđkörpern (Gummischlauch) und, wie aus der Glimm'schen Arbeit zu ersehen ist, physiologische Kochsalzlösung und ea. 5 proc. Milchzuckerlösung hemmen die Bakterienresorption aus der Bauchhöhle nicht wesentlich, offenbar, weil sie das Bauchfell wenig und zu kurze Zeit reizen. Zur Verringerung bezw. Verhütung der peritonealen Bakterienresorption gehört eben unbedingt eine Bauchfellreizung von gewisser Intensität und Dauer. Die einmal erzeugte Fähigkeit des reactiv entzündeten Peritoneums, in die Bauchhöhle injicirtes Bakterienmaterial vom allgemeinen Kreislauf fernzuhalten, verschwindet nicht bald, sondern kann nach meinen Versuchsergebnissen über: viele Tage und Wochen bewahrt bleiben. Damit wird es auch verständlich, dass Thiere, die eine Peritonitis überstanden haben, keine Bakterienresorption aus der Bauchhöhle zeigen brauchen. Da entzündliche Processe des Peritoneums gerade beim Kaninchen nicht selten vorkommen (parasitäre Lebererkrankungen), kann es nicht wundernehmen, wenn man hin und wieder auf ein Thier trifft, das auch ohne experimentelle Vorbehandlung des Bauchfells die peritoneale Bakterienresorption vermissen lässt. Ich erinnere an das Controlthier No. 40 (XIV. Versuchsgruppe), bei dem trotz nicht vorhergegangener bewusster Reizbehandlung des Peritoneums die Prüfung auf Prodigiosusresorption aus der Bauchhöhle negativ aus- 
fiel, während das dazu gehörige Versuchsthier No. 39 zahlreiche Prodigiosuskeime resorbirt hatte, und verweise nochmals auf den 41. Versuch Glimm's (l. c. S. 280 u. 281), bei dem ein altes, sehr schweres, vorher schon zu ausgedehnten Choleraimmunisirungsversuchen benutztes Kaninchen eine auffällig geringe peritoneale Bakterienresorption zeigte.

In dies Capitel der durch Bauchfellreizung veränderten Resorptionsverhältnisse gehört auch die von Schnitzler und Ewald ${ }^{1}$ ) mitgetheilte Beobachtung, dass längeres Tragen von Glaskugeln im Peritonealcavum die peritoneale Resorption in Folge von hochgradiger Verdickung des Bauchfells hemmt, und die Mittheilung von Clair mont und Haberer ${ }^{2}$, dass das Bestreichen der abdominalen Zwerchfellsfläche mit Collodium die Aufsaugungsfähigkeit des Peritoneums wesentlich herabsetzt.

Allen diesen angeführten Beobachtungen gehemmter peritonealer Resorption liegt als gemeinsame Ursache der Reizzustand zu Grunde, in den das Peritoneum versetzt ist, die reactive Peritonitis. Sie ist es, die kraft des gebildeten Exsudates dem Thierkörper eimen sicheren Schutz gegen die peritoneale Invasion von horhvirulenten Bakterien in übermässiger Zahl verleiht. Das auf die verschiedensten Reize hin mit mehr oder weniger ausgesprochener Exsudation antwortende Peritoneum kann in diesem Zustande reactiver Entzündung bezüglich der Resorptionsverhältnisse mit der granulirenden Wunde verglichen werden, von der aus eine Bakterienresorption nicht stattfindet, so lange nicht die Continuität zerstört und damit der schützende Wall durchbrocben wird.

Im Folgenden möchte ich einem sehr naheliegenden Einwande begegnen, den ich mir selbst oft gemacht habe: "Vielleicht erfolgt trotz Vorbehandlung des Peritoneums doch die Bakterienresorption in unverändertem Maasse; die resorbirten Bakterien werden aber von dem vorbehandelten Thier im Blute vernichtet oder wenigstens entwicklungsunfähig gemacht und entziehen sich damit dem culturellen Nachweise". Wenn auch diese Möglichkeit zunächst zugegeben werden muss, so sprechen doch sehr gewichtige Gründe gegen eine solche Auffassung. Nicht nur in der Blutcultur wurden

1) J. Schnitzler und K. Ewald, Zur Kenntniss der peritonealen Resorption. Dentsche Zeitschr. f. Chir. 1895. Bd. 41. S. 366 u. 367.

2) P. Clairmont und H. Haberer, Experimentelle Untersuchungen zur Physiologie und Pathologie des Peritoneums. Arch. f. klin. Chir. 1905: Bd. 76 . S. $37 \mathrm{ff}$. u. 55 . 
bei gut peritoneal vorbehandelten Kaninchen im Gegensatz zu den nicht oder ungenügend peritoneal vorbereiteten Thieren die in das Cavum peritonei injicirten Keime vermisst, sondern auch im Blutausstrichpräparat. Ferner fehlte bei den gut vorbehandelten Thieren nicht erst nach etwa $1 / 2$ Stunde oder später, sondern schon in den sehr bald nach der intraperitonealen Bakterieninjection entnommenen Herzblutproben färberisch oder culturell nachweisbare Keime. Man müsste demnach schon annehmen, dass die vermeintlich in grossen Mengen resorbirten Bakterien ausserordentlich schnell, fast momentan getödtet werden. Und die momentane Vernichtung zahlloser Bakterien müsste so vollständig sein, dass sich diese nicht einmal mehr im Aussstrichpräparat färben lassen, was nach allem bisher darüber Bekannten unmöglich ist. Und nicht nur Bakterien, sondern auch nicht lebende Partikelchen werden beim Vorhandensein eines exsudativen Bauchfellprocesses in viel geringerer Menge aus der Peritonealhöhle in den Kreislauf resorbirt als vom normalen Peritoneum, und werden um so mehr im Cavum peritonei festgehalten, je stärker die exsudative Peritonitis entwickelt ist (cf. meine Beobachtungen über die peritoneale Oelresorption). Es scheint also durch die reactive Peritonitis nicht nur die Bakterienresorption, sondern die Aufsaugung aller möglichen corpusculären Elemente gehemmt zu sein. Demnach handelt es sich bei den Ergebnissen meiner Resorptionsversuche nicht um eine scheinbare, sondern um eine wirkliche Aufhebung bezw. Hemmung der peritonealen Bakterienresorption.

Ist das Peritoneum nicht oder ungenügend vorbereitet, so erfolgt die Bakterienresorption aus der Bauchhöhle überraschend schnell. Wenn ich die zur intraperitonealen Bakterieninjection angelegte kleine Laparotomiewunde in ihren einzelnen Schichten vernähte und dann erst die Herzpunction ausführte, so fand ich regelmässig schon Keime der in die Bauchhöhle injicirten Bakteriencultur im Blute des linken Herzens. Nur dadurch konnte ich mit der Herzpunction dem Auftreten von resorbirten Keimen im Kreislauf zurorkommen, dass ich den zur Blutentnahme bestimmten Troikart schon vor der peritonealen Bakterieninjection in das Herz stach, nach der peritonealen Bakterieninjection nur die minimale Peritonealöffnung schloss und nun sofort mit der angesetzten Spritze ans der schon im Herzen situirten Troikartcanüle Blut ansog. Auf diese Weise gelang mir $1 \mathrm{mal}$ schon 35 Secunden post infect. peritonei die Blutentnahme aus dem Herzen. 
In der folgenden Tabelle habe ich meine Beobachtungen über die Schnelligkeit der peritonealen Bakterienresorption bei nicht vorbehandeltem Bauchfell übersichtlich zusammengestellt:

\begin{tabular}{|c|c|c|c|c|}
\hline $\begin{array}{l}\text { No, des } \\
\text { Thieres }\end{array}$ & \multicolumn{4}{|c|}{$B l u t m e n g e$} \\
\hline 58 & & $\mathrm{ecm}$ & bellrothes $\mathrm{He}$ & Cerzblut \\
\hline 54 & 2 & 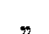 & & , \\
\hline 60 & 1,6 & $"$ & dunkelrothes & s" \\
\hline 56 & 2 & $n$ & hellrothes & $"$ \\
\hline 54 & 2 & " & " & $"$ \\
\hline 56 & 2 & $"$ & $\Rightarrow$ & $\Rightarrow$ \\
\hline 58 & 2 & $"$ & 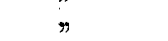 & $\%$ \\
\hline 52 & 2 & $\eta$ & $\eta$ & $\%$ \\
\hline 52 & 2 & $"$ & $\eta$ & $"$ \\
\hline 52 & 2 & $"$ & 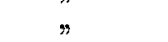 & $"$ \\
\hline 60 & 2 & $"$ & $"$ & . \\
\hline 59 & 2 & $"$ & $"$ & $"$ \\
\hline
\end{tabular}

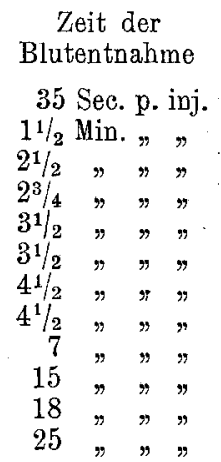

Colonienzahl auf der Blutagarplatte

Laut Tabelle ist $1 \mathrm{mal}$ schon $1 \frac{1}{2}$ Minuten nach abdominaler Injection der Prodigiosusversuchscultur 1 Prodigiosuskeim aus der Herzblutprobe, und zwar des linken Herzens, gezüchtet worden. Nach $2 \frac{1}{2}$ Minuten ging aus $1,6 \mathrm{ccm}$ Blut des rechten Herzens keine Colonie von Bact. coli haemolyt. an. Von da ab, also jenseits von $2 \frac{1}{2}$ Minuten, fielen alle Herzblutproben positiv aus. $2^{3} / 4$ Minuten nach peritonealer Prodigiosusinjection wuchsen schon 86 Prodigiosuscolonien; nach $31 / 2$ Minuten wurden 1 mal schon 2044 Prodigiosuskeime gezählt. Wir müssen also annehmen, dass etwa $2 \frac{1}{2}$ Minuten nach abdominaler Bakterieninjection die Lunge von den resorbirten Keimen passirt wird, wenige Secunden später die ersten Keime im grossen Kreislauf erscheinen, und dann die Keimzahl im Blute zunächst mit jeder weiteren Minute beträchtlich zunimmt.

Meine Resultate bezüglich der Schnelligkeit der peritonealen Bakterienresorption ergänzen die in der Literatur niedergelegten Mittheilungen über die Bakterienresorption im Thierkörper. Noetzel ${ }^{1}$ ) constatirte, ndass 10 Minuten nach der intraperitonealen Infection mit Milzbrandbacillen diese im Blute nachgewiesen werden können". Peiser ${ }^{2}$ ) hat experimentell festgestellt, dass sich ${ }_{n} 10-20$ Minuten nach der Infection des Peritoneums schon beträchtliche Bakterienmengen im Blute finden ". Aus den Untersuchungen von Schimmel-

1) W. Noetzel, Ueber peritoneale Resorption und Infection. Archiv für klin. Chir. 1898. Bd. 57. S. 314.

2) A. Peiser, Zur Pathologie der bakteriellen Peritonitis. Bruns' Beiträge z. klin. Chir. 1905. Bd. 45. S. 123. 
$\mathrm{busch}^{1}$ ) wissen wir, "dass Mikroorganismen von einer frischen blutenden Wunde ausserordentlich schnell in den Kreislauf gelangen und schon 5 Minuten nach der Infection in den inneren Organen nachweisbar sind".

Demnach macht es kaum einen Unterschied, ob man die Keime in eine Wunde oder in die nicht vorbehandelte, von normal resorbirendem Peritoneum ausgekleidete Bauchhöhle hineinbringt. In beiden Fällen sind die injicirten Keime binnen wenigen Minuten im allgemeinen Kreislauf und damit im ganzen Körper verbreitet. Kann man diese allgemeine Verbreitung von Keimen im Körper als etwas Günstiges ansehen? Bei der Wundresorption ist man gar nicht auf den Gedanken gekommen, darin eine Schutzvorrichtung des Körpers zu erblicken. Und bei Bauchhöhleninfectionen sollte die grosse Resorptionskraft des Peritoneums einen Schutz bieten? Mit den Resultaten meiner Arbeit muss ich diese Frage ebenso aufs Entschiedenste verneinen, wie es vor mir andere auf Grund werthvoller experimenteller Arbeiten gethan haben, ich nenne vor allem Noetzel, Peiser, Glimm. Sind eine geringe Anzahl virulenter Keime oder reichlich nicht oder wenig virulente Bakterien in die Peritonealhöhle gelangt, so werden diese nach schnell erfolgter Resorption im Blute bezw. an den Ablagerungsstätten in den Organen bald vernichtet. Unter diesen Bedingungen schadet die Keimresorption gewiss nicht; aber sie ist auch nicht nöthig, weil die Bakterien am peritonealen Invasionsorte genau so gut unschädlich gemacht würden. Handelt es sich aber um das Eindringen von reichlichem virulenten Bakterienmaterial in die Bauchhöhle, so ist die tödtliche oder wenigstens das Leben äusserst gefährdende allgemeine Sepsis gerade wegen der grossen Resorptionskraft des Peritoneums die unvermeidliche Folge. Was man in solchen Fällen mit der Ausschaltung der enormen peritonealen Resorptionsfähigkeit, mit der Aufhebung der Resorption von Unmengen virulenter Bakterien erreichen kann, lehren aufs Deutlichste die Ergebnisse meiner Versuche. Wer nur ein einziges Mal den Unterschied zwischen einem peritoneal inficirten Thier mit gut vorbehandeltem Peritoneum und einem ebenso inficirten nicht peritoneal vorbehandelten Controlthier gesehen hat hinsichtlich ihres Befindens post infectionem, kann in der ungeheuren Resorptions-

1) C. Schimmelbusch, Die Aufnahme bakterieller. Keime von frischen blutenden Wunden aus. Deutsche med. Wochenschr. 1894. S. 575. 
kraft des Peritoneums keine Schutzvorrichtung für den Thierkörper: im Falle einer peritonealen Infection erblicken. Genau so wie an: anderen Körperstellen kommt es anch beim Peritoneum darauf an, das Infectionsmaterial auf den Infectionsort zu beschränken. Gelingt den Schutzkräften des Organismus diese Localisirung, sei es sonstwo im Körper, sei es im Peritoneum, so ist damit die Lebenschance erheblich gebessert und der Heilungsprocess eingeleitet. Das am Localisationsorte gebildete Exsudat rechtzeitig zu erkennen und zu entleeren, um einer eventuellen tödtlichen Intoxication des Körpers vorzubeugen, ist ein weiteres wichtiges, aber erst in zweiter Linie in Frage kommendes therapeutisches Moment.

Dadurch, dass wir eine reactive Peritonitis erzeugen, bewirken wir nicht nur eine Localisirung der nachfolgenden peritonealen Infection in der Bauchhöhle, sondern vermehren gleichzeitig die natürlichen Schutzkräfte des Peritoneums, denen die eingedrungenen Bakterien innerhalb weniger Tage erliegen müssen (Bakteriolyse, Phagocytose).

Die von mir im Laufe der 89 Versuche (4 an Meersshweinchen, 85 an Kaninchen) gewonnenen Resultate fasse ich in folgende Schlusssätze zusammen:

1. Intraperitoneale Injectionen von kleinen und mittleren Oeldosen (Olivenöl, Sesamöl, Campheröl) bis zu etwa $10 \mathrm{ccm}$ sind für Kaninchen unschädlich, während grössere and grösste 0elquantitäten (20-50-100 ccm) die Thiere theils durch Fettembolie der Lunge, theils durch schwere locale und allgemeine Schädigung gefährden.

2. Durch intraperitoneale Oelinjection wird eine nach Art und Menge des Oels und nach etwaigen $\mathrm{Zu}$ sätzen zum Oel graduell wechselnde reactive Peritonitis hervorgerufen. Diese reactive Peritonitis ist keine specifische Wirkung von injicirtem 0 el, sondern lässt sich durch die verschiedensten Reizmittel hervorrufen.

3. Eine eben beginnende oder erst seit kurzer Zeit (wenige Stunden) bestehende reactive Peritonitis, mag sie durch chemische, mechanische oder bakterielle Reize ausgelöst sein, beschleunigt die Resorption der in die Bauchhöhle injicirten Bakterien. Kaninchen, die unter solchen Versuchsbedingungen peritoneal inficirt werden, erkranken in Folge dessen regelmässig schwerer und 
sterben häufiger und schneller, als peritoneal inficirte Controlthiere, deren Peritoneum überhaupt nicht gereizt worden ist.

4. Besteht dagegen eine derartige reactive Peritonitis schon mindestens 24 Stunden, so hemmt sie die Bakterienresorption aus der Bauchhöhle sehr wesentlich, bezw. hebt sie völlig auf, und nicht nur vorübergehend, sondern für viele Tage und Wochen.

5. Diese durch Blutentnahmen aus dem Herzen nachgewiesene Bakterienresorptionshemmung und die damit erreichte Beschränkung des Infectionsprocesses auf die Bauchhöhle sichert bezw. rettet das Leben des durch peritoneale Injection hochvirulenter Kejme sonst aufs Schwerste gefährdeten Kaninchens.

6. Die von der allgemeinen Circulation ferngehaltenen, auf die Bauchhöhle beschränkten Keime, selbst virulentester Art, werden durch die hier in Folge der peritonealen Vorbehandlung angehäuten baktericiden Kräfte binnen kurzer Zeit (in etwa 4 Tagen) vernichtet.

7. Die Bakterienresorption seitens des nicht vorbehandelten normalen Kaninchenperitoneums erfolgt ausserordentlich schnell. Schon vor Ablauf von 3 Minuten sind die aus der Bauchhöhle resorbirten Keime im grossen Kreislauf nachweisbar.

Anmerkung: Aus der sehr umfangreichen Literatur über peritoneale Resorption und Peritonitis habe ich nur die Arbeiten citirt, an die meine experimentellen Studien unmittelbar anknüpften. Von einem weiteren Literaturnachweis konnte ich um so eher absehen, als inzwischen von F. Fromme in Veit's Handbuch d. Gyn. Bd. 4. II, Hälfte, 1910 eine Uebersicht der wichtigsten einsehlägigen Arbeiten gegeben ist.

\section{Erklärung der Abbildung auf Tafel XI.}

Mit Sudan-Hämatoxylin gefärbter Gefrierschnitt aus der Lunge des Kaninchens No. 4, II. Versuchsgruppe (S. 572) bei 32 maliger: Vergrösserung.

Verstopfung selbst grösserer arterieller Gefässbahnen mit Oel (Oel roth gefärbt). In Folge der Gefässverstopfung ausgedehnte Infarcirnng des Lungengewebes mit extravasirtem Blut (Braunfärbung). Compensatorisohes Emphysem der spärlichen noch respirationsfähig gebliebenen Lungenalveolen. 


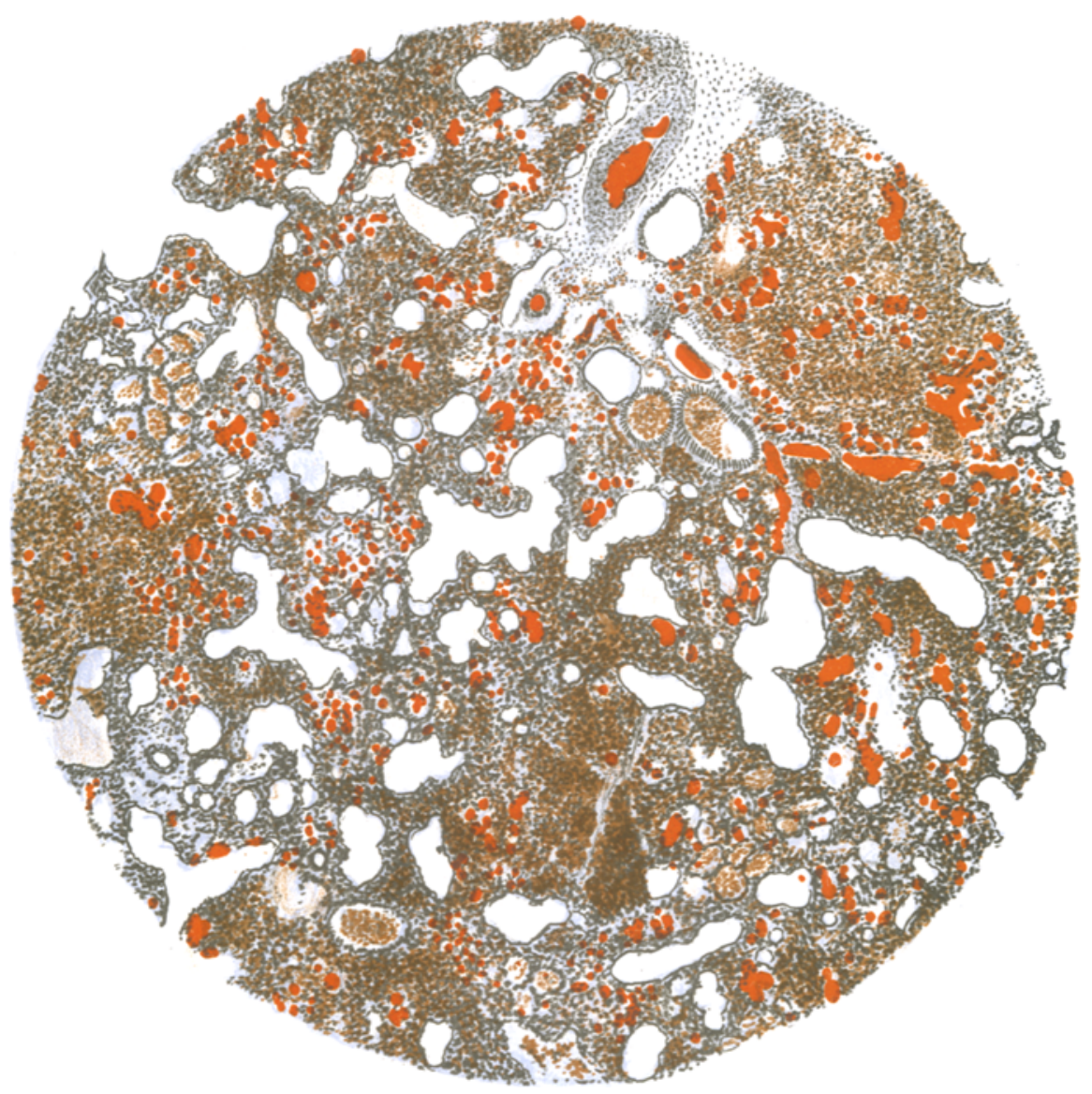

